\title{
Examining the Relationship Between Modifiable Risk Factors and Levels of Functioning Among Appalachian Patients With Heart
} Failure

Trisha M. Petitte

Follow this and additional works at: https://researchrepository.wvu.edu/etd

\section{Recommended Citation}

Petitte, Trisha M., "Examining the Relationship Between Modifiable Risk Factors and Levels of Functioning Among Appalachian Patients With Heart Failure" (2017). Graduate Theses, Dissertations, and Problem Reports. 6412.

https://researchrepository.wvu.edu/etd/6412

This Dissertation is protected by copyright and/or related rights. It has been brought to you by the The Research Repository @ WVU with permission from the rights-holder(s). You are free to use this Dissertation in any way that is permitted by the copyright and related rights legislation that applies to your use. For other uses you must obtain permission from the rights-holder(s) directly, unless additional rights are indicated by a Creative Commons license in the record and/ or on the work itself. This Dissertation has been accepted for inclusion in WVU Graduate Theses, Dissertations, and Problem Reports collection by an authorized administrator of The Research Repository @ WVU.

For more information, please contact researchrepository@mail.wvu.edu. 
Examining the Relationship Between Modifiable Risk Factors and Levels of Functioning Among Appalachian Patients With Heart Failure

\author{
Trisha M. Petitte
}
Dissertation submitted to the School of Nursing at West Virginia University

in partial fulfillment of the requirements for the degree of

Doctor of Philosophy in Nursing

Jennifer Mallow, Ph.D., Chair

Georgia Narsavage, Ph.D.

R. David Parker, Ph.D.

Carl Shrader, MD, Ph.D.

School of Nursing

Morgantown, West Virginia

2017

Keywords: heart failure, risk factors, physical functioning, social well-being, emotional well-being

Copyright 2017 Trisha M. Petitte 


\begin{abstract}
Examining the Relationship Between Modifiable Risk Factors and Levels of Functioning Among Appalachian Patients With Heart Failure
\end{abstract}

Trisha M. Petitte

Background: Heart failure is becoming more prevalent in the United States due to our aging population. More than $10 \%$ of people over the age of 70 have heart failure. Risk factors include coronary artery disease (CAD), which includes myocardial infarction and angina. Hypertension precedes heart failure in $75 \%$ of cases. Risk factors for CAD include obesity, high glycemic intake, high dietary sodium intake, sedentary lifestyle, and cigarette smoking. In West Virginia, the heart failure death rate is 32.6 per 100,000 population, accounting for $3 \%$ of all deaths. The highest rates of hospitalization for heart failure in the nation are found in Appalachia yet a gap exists in the literature on how modifiable risk factors are related to the well-being of people living in this region.

Aims: The aims of this study were to determine the relationship between nutrition, obesity, physical activity, and smoking on physical, social, and emotional well-being among Appalachian patients with heart failure.

Methods: A cross-sectional, descriptive, correlational study using a convenience sample of 115 patients from a nursing home, two outpatient clinics, and a tertiary-care hospital was conducted to examine the relationship between modifiable risk factors and well-being as measured by the Minnesota Living With Heart Failure Questionnaire (MLHFQ). Modifiable risk factors were measured using (1) the American Heart Association Life's Simple 7 Questionnaire to assess nutrition habits, (2) BMI as a measure of obesity, (3) the Duke Activity Status Index (DASI) for physical activity, and (4) the Global Adult Tobacco Survey (GATS) to determine smoking status. Bivariate and descriptive analyses were performed and nonparametric analogs were used to examine the relationship between predictor and outcome variables. One-way analysis of variance (ANOVA) tests were used to further analyze risk factors in relation to levels of well-being.

Results: A majority of participants in this study were older, white, obese or overweight, and of lower socioeconomic status and had New York Heart Association (NYHA) class III or IV disease. Statistically significant findings included higher levels of physical activity being related to enhanced levels of physical, social, and emotional well-being. Nutritional status was found to be significantly related to higher levels of social well-being.

Conclusion: Knowledge of modifiable risk factors and their relationship to the well-being of individuals with heart failure in Appalachia is necessary to develop appropriate secondary prevention measures aimed at reducing or eliminating these risk factors. Physical activity programs may have the greatest impact on physical, social, and emotional well-being in this study population. Identifying resources in rural areas of Appalachia is necessary to promote behavior modification to reduce modifiable risks to ultimately minimize disease progression. 


\section{Acknowledgments}

After Dr. Georgia Narsavage left for a position at the University of South Carolina, Dr. Jennifer Mallow stepped in to serve as my dissertation committee chair. Dr. Mallow supported me with continual feedback and direction throughout my proposal defense, research, analysis, and completion of this dissertation. Her input and guidance were invaluable. Dr. Narsavage has been a gracious mentor since I began teaching in the WVU School of Nursing. She encouraged me to pursue my Ph.D. and was instrumental in the development of my research skills by providing me with the opportunity to work on a National Institutes of Health, National Cancer Institute grant.

I would not have been able to complete the analysis without the guidance of my biostatistician, Dr. R. David Parker. Dr. Carl Shrader's suggestion to expand my recruitment to additional healthcare sites added depth to my research and diversity to my target population. I thank them for the impact they had on my research.

With the help of Dr. Ashley Petrone and her graduate students Rhae Eisenman and Kelsey Steele, I was able to complete my recruitment and data collection a month earlier than projected, and for this I am truly grateful.

Thank you to Dr. Gina Maiocco, Ph.D. program director, for guiding me through the program and especially for her help in navigating the Institutional Review Board process.

The outstanding faculty in the WVU School of Nursing graduate program provided me with new knowledge in every course and made learning challenging but rewarding.

The completion of this Ph.D. program and dissertation was more bearable with the continual support of my fellow students, especially Dr. Monica Iaquinta, Karen Jagiello, Dr. April Shapiro, Deborah Strickland, and Billy Vance. 
My dedicated editor, Kathy Cummins, came out of retirement to help me over the past year with countless revisions of this manuscript. Her expertise and perfectionism are beyond compare. Thank you also to Chris Budig, who supported my work with unending patience and good humor.

Support from the Jonas Scholar program and the WVU School of Nursing research grant awarded by Dean Tara Hulsey was greatly appreciated and made this research possible. 


\section{Dedication}

To my father who taught me the value of lifelong learning and to my mother who, by example, showed me that it is never too late to go back to school. I also dedicate this work to Dr. Clyda Petitte, who continues to enjoy her life despite living with the challenges of heart failure. Finally, to my four sisters, who have always been, and will always be, there for me. 


\section{Table of Contents}

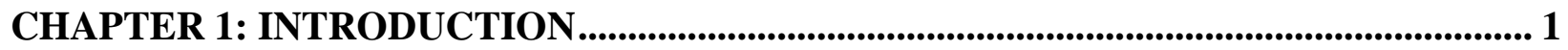

Background of the Problem ............................................................................................................................ 4

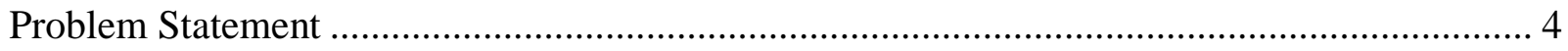

Prevalence of the Problem........................................................................................................ 4

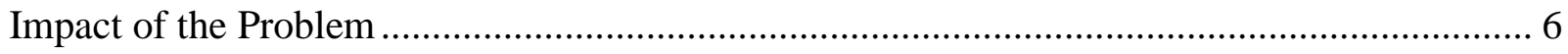

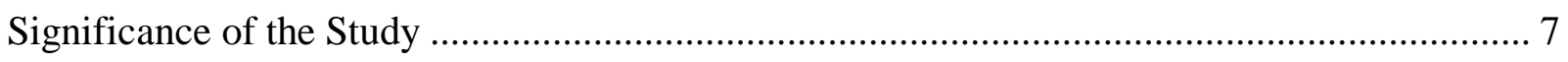

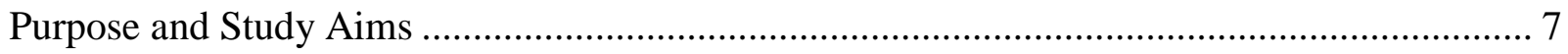

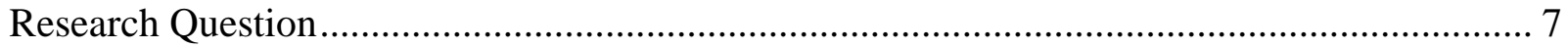

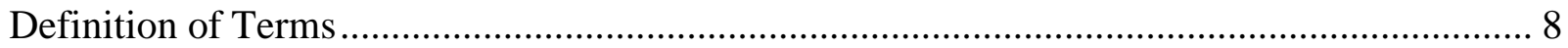

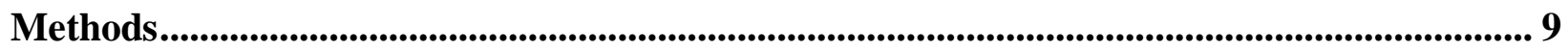

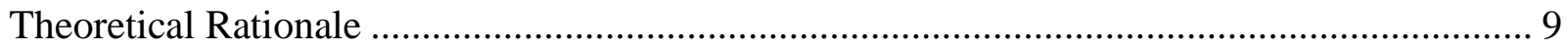

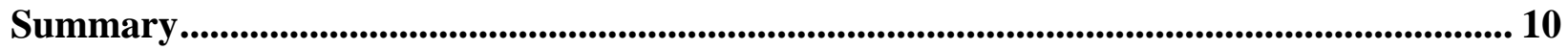

CHAPTER 2: REVIEW OF THE LITERATURE................................................................ 12

Literature Search Process ................................................................................................................. 12

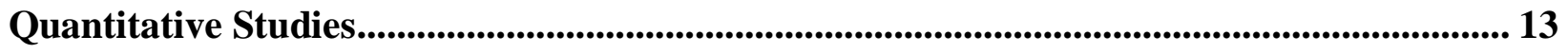

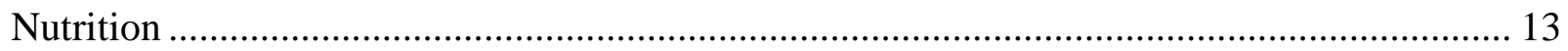

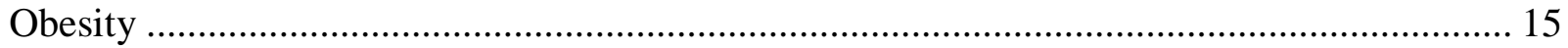

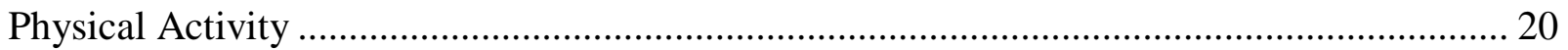


Smoking

Literature on Heart Failure in Rural Populations.................................................................... 25

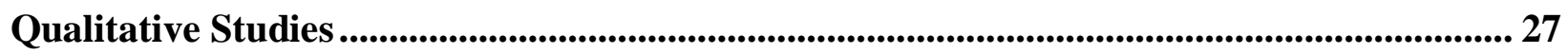

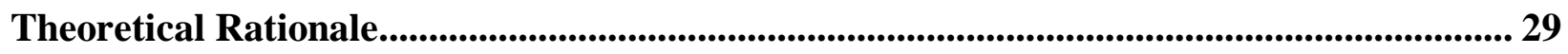

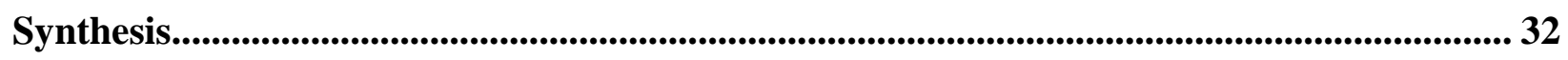

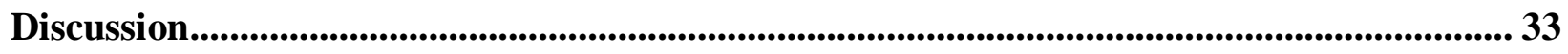

Figure 1. Literature search result: identification, exclusion, eligibility, and included ........ 37

Figure 2: Neuman's Systems Model: Heart Failure Patients .......................................... 38

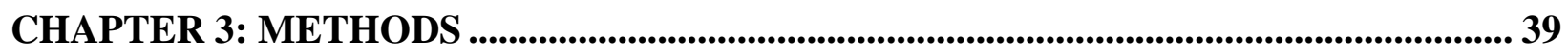

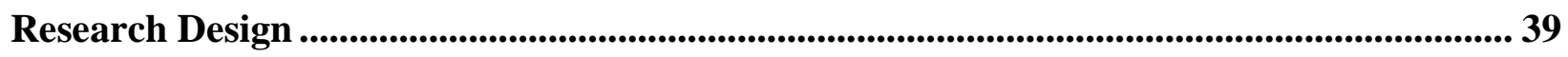

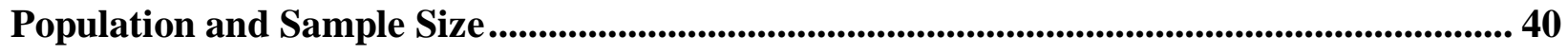

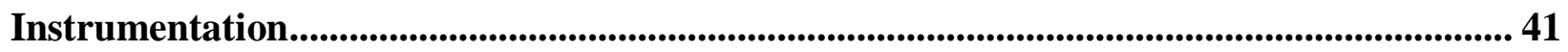

American Heart Association Life's Simple 7 Questionnaire .............................................. 41

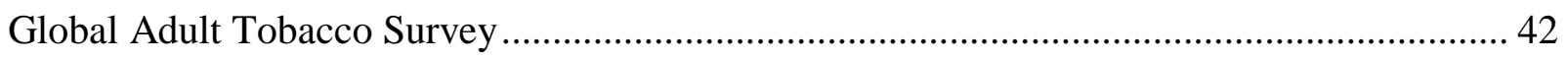

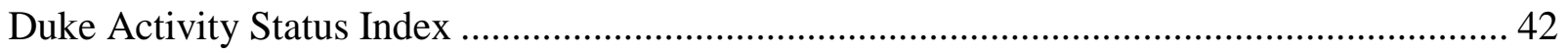

Minnesota Living With Heart Failure Questionnaire .................................................. 44

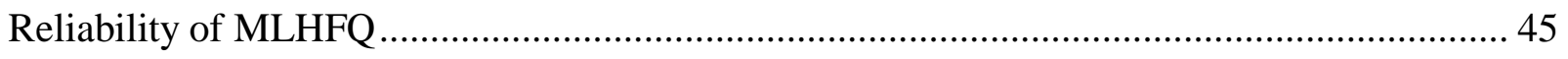

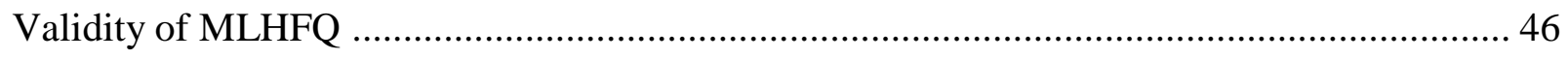

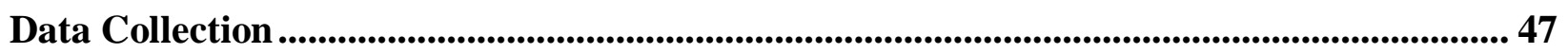

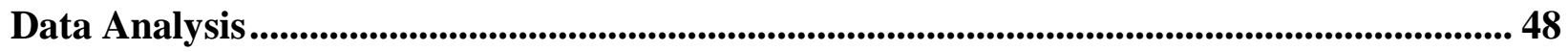


Human Rights and Ethical Considerations

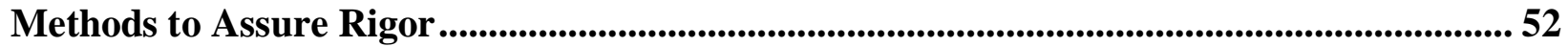

Advantages and Limitations of the Design .................................................................................... 52

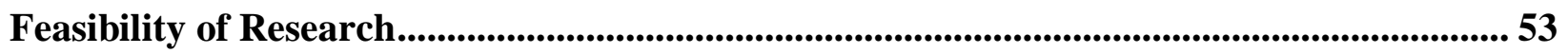

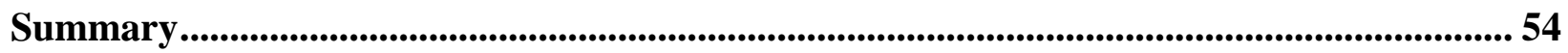

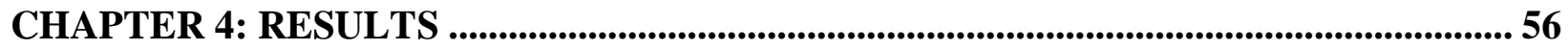

Data Collection ................................................................................................................................................. 56

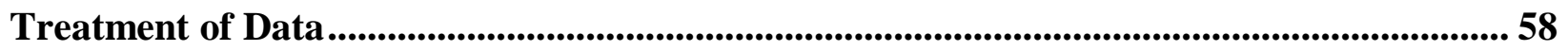

Assessment of Statistical Assumptions ................................................................................................. 59

Results .......................................................................................................................................................... 60

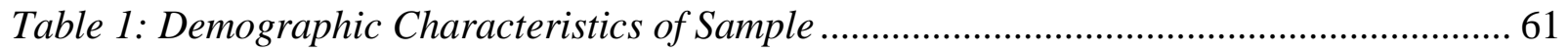

Table 2: Demographic Continuous Variables of Sample .................................................. 62

Table 3: Sample Characteristics: Clinical Variables ...................................................... 64

Table 4: Results of Chi-square $\left(\chi^{2}\right)$ Test for Independence .............................................. 66

Table 5: Differences in Physical Well-being Scores by Gender and Smoking Status:

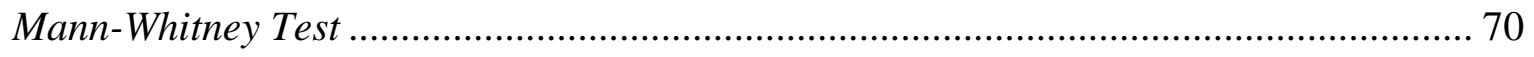

Table 6: Differences in Emotional Well-being Scores by Gender and Smoking Status:

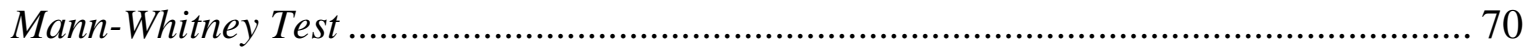

Table 7: Differences in Social Well-being Scores by Gender and Smoking Status:

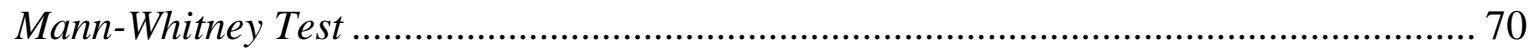


Table 8: Differences in Physical Well-being Scores by BMI and Nutritional Status:

Kruskal-Wallis Test

Table 9: Differences in Emotional Well-being Scores by BMI and Nutritional Status:

Kruskal-Wallis Test 72

Table 10: Differences in Social Well-being Scores by BMI and Nutritional Status:

Kruskal-Wallis Test

Table 11: Correlations between Predictor Variables and Outcomes: Spearman's Rho

Table 12: Correlations between Demographic Variables and Predictor Variables:

Spearman's Rho

Table 13: Independent Samples T-test: Differences in Nutrition Status Score between

Male and Female Subjects

Table 14: ANOVA: Impact of Nutritional Status on Physical, Social, and Emotional

Well-being

Table 15: ANOVA: Impact of Obesity on Physical, Social, and Emotional Well-being 78

Table 16: Differences in Physical, Social, and Emotional Well-being Scores by Level of Physical Activity: Mann-Whitney Test

Table 17: ANOVA: Impact of Smoking Status on Physical, Social, and Emotional Wellbeing

Summary 81

CHAPTER 5: FINDINGS 83

Theoretical Framework 83 


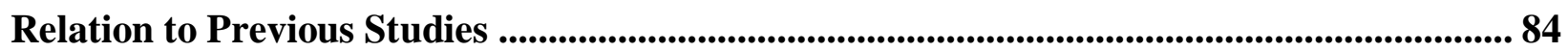

Heart Failure in Rural Populations................................................................................... 89

Implications for Practice ........................................................................................................... 91

Future Research ................................................................................................................................................ 95

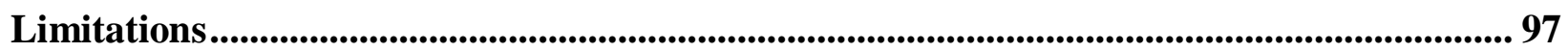

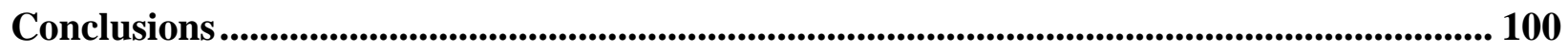

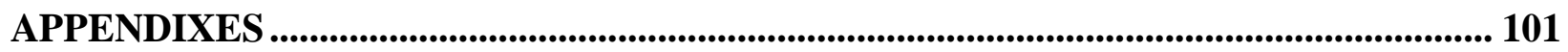

Appendix A: American Heart Association Life's Simple 7 Dietary Questionnaire ............ 101

Appendix B: Global Adult Tobacco Survey …….................................................................................. 102

Appendix C: Duke Activity Status Index............................................................................................. 103

Appendix D: Minnesota Living With Heart Failure Questionnaire ........................................ 104

Appendix E: Recruitment Flyer ............................................................................................................... 106

SUPPLEMENTAL MATERIALS .......................................................................................................... 107

Table S1: Literature review matrix ........................................................................................................... 107

Table S2: Risk factor measures ....................................................................................................................... 120

Table S3: Outcome measure instrument ............................................................................................... 120

Table S4: Data collection process ............................................................................................................ 120

Table S5: Dissertation project timeline …................................................................................................ 121

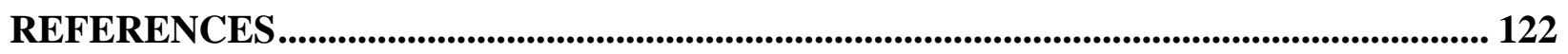




\section{Chapter 1: Introduction}

Cardiovascular disease encompasses a range of major clinical disease conditions including stroke, congenital heart disease, rhythm disorders, subclinical atherosclerosis, coronary artery disease (CAD), heart failure, valvular disease, and peripheral arterial disease (Mozaffarian et al., 2016). The Framingham Heart Study suggests that the most common cause of heart failure is no longer hypertension or valvular heart disease, as it was in previous decades, but rather CAD, which includes angina and myocardial infarction (Gheorghiade et al., 2006). Although CAD is now the most common cause of heart failure, hypertension precedes heart failure in $75 \%$ of all cases (Mozaffarian et al., 2016). People with blood pressure >160/90 mmHG have twice the risk of developing heart failure as those with BP <140/90 (Mozaffarian et al., 2016). According to 2013 data from the National Heart, Lung, and Blood Institute (Mozaffarian et al., 2016, p. e277), one in nine deaths has heart failure mentioned on the death certificate. The lifetime risk of developing heart failure is $20 \%$ among persons 40 years of age and older (Casper et al., 2010). Prevalence of heart failure is rising and is greater than $10 \%$ in people over 70 years of age (Pfister et al., 2014).

Risk factors for CAD and heart failure have been identified as poor lifestyle choices including cigarette smoking, obesity, high glycemic intake, and high dietary sodium intake potentially leading to hypertension (Esch \& Hendryx, 2011; Lama Tamang, Tang, Chuang, Patel, \& Wong, 2014; Mozaffarian et al., 2016). According to the Physicians Health Study, the lifetime risk of heart failure is higher in men with hypertension (Djousse, Driver, \& Gaziano, 2009); hypertension is found in an estimated $41 \%$ of the male and female population in West Virginia (WV Health Statistics Center, 2015). Conversely, lower risk of heart failure is found in those with normal weight, no history of smoking, regular physical activity, moderate alcohol intake, 
and diet including cereal grains, fruits, and vegetables. Because the prevalence of risk factors leading to heart failure is higher, on average, among the Appalachian population, there are also higher rates of heart failure morbidity and mortality in this population (Center for Medicare and Medicaid Services, 2014; WV Health Statistics Center, 2012).

Unhealthy behaviors that can lead to heart failure have been found to be more prevalent in Appalachian populations (Esch \& Hendryx, 2011; Mamudu et al., 2015; Mudd-Martin et al., 2014). Two thirds of people living in the Appalachian regions of Kentucky, North Carolina, Tennessee, Virginia, and West Virginia are overweight or obese (Mamudu et al., 2015). West Virginia has a higher rate than the national average of persons not engaging in physical activity (31\% versus 29\%, respectively) (Mamudu et al., 2015). Cardiovascular risks attributed to unhealthy diets, smoking, lack of physical activity, and inadequate preventive care were identified by study participants from an Appalachian population (Mudd-Martin et al., 2014). Esch and Hendryx (2011) found that higher rates of poverty, lower rates of college education, and higher prevalence of obesity in rural Appalachia were significant predictors of cardiovascular disease mortality.

Functional status of heart failure patients is often measured by the New York Heart Association (NYHA) functional classification (Heo, Moser, Riegel, Hall, \& Christman, 2005; Holland, Rechel, Stepien, Harvey, \& Brooksby, 2010; Pollentier et al., 2010). The NYHA classes as defined by the American Heart Association (AHA) Criteria Committee (1994) are:

Class I. Patients with cardiac disease but without resulting limitation of physical activity. Ordinary physical activity does not cause undue fatigue, palpitation, dyspnea, or anginal pain. 
Class II. Patients with cardiac disease resulting in slight limitation of physical activity. They are comfortable at rest. Ordinary physical activity results in fatigue, palpitation, dyspnea, or anginal pain.

Class III. Patients with cardiac disease resulting in marked limitation of physical activity. They are comfortable at rest. Less than ordinary activity causes fatigue, palpitation, dyspnea, or anginal pain.

Class IV. Patients with cardiac disease resulting in inability to carry on any physical activity without discomfort. Symptoms of heart failure or the anginal syndrome may be present even at rest. If any physical activity is undertaken, discomfort is increased.

Healthcare providers assign an NYHA class based on subjective assessment of their patients with heart failure. Functional capacity as determined by the NYHA classification is an estimate of what the patient's heart will allow them to do. Several studies have used the NYHA classes to measure concurrent validity and reliability of the Minnesota Living With Heart Failure Questionnaire (MLHFQ), which is used extensively in research on heart failure (Meyer \& Laederach-Hofmann, 2003; Nogueira et al., 2010; Quittan et al., 2001).

The MLHFQ is a 21-item instrument widely used as a measure of health-related quality of life (Garin et al., 2013). It is used to measure three domains: physical, emotional, and social. The physical domain includes measures of swelling in legs; resting during the day; difficulty in walking or climbing stairs; difficulty working around the house or yard; difficulty going places away from home; difficulty sleeping; shortness of breath; and being tired or fatigued. The emotional domain is measured by questions including whether the patient has feelings of being a burden to family and friends; has feelings of a loss of self-control; and experiences worrying, difficulty concentrating, and feeling depressed. The social domain includes measures of 
difficulty working to earn a living; difficulty in participating in recreational pastimes, sports, or hobbies, and difficulty with sexual activities.

It is not clear to what extent lifestyle choices relate to functional status for people with heart failure living in Appalachia, and there have not been any published studies on risk factors specifically associated with heart failure in the Appalachian population. The purpose of this study was to examine the relationship between each of four specific modifiable risk factorsnutrition, obesity, physical activity, and cigarette smoking — and levels of functioning in terms of physical, social, and emotional well-being among Appalachian patients with heart failure.

\section{Background of the Problem}

\section{Problem Statement}

People living in Appalachia have high rates of obesity, smoking, poor nutritional habits, and sedentary lifestyles. Although these modifiable risk factors have been shown to be associated with heart failure, there have been no studies done specifically on the impact on functioning and modifiable risk factors among people living in Appalachia. Because people in Appalachia have unique characteristics, the numbers and types of risk factors may be different from those found in other parts of the country.

\section{Prevalence of the Problem}

The West Virginia heart failure death rate per 100,000 population is 32.6 (WV Health Statistics Center, 2015). Fourteen percent of people over 65 years of age in Monongalia County, West Virginia, have been diagnosed with heart failure and 3\% of all deaths in WV are due to heart failure (Center for Medicare and Medicaid Services, 2014; WV Health Statistics Center, 2012). The West Virginia Behavioral Risk Factor Surveillance System (BRFSS; WV Health 
Statistics Center 2015) estimates that over a quarter of West Virginia citizens have fair or poor general health, had no routine medical check-up in the past year, have no leisure time physical activity, and currently smoke cigarettes. Nearly half have hypertension and hyperlipidemia, over a third were estimated to be overweight or obese, and $90 \%$ eat less than five servings of fruits and vegetables per day (WV Health Statistics Center, 2015). The current rate of heart failure along with the multitude of modifiable risk factors and health disparities indicates that the incidence of heart failure in the West Virginia population is likely to increase in the future.

Heart failure is known to occur as a result of poor lifestyle choices (Zizzi, Abildso, Henderson, \& Cobb, 2014). Among adults in West Virginia, 35.7\% are obese compared to 28.9\% in the United States (Centers for Disease Control and Prevention [CDC], 2015). This is significant because according to the Framingham Heart Study, for every incremental increase of one (1) in body mass index (BMI) there is a 5\% increase in risk for heart failure among men and an even higher increase in risk for women (7\%) (Kenchaiah et al., 2002). More than $31 \%$ of adults in West Virginia as compared to $26.6 \%$ in the United States do not engage in any leisure time physical activity, which is defined as running, calisthenics, golf, gardening, or walking (WV Health Statistics Center, 2015). Over half of adults in the United States are aerobically active for 150 minutes per week, while only $47.2 \%$ of adults in West Virginia meet this minimum weekly recommendation for physical activity. As a measure of nutrition, BRFSS prevalence estimates show that $90.2 \%$ of West Virginia residents eat fewer than five servings of fruits and vegetables daily as compared to $82.9 \%$ of all United States citizens (WV Health Statistics Center, 2015). West Virginia adult residents also have a higher smoking prevalence (26.7\%) compared to the rest of the United States $(16.8 \%)$ (CDC, 2014). These modifiable risk factors need to be addressed and prioritized in West Virginia to reverse the rising trend in the incidence of heart 
failure (Pfister et al., 2014). Knowledge gained from this study on modifiable risk factors that are most detrimental to functioning among heart failure patients may be instrumental in future development of viable interventions aimed at eliminating these factors.

\section{Impact of the Problem}

Because residents of West Virginia have higher rates of modifiable risk factors for heart failure than persons in the United States as a whole, the burden on the state's healthcare resources is significant. The economic cost of heart failure in the United States exceeds 37 billion dollars, comprising direct medical costs and indirect costs due to loss of productivity (Bui, Horwich, \& Fonarow, 2011; Casper et al., 2010). The huge financial burden attributable to heart failure is in part due to frequent rehospitalizations. The Appalachian region has among the highest rates of heart failure hospitalizations in the nation, resulting in increased financial burden in an area that is already economically depressed (Casper et al., 2010). Despite improving treatments, heart failure still has a one-year mortality rate of 6\% to 24\% (Pfister et al., 2014). According to the Framingham Heart and Olmstead County studies, death rates due to heart failure are high, with approximately $50 \%$ of patients dying within five years of diagnosis (Ebong, Goff, Rodriguez, Chen, \& Bertoni, 2014). People with heart failure have impaired physical functioning including exercise intolerance, shortness of breath, and fatigue (Garin et al., 2013). They have decreased levels of social functioning in terms of inability to participate in social activities due to the physical limitations caused by heart failure. Emotional well-being is adversely affected due to the decline in both physical and social functioning. Recent research has shown that the prevalence of depression and anxiety among those with heart failure is as high as $26 \%$ and $20.5 \%$, respectively, and that many clinicians do not regularly screen for these conditions (Vanhoof et al., 2014). Because quality of life has been shown to be more negatively 
impaired by heart failure that other chronic conditions such as arthritis and bronchitis, an emphasis on treatment aimed at managing symptoms and improving quality of life is paramount (Chung, Moser, Lennie, \& Frazier, 2013).

\section{Significance of the Study}

The identification of modifiable risk factors among an Appalachian population may help guide prevention and intervention strategies for those vulnerable for or already diagnosed with cardiovascular disease. There has been little research on modifiable risk factors in patients with heart failure living in Appalachia. The findings from this study identified modifiable risk factors among patients with heart failure that relate to levels of functioning in terms of physical, social, and emotional well-being, which can aid in the development of interventions aimed at limiting

these risk factors. Determining which risk factors have the largest detrimental effect on levels of functioning may allow clinicians to focus on interventions targeted at reducing or eliminating these risk factors, thereby having the greatest impact on improving functioning among patients with heart failure. Nurses can play an important role in developing and implementing these interventions in this vulnerable population.

\section{Purpose and Study Aims}

The purpose of this study was to examine the relationship between modifiable risk factors and levels of functioning in terms of physical, social, and emotional well-being among Appalachian patients with heart failure.

\section{Research Question}

The research question for this study was: What is the relationship of modifiable risk factors and levels of functioning as measured by physical, social, and emotional well-being for Appalachian patients with heart failure? 
Four specific areas of inquiry directed the research question, as follows:

1. Among Appalachian patients with heart failure, what is the relationship between nutrition and levels of functioning as measured by physical, social, and emotional well-being?

2. Among Appalachian patients with heart failure, what is the relationship between obesity and levels of functioning as measured by physical, social, and emotional well-being?

3. Among Appalachian patients with heart failure, what is the relationship between physical activity and levels of functioning as measured by physical, social, and emotional well-being?

4. Among Appalachian patients with heart failure, what is the relationship between smoking and levels of functioning as measured by physical, social, and emotional well-being?

\section{Definition of Terms}

For the purposes of this study the following definitions of heart failure, modifiable risk factors, physical functioning, and social and emotional well-being were used. The American College of Cardiology defines heart failure as a complex clinical syndrome that results from any structural or functional impairment of ventricular filling or ejection of blood (Yancy et al., 2013), Heart failure symptoms include dyspnea, fatigue, and fluid retention. Heart failure is largely a clinical diagnosis because there is no single diagnostic test, therefore disease detection must be based on a careful history and physical examination.

Modifiable risk factors are those factors that can be reduced or eliminated through medication adherence and/or behavior modification (AHA, 2016). Physical functioning is 
defined by a person's ability to perform activities of daily living including working and engaging in various activities with family and friends (Garin et al., 2013). Social well-being includes the ability to earn a living, the ability to engage in recreational pastimes and sexual activities, and having the economic resources to obtain medical care. Levels of self-control over one's life, worry, ability to concentrate or remember things, depression, and having the feeling of being a burden comprise emotional well-being.

\section{Methods}

A quantitative study using a cross-sectional, convenience sample of patients at Sundale Nursing Home, Ruby Memorial Hospital, the WVU Heart and Vascular Institute, and the WVU Family Medicine Outpatient Clinic was conducted to examine the relationship between modifiable risk factors and levels of functioning in terms of physical, social, and emotional wellbeing. This relationship was examined using the Minnesota Living With Heart Failure Questionnaire (MLHFQ), a validated and reliable instrument to determine levels of disability based on functional capacity due to heart failure (hereafter known as levels of functioning) (Garin et al., 2013). The MLHFQ scores identify disability related to physical, social, and emotional well-being among patients with heart failure. The relationship of modifiable risk factors to levels of functioning in the subjects of this study was examined based on the physical, emotional, and social well-being scores obtained through the MLHFQ administered to people who live in Appalachia.

\section{Theoretical Rationale}

Neuman's Systems Model provided the theoretical underpinnings for this study. Betty Neuman initially developed the model for graduate nursing students to introduce the magnitude 
of nursing issues prior to teaching course content on specific nursing problem areas (Fawcett, 2005b). The philosophical basis of the model is "helping each other live." Beliefs about wholism, reality, and wellness along with assumptions about human beings, spirituality, the environment, health, and nursing are integral to the model.

The focus of Neuman's Systems Model is the wellness of the client in relation to environmental stress and evoked stress reactions (Neuman \& Fawcett, 2011). A main concept of the model is the client/client system, which encompasses the individual, family, community, and social issues. There are five interacting variables in the concept: the physiological, psychological, sociocultural, developmental, and spiritual. The optimal goal for use of the model is attainment and retention of wellness in the client, despite reactions in the client system, including intrapersonal, interpersonal, and extrapersonal stressors from both internal and external sources.

\section{Summary}

Heart failure is a debilitating disease that negatively impacts those afflicted by it. People with heart failure have difficulty performing their jobs, household tasks, and, in the later stages of the disease, self-care. These functional limitations due to heart failure symptoms are often accompanied by social and emotional problems and decreased quality of life (Chung et al., 2013; Vanhoof et al., 2014). Medical costs are high due to emergency room visits, hospitalizations, follow-up appointments, and multiple medications.

Nurses can play an integral role in educating people with heart failure about the dangers of the risk factors that are intrapersonal stressors for heart failure and can enhance understanding of the importance of healthy lifestyles. The nurse is a vital member of the interdisciplinary team that must work together in identifying the modifiable risk factors leading to heart failure. 
Developing successful health promotion strategies to preserve health and prevent progression of heart failure will require nursing knowledge and expertise. Therefore this study used a substructured model of Neuman's secondary prevention and intrapersonal stressors to examine the relationship between modifiable risk factors and levels of functioning in terms of physical, social, and emotional well-being in an Appalachian population. 


\section{Chapter 2: Review of the Literature}

A literature search was conducted to examine what is known about modifiable risk factors associated with levels of functioning in persons with heart failure. Search results revealed that research on risk factors is vast, and a number of predictive models exist for determining the probability of having a cardiovascular event including heart failure. The search also included looking for research on modifiable risk factors specifically among rural Appalachian populations.

\section{Literature Search Process}

EBSCOhost was used to search the CINAHL, MEDLINE, PsychARTICLES, and PsychINFO databases in four separate searches for each of the risk factors being studied in the current study: nutrition, obesity, physical activity, and smoking. The search terms "heart failure" and "obesity," "smoking," "nutrition," and "physical activity" were designated to appear in the article title, and "risk factors" was to appear in the abstract. This strategy was used to ensure that the literature was focused solely on heart failure, as opposed to all cardiovascular diseases, and each of the individual risk factors. Because this search strategy found only one article for "heart failure" and "smoking," the search was expanded to include articles with "heart failure" and "smoking" in the title and "risk factors" appearing in all text. The search was limited to peer-reviewed articles, studies in humans, subjects 18 years of age and older, publication in the English language, and publication dates between 2010 and 2016. The search identified 38 articles (Supplemental Materials, Table S1). Fifteen articles resulted from the "obesity" and "heart failure" search with one being a duplicate and one not in the English language. For the search terms "smoking" and "heart disease" seven articles were identified. Two were duplicates, 
leaving five articles for inclusion in the review. The "nutrition" and "heart disease" search netted six articles with one not in the English language. Ten articles were identified through the "physical activity" and "heart disease" search, but two of them were duplicates, leaving eight for inclusion in the literature synthesis. In total, 31 articles were reviewed.

\section{Quantitative Studies}

Thirty-one quantitative studies were reviewed (See Figure 1). Fourteen studies were secondary analyses, seven were integrative literature syntheses, and three were prospective cohort studies; the remaining five articles included a systematic review, a meta-analysis, a correlational case-control study, a cross-sectional descriptive study, and an observational study. Of these 31 studies, 22 were done in the United States, three in the United Kingdom, and one each in Australia, Denmark, Japan, Korea, Spain, and Sweden.

\section{Nutrition}

Two of the five articles exploring the relationship between nutrition and heart failure were secondary analyses using data from the European Prospective Investigation into Cancer and Nutrition (EPIC), which was a study of 25,639 men and women, 39 and 79 years of age, recruited between 1993 and 1997 in Norfolk, UK. One study examined the association between bone mineral density and the development of heart failure (Pfister et al., 2014) and the other study was aimed at determining the association between plasma vitamin $\mathrm{C}$ and heart failure (Pfister, Sharp, Luben, Wareham, \& Khaw, 2011). Pfister et al. (2014) studied 380 patients who developed heart failure during the nine-year follow-up period who had a bone density test done through a quantitative ultrasound of the calcaneum. An inverse association between bone mineral density and the risk of heart failure was revealed, supporting the need for cardiac assessment in 
patients with reduced bone mineral density. The analysis on plasma vitamin C (Pfister et al., 2011) was conducted on 1,258 people who developed heart failure during the 13-year follow-up, and an inverse association was also found between plasma vitamin $\mathrm{C}$ levels and the risk of heart failure.

The National Health and Nutrition Examination Survey (NHANES) was used in two studies to evaluate adherence to national guidelines for sodium intake and recommendations for a low-fat, low-cholesterol diet and medication adherence among patients with early, Stage A heart failure (Kovell, Juraschek, \& Russell, 2015; Lama Tamang et al., 2014). Findings revealed that people with heart failure are inadequately treated for risk factors including hypertension, hyperlipidemia, and diabetes (Lama Tamang et al., 2014). Adherence to lifestyle modifications including physical activity, smoking, alcohol consumption, and sodium intake is poor, pointing to the urgent need for secondary prevention measures to minimize risk factors and increase adherence to lifestyle modification guidelines. Kovell et al. (2015) emphasized the high prevalence of Stage A heart failure, defined as an absence of heart failure symptoms in U.S. adults who have comorbid conditions including coronary artery disease, diabetes, hypertension, or chronic kidney disease. Many of those with Stage A heart failure are not being properly treated for these comorbidities and are at increased risk for progression to symptomatic heart failure, which points to the importance of primary care providers assessing for risk factors and aggressively treating comorbid conditions.

Esch and Hendryx (2011) examined the relationship between salt intake and the development of heart failure and concluded that high salt intake is related to left ventricular hypertrophy (LVH) independent of blood pressure. Because high blood pressure and LVH are risk factors for heart failure patients, those who have high salt intake are at risk for retention of 
salt and water, leading to exacerbation of heart failure symptoms and disease progression. A reduction in salt intake from 9-12 g/day to the recommended level of $<5-6 \mathrm{~g} /$ day will have beneficial effects among patients with heart failure (He, Burnier, \& Macgregor, 2011).

\section{Obesity}

Obesity is a risk factor for heart failure in both men (11\%) and women (14\%) and because obesity prevalence is increasing, the incidence of heart failure will continue to rise (Alpert, Lavie, Agrawal, Aggarwal, \& Kumar, 2014; Ebong et al., 2014). The literature syntheses on heart failure and obesity included the epidemiology and clinical manifestations of obesity; metabolic risk factors; the obesity paradox; chronic kidney disease; cardiopulmonary exercise testing; and effect of cachexia and frailty on patient outcomes (respectively, Alpert et al., 2014; Ebong et al., 2014; Horwich \& Fonarow, 2010; Jindal, Whaley-Connell, \& Sowers, 2013; Lavie et al., 2013; Lavie et al., 2014). A study of 200 patients with heart failure indicated that reduced physical fitness levels along with increased risk for comorbidities explain the detrimental effects of obesity on cognitive dysfunction (Alosco et al., 2015). The authors recommend prospective studies of heart failure patients to verify this association and determine the pathophysiology of weight loss and potential improvements in cognitive function. A prospective cohort study of patients with and without metabolic syndrome admitted to a hospital in Japan for treatment of worsening heart failure examined the impact of obesity on prognosis (Narumi et al., 2014). Metabolic syndrome was defined as follows: BMI $\geq 25 \mathrm{~kg} / \mathrm{m}^{2}$; triglycerides $\geq 150 \mathrm{ml} / \mathrm{dL} ; \mathrm{HDL}<40 \mathrm{mg} / \mathrm{dL}$ in men and $<50 \mathrm{mg} / \mathrm{dL}$ in women; fasting blood sugar $\geq 110$ $\mathrm{mg} / \mathrm{dL}$ or diabetes diagnosis; and blood pressure $\geq 130 \mathrm{mmHg}$ systolic and/or $\geq 85 \mathrm{mmHg}$ diastolic or a prescription of antihypertensive medication. Patients were followed for two years and were divided into obese and non-obese groups. The effect of metabolic syndrome on 
prognosis was measured with outcomes including death due to heart failure, myocardial infarction, stroke, other vascular problems, sudden cardiac death, or rehospitalization for heart failure exacerbation. Results found favorable outcomes among obese patients without metabolic syndrome but not in obese patients with metabolic syndrome.

Three studies focused on the "obesity paradox" that may exist among patients with heart failure in that those who are mildly obese or overweight have been found to have a better prognosis than patients who are normal weight (Ebong et al., 2014; Lavie et al., 2014; Zapatero et al., 2012)). Evidence shows that obesity induces changes in cardiac hemodynamics, structure, function, and conduction leading to endothelial dysfunction and vascular changes (Ebong et al., 2014). These changes contribute to metabolic derangements involving insulin resistance, secretion of adipokines and inflammatory markers, and cardiac lipotoxicity. In addition, patients who are obese have increased incidence of obstructive sleep apnea and obesity hypoventilation syndrome, which are risk factors for heart failure. Yet, mildly obese or overweight heart failure patients can have a better prognosis than those with normal weight. Further understanding of the obesity paradox is needed before weight loss guidelines for heart failure management can be developed. Lavie et al. (2014) explored the obesity paradox specifically examining frailty and cardiac cachexia in relation to poor prognosis among heart failure patients. The recommendations drawn from this synthesis were that weight loss in heart failure patients should be reserved for those with BMI $>35 \mathrm{~kg} / \mathrm{m}^{2}$ and that improving cardiorespiratory fitness, increasing lean muscle mass, and muscle strengthening could lead to improvements in prognosis. Zapatero et al. (2012) performed a secondary analysis of the Minimum Basic Data Set of patients $(\mathrm{N}=370,983)$ discharged with a primary or secondary diagnosis of heart failure from internal medicine services in hospitals of the Spanish National Health System between 2006 and 2008. 
The purpose of the study was to determine the association of obesity and malnutrition on acute heart failure. International Classification of Diseases, $9^{\text {th }}$ Revision Clinical Modification (ICD-9CM) codes for obesity and malnutrition were used to identify these conditions in patients with heart failure listed as a primary or secondary diagnosis. Findings support the obesity paradox by showing that obesity in patients was associated with reduced in-hospital mortality risk and reduced possibility of early readmission. Conversely, patients with malnutrition had increased inhospital mortality and increased risk of readmission within 30 days of discharge.

Alpert et al. (2014) concluded that severe obesity produces hemodynamic alterations that possibly lead to cardiac remodeling and changes in ventricular function that can result in left ventricular and right ventricular heart failure. Their findings suggest that weight loss is an effective method of reversing abnormalities of cardiac performance and morphology that can improve the clinical manifestations of heart failure in patients with cardiomyopathy. Horwich and Fonarow (2010) concluded that an urgency exists to identify modifiable risk factors of diabetes, obesity, and metabolic syndrome leading to heart failure. Because these risk factors are reaching epidemic levels, lifestyle interventions aimed at decreasing the prevalence of these syndromes are paramount and aggressive treatment of hypertension, dyslipidemia, and hyperglycemia is needed to reverse the increasing incidence of heart failure in the United States.

Lavie et al. (2013) studied cardiopulmonary exercise testing and the impact of obesity on treatments including heart transplantation and use of left ventricular assistive devices (LVADs), along with the role of weight loss in the prevention and treatment of heart failure. Findings showed that a BMI $\geq 30 \mathrm{~kg} / \mathrm{m}^{2}$ is associated with poor outcome in heart transplants in patients with heart failure. The implantation of LVADs is not contraindicated in obese patients and may 
assist in successful intentional weight loss but continual monitoring is necessary to prevent dangerous weight reduction that may lead to cachexia and the obesity paradox.

Limited data exist upon which recommendations are based for intentional weight loss in patients with heart failure. Nagarajan, Cauthen, Starling, and Tang (2013) analyzed data on 501 patients with advanced heart failure who were referred to a tertiary-care center between 2007 and 2010 for cardiac transplantation. Patients were categorized into three groups: non-obese (BMI $\leq 30 \mathrm{~kg} / \mathrm{m}^{2}$ ), obese (BMI $30.1-40 \mathrm{~kg} / \mathrm{m}^{2}$ ), and morbidly obese (BMI $\geq 40 \mathrm{~kg} / \mathrm{m}^{2}$ ). Among patients with end-stage heart failure, obese patients had more favorable outcomes than non-obese patients. Because heart failure is a cachectic disease they theorized that the high metabolic reserve in obese patients allows for tolerance of the catabolic effects of heart failure. Lower Btype natriuretic peptide (BNP) levels are seen in obese patients, but very high BNP levels were found in the morbidly obese patients. The obesity paradox has been confirmed in many studies, but results from this study show that this paradox may not extend to the morbidly obese.

Secondary analysis of the Atherosclerosis Risk in Communities Study (ARIC), a study of community-based, middle-aged individuals, was done to determine the prognostic value of $\mathrm{N}$ terminal pro-brain natriuretic peptide (NT-proBNP) levels for heart failure risk across BMI categories (Ndumele et al., 2016). The ARIC study was conducted in four communities in Maryland, Mississippi, North Carolina, and Minnesota with recruitment and baseline data collection occurring between 1987 and 1989. Patients were followed up at three-year intervals with the last follow-up visit completed between 2011 and 2013. Findings revealed an inverse relationship between BMI and NT-proBNP levels. NT-proBNP is independently associated with heart failure and provides a prognostic indicator of heart failure beyond traditional risk factors even among patients with obesity. Because obesity is a risk factor for heart failure, these results 
suggest that even modest NT-proBNP levels may be a useful clinical indicator of heart failure incidence in patients with $\mathrm{BMI} \geq 30$. Although NT-proBNP levels were not measured in this current study, if findings showed a relationship between obesity and outcome measures, this would indicate that primary and secondary prevention recommendations for NT-proBNP screening among obese people in Appalachia may be warranted.

Schmidt, Botker, Pedersen, and Sorensen (2014) conducted a population-based cohort study using data from the Draft Board in Northern Denmark and the Danish National Patient Registry and examined the relationship between young adulthood obesity and long-term risk of heart failure. Draft Board data were collected from men in the 1955 and 1965 birth cohorts $(\mathrm{N}=$ $12,850)$ and follow-up data from up to 36 years later were collected on 107 patients from those cohorts who were diagnosed with heart failure. Findings showed that men with obesity in early adulthood were at increased risk for both ischemic heart disease (IHD) and heart failure. The absolute risk was highest for IHD, but the relative risk was even higher for heart failure. Additionally, hypertension was determined to be the most influential mediator of BMI-associated risk of IHD and heart failure.

A prospective cohort study using data from the British Heart Study $(\mathrm{N}=12,850)$, a study of men from 24 British towns, was undertaken to examine the contribution of plasma leptin concentration in relation to the risk factors of BMI and waist circumference in the incidence of heart failure (Wannamethee, Shaper, Whincup, Lennon, \& Sattar, 2011). The British Heart Study collected data on men 40 to 59 years of age between 1978 and 1980 and a 20-year follow-up was done on surviving men (aged 60 to 79 years) from 1998 to 2000. Two hundred twenty-eight men diagnosed with heart failure out of the 4,080 men analyzed at a mean nine-year follow-up period were included in this study. Leptin regulates alterations in myocardial metabolism leading to 
cardiac hypertrophy and possibly cardiac remodeling and is normally increased in patients with heart failure. Results indicated that in men with no preexisting coronary heart disease at baseline, obesity and heart failure may be mediated by leptin. However, among those with existing heart disease, leptin was not a factor in the association between BMI and heart failure. In this study, BMI was used as a measure of obesity as a predisposing factor for heart failure.

\section{Physical Activity}

Seven articles on physical activity among patients with heart failure were reviewed including a meta-analysis, three literature syntheses, two secondary analyses, and one crosssectional descriptive study. A meta-analysis of 10 cohort studies $(\mathrm{N}=282,889)$ was conducted with follow-up periods ranging from 7 to 30 years (Echouffo-Tcheugui, Butler, Yancy, \& Fonarow, 2015). Subjects who had the highest and lowest levels of physical activity were included in the analysis $(\mathrm{N}=165,695)$. Results showed an association between regular physical activity and lower incidence of heart failure. A similar association exists between level of physical fitness and the incidence of heart failure. This inverse relationship between physical activity and fitness and risk of heart failure was found in both men and women and in cohorts from the United States and Northern Europe. Additionally, significant effects of physical activity on heart failure exist in the elderly.

Du, Everett, Newton, Salamonson, and Davidson (2012) explored the conceptual underpinnings of self-efficacy to barriers to being physically active. Findings showed that low adherence to physical activity recommendations is found among persons with heart failure. Physical activity is an important component of heart failure management and self-efficacy is known to be the strongest predictor of adherence. The authors suggest the theoretical foundation of self-efficacy could provide the basis for community-based exercise programs, which may be 
superior to traditional exercise programs in terms of reaching larger groups of people in addition to promoting long-term adherence to physical activity recommendations. A study of 116 patients with chronic heart failure in Korea also revealed the importance of exercise self-efficacy in improving patient-centered outcomes, physical functioning, physical activity, and quality of life (Lee et al., 2017). The authors suggest that nurses need to be proactive in promoting exercise self-efficacy through patient education aimed at teaching patients with heart failure the importance of physical activity despite challenges inherent to their chronic condition.

Similar findings by Nayor and Vasan (2015) showed that increased levels of physical activity and decreased levels of sedentary time along with improved cardiorespiratory fitness are associated with a lower risk of heart failure. They suggest the mechanisms that may explain these findings include reducing the prevalence of cardiovascular risk factors, preventing cardiac remodeling, enhancing physiologic remodeling, and improving vascular, renal, pulmonary, skeletal muscle, neurohormonal, and cardiac functioning (Nayor \& Vasan, 2015). Additional research is needed to determine the type of physical activity, optimal timing, and duration of exercise necessary to prevent heart failure.

Miller and Gunstad (2016) described the relationship between physical activity and cognition in older adults with heart failure. They found that lower levels of functional capacity have consistently been linked to poorer cognitive outcomes among patients with heart failure and that cognitive dysfunction is associated with adverse health outcomes and increased disability and mortality. As heart failure progresses there is an increased risk of cognitive dysfunction and an associated decline in physical activity due to functional limitations. Interestingly, highintensity exercise has a positive effect on cognitive functioning and there does not appear to be 
an increased risk of adverse events when patients with heart failure engage in this level of exercise.

deFilippi et al. (2012) analyzed data from the Cardiovascular Heart Study (CHS), a multicenter, prospective, observational cohort study of cardiovascular disease in older adults. Data were collected from 1989 to 1990 for the initial cohort and 1992 to 1993 for a solely African American cohort. Measures of physical activity and troponin T (cTnT) and N-terminal pro-B-type natriuretic peptide (NT-proBNP) serum levels were included in the analysis. Results revealed that new onset of heart failure is inversely associated with the extent of physical activity. A strong inverse relationship exists between higher levels of physical activity in ambulatory older adults and a lower probability of increases in cTnT and NT-proBNP over time. Recommendations were made for regular monitoring of these biomarkers to provide an early indication of the pathophysiology associated with a sedentary lifestyle and the risk of developing heart failure. Neither cTnT nor NT-proBNP levels were measured in this present study; however, findings revealed a relationship between physical activity and outcome measures, thus secondary prevention recommendations for screening of these serum levels among people in Appalachia may be warranted.

Kraigher-Krainer et al. (2013) examined the relationship between inactivity in the elderly and heart failure risk using data from the Framingham Heart Study, a prospective cohort study of a community-based sample. Baseline data were collected in 1948, with follow-up every two years. Study data were from the 20th biannual examination (1986-1990) and excluded those with heart failure (at baseline), myocardial infarction, renal disease, and absence of data for physical activity $(\mathrm{N}=1,142)$. Lower physical activity was found to be associated with higher incidence of heart failure. This association existed in both heart failure with preserved ejection fraction 
(HFPEF) and heart failure with reduced ejection fraction (HFREF). Among the elderly, greater physical activity was associated with a lower risk of HFPEF.

Data from the National March Cohort were collected during a Swedish Cancer Society fundraising event in 3,600 cities and villages in Sweden to investigate nonlinear associations of total and leisure time activity with the risk of heart failure (Andersen et al., 2014). Data on persons who were not previously diagnosed with heart failure were included in the study. Participants completed a 32-page questionnaire on physical activity, diet, medical history, and lifestyle factors. Results demonstrated that both total physical activity and leisure time physical activity were inversely related to the risk of developing heart failure. These findings support the recommendation that people engage in 150 minutes or more of moderate-intensity physical activity per week to reduce heart failure risk.

\section{Smoking}

The literature on heart failure and smoking consisted of four secondary analysis studies using data from the Cardiovascular Health Study (CHS) (Ahmed et al., 2015); the Health, Aging, and Body Composition (Health ABC) study (Gopal et al., 2012); the Multicenter Automatic Defibrillator Implantation Trial-Cardiac Resynchronization Therapy (MADIT-CRT) study (Plank et al., 2014); and the Survival and Ventricular Enlargement (SAVE) trial (Shah et al., 2010). CHS is an ongoing, prospective population-based study of cardiovascular risk factors among community-dwelling adults 65 years of age and older $(\mathrm{N}=4,482)$. Ahmed et al. (2015) found the risk of heart failure and death for former smokers who have quit for more than 15 years becomes similar to that of persons who have never smoked. Former heavy smokers (>32 pack-years of former smoking) were found to have a risk similar to that of current smokers of developing heart failure but have a lower risk of mortality. The Health ABC study was 
conducted on community-dwelling men and women living in Pittsburgh, PA, and Memphis, TN (Gopal et al., 2012). Physiological measures, blood samples, performance measures, and questionnaire responses were obtained at baseline, and follow-up was done every six months alternating between in-person and telephone interviews. Analysis of data from 1,165 nonsmokers, 738 past smokers, and 221 current smokers showed that current and past cigarette smoking increases heart failure risk. Among current smokers the risk is high regardless of packyears of exposure, and in past smokers the higher the pack-years of exposure the greater the risk of heart failure. Plank et al. (2014) analyzed data from the MADIT-CRT study, which included patient data from 110 hospitals in the United States, Canada, and Europe $(\mathrm{N}=1,820)$. Exclusion criteria eliminated 331 patients $>75$ years of age, 19 patients who did not have device implantation data, 25 patients with no smoking data, and 3 patients without smoking or device data, leaving 1,442 subjects in the analyses. Results showed that current smokers with mild heart failure and left ventricular dysfunction are at significantly higher risk of ventricular tachyarrhythmia or death than past smokers or nonsmokers.

The SAVE trial data were used to determine the risk decrease associated with smoking cessation in patients with left ventricular systolic dysfunction after myocardial infarction (MI) (Shah et al., 2010). The SAVE trial was a randomized controlled trial of the efficacy and safety of captopril (ACE inhibitor) after a high-risk MI with a left ventricular ejection fraction $<40 \%$. Patients were enrolled 3 to 16 days after an MI. Smoking status was assessed at randomization, two weeks after randomization, and three months after randomization for the first year and every four months after randomization for five years. At the time of enrollment, subjects were asked whether they had ever smoked cigarettes and whether they had smoked within three weeks of hospitalization. Smoking status was assessed at each follow-up by asking whether subjects had 
smoked since the previous visit. Intermittent smokers at follow-up were classified as smokers. Findings were that among patients with left ventricular dysfunction after an MI, smoking cessation is associated with a $40 \%$ lower risk of all-cause mortality and a $30 \%$ lower risk of death or recurrent MI or heart failure hospitalization.

An observational study aimed at determining the association of nocturnal ventricular arrhythmias in patients with heart failure was conducted on 86 men who were admitted to the hospital for two consecutive nights of attended polysomnography (Javaheri, Shukla, \& Wexler, 2012). Subjects received a detailed physical exam, lab work, and a pulmonary function exam, and a sleep history was obtained. Major findings of the study were that the incidence of nocturnal ventricular tachyarrhythmia is higher among current smokers, those with sleep apnea, and those with plasma alkalosis. Sleep difficulty is measured by one of the questions on the MLHFQ (Rector, 2005), which was administered in the current study.

\section{Literature on Heart Failure in Rural Populations}

A literature search with "heart failure" and "rural" in the title and "risk factors" in the abstract found four articles published since 2010, and these were examined to investigate previous findings regarding risk factors for heart failure in rural populations. None of the literature focused on risk factors for heart failure specific to the Appalachian population despite the fact that hospitalization rates for heart failure in Appalachia are among the highest in the nation (Casper et al., 2010).

In a study on older adults with heart failure residing in rural areas of southwestern and southeastern Ontario, Canada, the health promotion behaviors (HPB) and barriers to accessing care were examined (Goetz-Perry, 2010). The study expands on previous research that revealed rural values and context complicate existing barriers faced by clients and result in tradeoffs and 
delays to accessing support for HPB. Rural values also compounded conflicts in the clientprovider relationship. The findings illustrate that the decisions of rural older adults with heart failure to access support for HPB are influenced by perceived needs, rural values, and contextual issues, which focus on issues unique to rural populations such as health disparities, low literacy, and social support systems. A multitude of external factors exist, which include support from informal caregivers and primary healthcare professionals, and study results reveal gaps in the types of support people in rural areas receive. The findings validate the importance of tailoring complex nursing interventions to the needs and context of recipients with multiple comorbidities experiencing health disparities and were used to identify discrete elements to be included in the design of a nurse-led heart failure intervention program intended to meet the unique needs of rural recipients.

Muus et al. (2010) studied hospital discharge data on 36,566 veterans with heart failure and found that those living in rural areas readmitted to the hospital within 30 days of discharge tended to be older, had higher disability status, and had longer hospitals stays. Follow-up visits with Veterans Affairs (VA) were inversely associated with readmissions among both rural and urban veterans. In addition, rural veterans over the age of 65 years who had VA emergency room visits following discharge had a higher risk of readmission. Findings suggest rural veterans with heart failure need special attention during discharge planning and require follow-up with primary care providers.

Five hundred seventy-five adults living in rural areas in California, Kentucky, and Nevada were recruited from outpatient clinics and hospitals and were randomly assigned to one of three groups: usual care, an education program with minimal follow-up, or an education program with attention to individualization and biweekly follow-up (Moser et al., 2015). 
Subjects completed the Short Test of Functional Health Literacy in Adults (STOFHLA) to measure health literacy and they were followed up for at least two years. Findings revealed that health literacy is a predictor of all-cause mortality and rehospitalization among rural patients with heart failure. Because lower levels of health literacy are known to exist among the Appalachian population, surveys used must be at a lower readability level. The MLHFQ has a mean grade level of 7.35 (Gromoske, Oldridge, \& Brondino, 2011).

Verdejo, Ferreccio, and Castro (2015) studied the literature beginning with the earliest research published in 1966 on heart failure among people living in rural areas and found that they are at increased risk of adverse cardiovascular events. The investigators found that rural areas have fewer healthcare providers, a greater distance to healthcare centers, fewer physicians, increased reliance on general practitioners, and a high turnover among healthcare staff. Results point to the need for improved multidisciplinary support to facilitate early heart failure diagnosis and optimize treatment through the use of monitoring technologies, closer adherence to therapeutic guidelines, and outpatient self-management for rural patients with heart failure in an effort to prevent hospitalization and death.

\section{Qualitative Studies}

An expanded search using "rural" and "qualitative research" in all text and "heart failure" in the abstract resulted in five articles. Weierbach, Glick, and Lyder (2011) conducted semistructured interviews on 20 elderly people with heart failure and identified the following four themes: Accepting Limitations, Disappointments and Unmet Expectations, Figure It Out, and Complex Connections. Freydberg, Strain, Tsuyuki, McAlister, and Clark (2010) conducted semistructured interviews on 42 patients and 30 caregivers in rural Canada and found that work was seen as an integral part of life in rural settings. Subjects conveyed that work is pleasurable 
and a vital part of meaningful life in rural areas. Heart failure and self-care were framed in broader narratives of work and its benefits and the threats and disruptions to work caused by heart failure. Stevenson, Pori, Payne, Black, and Taylor (2015) interviewed 25 veterans and found that these patients think in terms of symptoms that increase the impact that heart failure has on their lives; that they do not have a clear view of the relationship between daily weights and controlling heart failure; and that discharge instructions should clearly associate the symptoms related to worsening of heart failure. Retrum et al. (2013) conducted semistructured interviews of 28 patients readmitted within six months of a heart failure admission. Findings from these interviews revealed that patient experiences were highly heterogeneous and that the readmissions were not easily categorized as preventable versus not preventable and were not easily attributable to a single cause. Results suggest future interventions designed to reduce heart failure readmissions should be multifaceted, be systemic in nature, and integrate patient input.

Goetz-Perry's doctoral research (Goetz-Perry, 2010), discussed above, involved interviews with 27 participants: rural older adults with heart failure $(n=10)$, their informal caregivers $(n=6)$, and their primary healthcare providers $(n=11)$. The findings illustrated that the decisions of rural older adults with heart failure to access support for health promotion behaviors are influenced by perceived needs, rural values, contextual issues, and external factors and that gaps exist in the types of support they receive. The study expands on previous research that revealed that rural values and context complicate existing barriers faced by clients and result in tradeoffs and delays to accessing support for health promotion behaviors. Rural values also compounded conflicts in the client-provider relationship. The findings validate the importance of tailoring complex nursing interventions to the needs and context of recipients with multiple comorbidities experiencing health disparities and were used to identify discrete elements to be 
included in the design of a nurse-led heart failure intervention program tailored to the unique needs of rural recipients.

\section{Theoretical Rationale}

Neuman's Systems Model provided the theoretical underpinnings for this study. Betty Neuman initially developed the model for graduate nursing students to introduce the magnitude of nursing issues prior to teaching course content on specific nursing problem areas (Fawcett, 2005a). The philosophical basis of the model is "helping each other live." Beliefs about wholism, reality, and wellness along with assumptions about human beings, spirituality, the environment, health, and nursing are integral to the model.

The focus of Neuman's Systems Model is the wellness of the client in relation to environmental stress and evoked stress reactions (Neuman \& Fawcett, 2011). A main concept of the model is the client/client system, which encompasses the individual, family, community, and social issues. There are five interacting variables in the concept: the physiological, psychological, sociocultural, developmental, and spiritual. The optimal goal for use of the model is attainment and retention of wellness in the client, despite reactions in the client system, including intrapersonal, interpersonal, and extrapersonal stressors from both internal and external sources.

At the central core of the model are basic survival factors such as regulation of body temperature, genetic response patterns, and body organ strengths or weaknesses (Neuman \& Fawcett, 2011). Surrounding the central core are, first, lines of resistance that protect the basic structure's survival factors through stabilization of the client system, promoting a return to wellness. Next is the normal line of defense, which is the client/client system's normal state of wellness. The outermost boundary of the model is the flexible line of defense, which provides a 
protective buffer that prevents stressors from invading in an attempt to maintain the client's normal or stable state.

Neuman defines three types of stressors that can affect these lines of defense: intrapersonal, interpersonal, and extrapersonal (Neuman \& Fawcett, 2011). Intrapersonal stressors are those internal to the client/client system, such as conditioned responses and behaviors. Interpersonal stressors are external environmental forces outside but proximal to the client/client system, which often occur due to role expectations or communication patterns. Social policy or financial concerns typify extrapersonal stressors, which occur outside the client/client system structure.

Reconstitution is defined by Neuman as the energy increase related to the degree of reaction to a stressor (Neuman \& Fawcett, 2011). Reconstitution requires energy from the client, or basic structure, to move through the lines of resistance and normal line of defense to regain stability and wellness in the client. Successful reconstitution requires mobilization of client resources to prevent further stressor reaction and optimization of existing resources for client system stability or wellness preservation. Inability to achieve reconstitution results in death due to the failure of the basic structure.

Neuman developed the concept of Prevention as Intervention, which has three distinct dimensions: Primary Prevention as Intervention; Secondary Prevention as Intervention; and Tertiary Prevention as Intervention (Fawcett, 2005a). Primary prevention is the knowledge that is applied in client assessment and intervention to identify and reduce risk factors related to environmental stressors to prevent potential reactions. Secondary prevention is related to the symptoms that result from reaction to a stressor and involves treatment of symptoms to attain 
client stability resulting in wellness and energy conservation. Last, tertiary prevention consists of wellness maintenance following treatment provided through secondary prevention interventions. Neuman's Systems Model as applied to patients with heart failure is appropriate because of the intrapersonal stressors of poor nutrition, obesity, lack of physical activity, and smoking that impact both the flexible and normal lines of defense (See Figure 2). Through primary prevention heart failure may be avoided; however, once a person has heart failure the importance of secondary prevention is paramount. Educating the client about heart failure and its treatments is essential to restoring wellness and delaying disease progression. Secondary prevention through the early identification of heart failure will strengthen the normal line of defense through early treatment aimed at restoring a state of wellness. The flexible line of defense must be reinforced to protect against current stressors and prevent future stressors from invading, in an attempt to maintain or restore the client's normal or stable state of physical functioning and social and emotional well-being.

Secondary prevention interventions in the model include manipulation of stressors and reactions to stressors; facilitation of treatment and intervention measures; supporting positive factors toward wellness; promoting advocacy by coordination and integration; and optimizing the client/client system's internal and external resources to attain stability and energy conservation (Fawcett, 2005a). Secondary prevention among people with heart failure is important because primary prevention was not achieved and the flexible line of defense has been penetrated due to a new diagnosis or exacerbation of heart failure. Intrapersonal stressors in the form of poor diet, obesity, sedentary lifestyle, and smoking often exist and are capable of penetrating and moving the flexible line of defense and may also impact the normal line of defense. To combat these stressors, secondary prevention for heart failure should include 
strengthening of the client/client system's internal and external resources, which would include changing lifestyle behaviors that impact heart failure disability. Treatment of the negative behavior factors to return clients to their usual state of wellness is important at this stage (Dalusung-Angosta, 2013). The nursing goal for secondary prevention is to prevent further complications from heart failure and to decrease the stressors, thereby strengthening the lines of resistance that protect the basic core. Prevention at this level must include education about the risks leading to heart failure and lifestyle modification aimed at the elimination of these risk factors. Neuman's Systems Model provides an excellent framework for the study, given its emphasis on secondary prevention, as one of the dimensions of Prevention as Intervention, aimed at reducing the identified risk factors that are intrapersonal stressors for heart failure (Dalusung-Angosta, 2013; Fawcett, 2005a).

\section{Synthesis}

Low bone mineral density and low vitamin C levels were both found to be inversely related to the risk of heart failure (Pfister et al., 2014; Pfister et al., 2011). High salt intake among persons with heart failure leads to salt and water retention that can lead to an exacerbation or progression of their disease, therefore a reduction in salt intake from 9-12 g/day to the recommended level of <5-6 g/day should be prescribed (Esch \& Hendryx, 2011). NHANES data revealed that people with heart failure are inadequately treated for risk factors including hypertension, hyperlipidemia, and diabetes (Lama Tamang et al., 2014). Proper treatment of these comorbidities must include lifestyle modifications including dietary changes.

A study of 200 patients with heart failure indicated that reduced physical fitness levels along with increased risk for comorbidities explain the detrimental effects of obesity on cognitive dysfunction (Alosco et al., 2015). Obese patients with metabolic syndrome had less 
favorable prognoses when compared to obese patients without metabolic syndrome based on outcomes including death due to heart failure or rehospitalization for heart failure exacerbation (Narumi et al., 2014). The "obesity paradox" has been studied in people with heart failure and results revealed that those who are mildly obese or overweight have been found to have a better prognosis than patients who are normal weight (Ebong et al., 2014; Zapatero et al., 2012). The obesity paradox led to a recommendation that weight loss in heart failure patients should be reserved for those with $\mathrm{BMI}>35 \mathrm{~kg} / \mathrm{m}^{2}$ and that frail patients with heart failure need exercise programs aimed at improving cardiorespiratory fitness, increasing lean muscle mass, and muscle strengthening that could lead to improvements in prognosis (Lavie et al., 2014). Obese people with heart failure have lower levels of B-type natriuretic peptide (BNP) than those who are not obese; however, very high BNP levels were found in morbidly obese patients, suggesting that the obesity paradox may not extend to the morbidly obese (Nagarajan et al., 2013).

\section{Discussion}

The literature on risk factors among people with heart failure provides findings in varied areas of inquiry. Although some risk factors are nonmodifiable, there are many modifiable risk factors that, given the proper intervention, could be reduced or eliminated, resulting in a decreased incidence of heart failure. Poor nutrition plays an important role in the development and progression of heart failure. Reducing and monitoring salt intake is vital in the prevention and management of heart failure. Obesity is a risk factor for heart failure but a paradox exists that shows that, because of the cachectic nature of heart failure, persons who are overweight or obese have more favorable outcomes than persons of normal weight. Physically active people have a lower incidence of heart failure. Additionally, physical activity is important in persons with heart failure to help them maintain functional capacity and slow the progression of disease. 
Smoking has also been shown to be a risk factor for heart failure. Smoking cessation has a beneficial effect on health outcomes for people with heart failure.

The literature on nutrition and heart failure points to the need for increases in the intake of calcium-rich foods, fruits, and vegetables since the association with bone density and higher levels of vitamin C plasma levels may be predictive of heart failure. Because poor nutrition is a risk factor for heart failure it was assessed in this study through the use of the American Heart Association Life's Simple 7 Questionnaire (AHA, 2010). This questionnaire assesses fruit and vegetable intake, providing an indicator of whether subjects may be at risk for low vitamin C levels, thereby increasing their risk of heart failure.

The prevalence of obesity in West Virginia is among the highest in the nation (CDC, 2015), so it was essential to address it in this study. This study explored the relationship of obesity as measured by body mass index (BMI) with physical functioning and social and emotional well-being. The health consequences of obesity are vast but there are some unique characteristics of obesity in patients with heart failure that must be considered, as revealed in the literature review. In this study, BMI was measured along with diabetes and hypertension, which are requisites for metabolic syndrome and thus subjects with these conditions are predisposed to that diagnosis, placing them at higher risk for poorer outcomes. The current study measured sodium intake using the Life's Simple 7 Questionnaire (AHA, 2010) to allow some insight into lifestyle choices that may negatively impact blood pressure and heart failure symptoms. Rather than ICD-9-CM codes (as used by Zapatero et al., 2012), in this study BMI was used to assess obesity and its relationship with physical functioning, social well-being, and emotional wellbeing. 
The obesity paradox could be measured in this study through the use of BMI as well, comparing obese and underweight patients in terms of the outcome measures of physical functioning and social and emotional well-being. A relationship between obesity and outcomes among heart failure patients in Appalachia could provide a basis for future research aimed at interventions to reduce obesity, thereby preventing disease progression and complications.

In this study, physical activity levels were measured using the Duke Activity Status Index (DASI). This questionnaire measures both physical and sedentary activities. A relationship between activity levels and outcome measures could dictate the need for possible secondary prevention aimed at increasing physical activity, which may result in enhanced physical, social, and emotional well-being.

Cognitive function, which the literature review revealed can be related to both physical activity and obesity among persons with heart failure, was not measured directly in the current study, but it was taken into consideration since subjects were required to complete questionnaires. Recruitment of subjects was done carefully and those with decreased cognitive ability or dementia were excluded. However, one of the questions on the MLHFQ asks the patient about difficulty concentrating or remembering things, and although this is a measure of emotional well-being it may indicate a level of cognitive dysfunction (Garin et al., 2014).

This study examined the relationship of modifiable risk factors and levels of functioning among Appalachian patients with heart failure to help further support for specialized interventions in this population. For rural populations, the literature review found that self-care, a measure related to level of functioning, is important among people in rural settings (Freydberg et al., 2010). Questions on the MLHFQ address hospital stays and ability to work to earn a living, which has been shown to be paramount to those living in rural areas and loss of which negatively 
affects those with heart failure (Retrum et al., 2013; Stevenson et al., 2015; Weierbach et al., 2011). Since little research has been done in Appalachia, this study provides insight into the effect that heart failure has on the lives of those living in this region.

There is a gap in the literature on heart failure in the Appalachian population, a population unique in its health behaviors, socioeconomic status, and access to healthcare. In addition, a major gap in the literature exists for modifiable risk factors in relation to levels of functioning among persons with heart failure in the Appalachian population. Literature that does exist on the Appalachian population is not specific to the northern Appalachian region, where this study took place, nor does it focus solely on heart failure but includes all coronary artery and/or cardiovascular disease.

This study provides knowledge of which risk factors have a detrimental effect on levels of functioning and allows clinicians to focus on interventions targeted at reducing or eliminating these risk factors, thereby having the greatest impact on improving functioning among those with heart failure. The identification of these risk factors in the Appalachian population provides the basis for secondary prevention measures aimed at reducing the incidence of heart failure. 

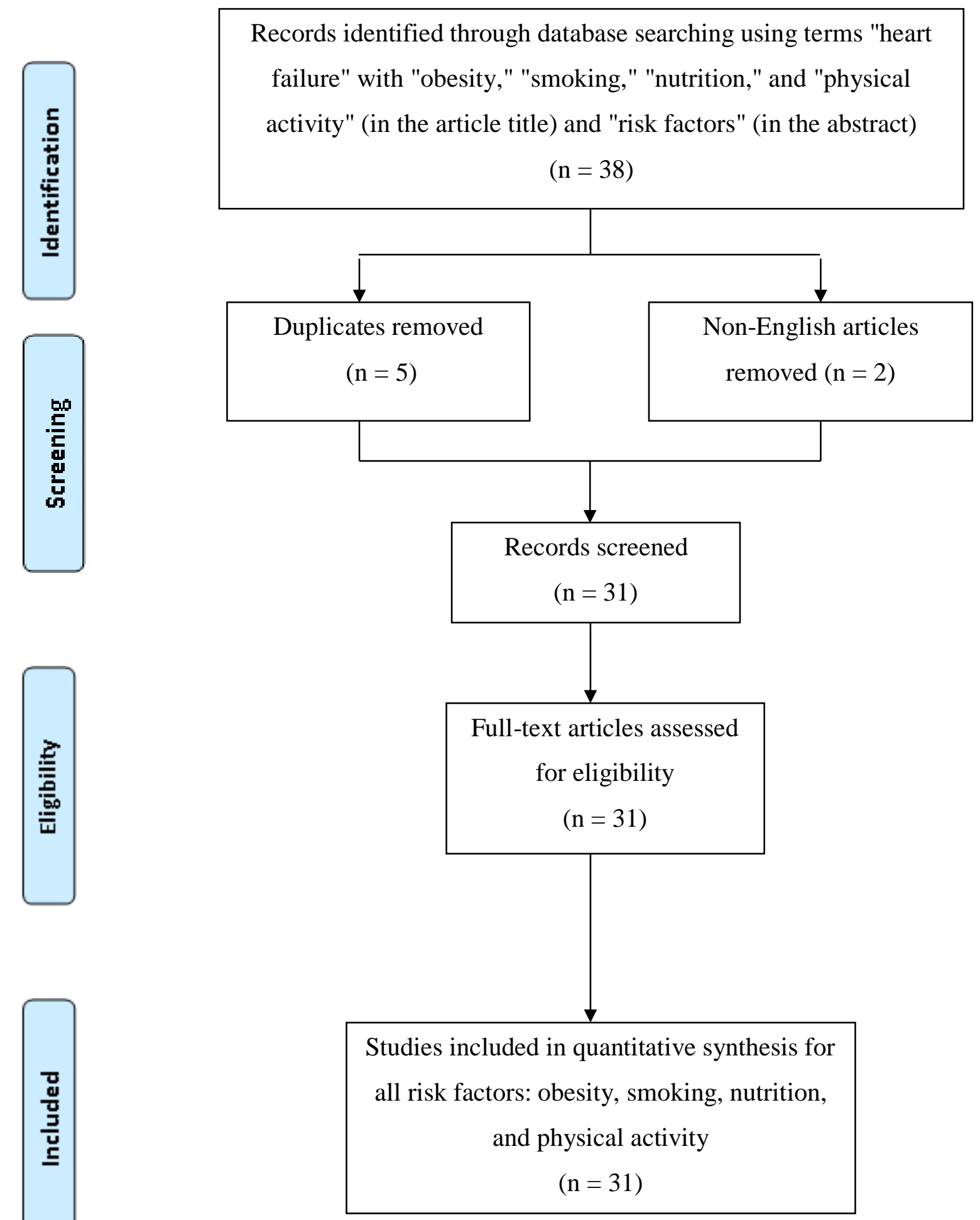

Figure 1. Literature search result: identification, exclusion, eligibility, and included 


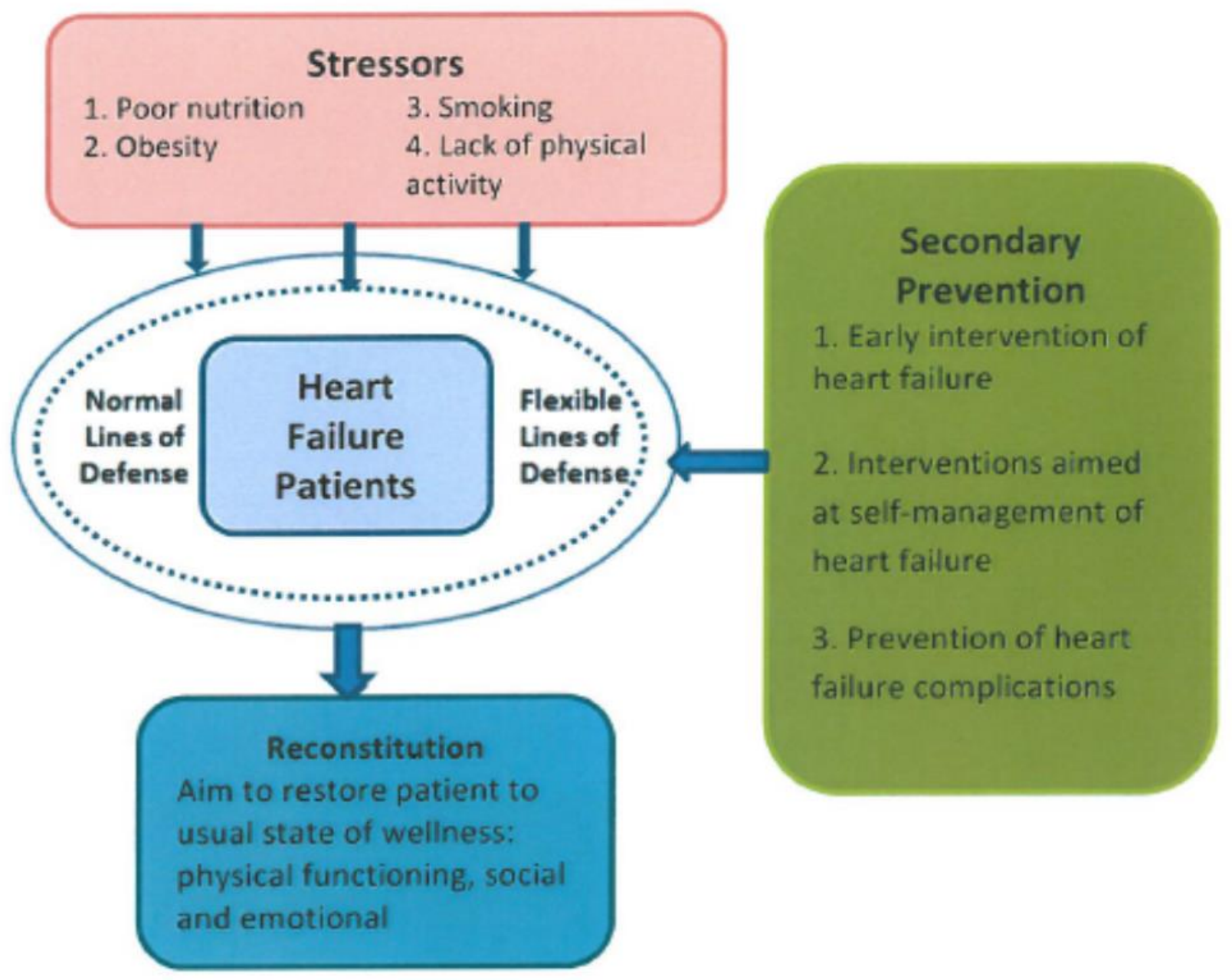

Figure 2: Neuman's Systems Model: Heart Failure Patients 


\section{Chapter 3: Methods}

A cross-sectional, descriptive study was conducted to describe modifiable risk factors associated with heart failure outcomes among people living in Appalachia and the relationships of the identified risk factors. Modifiable risk factors studied include nutrition, obesity, physical activity, and smoking. Heart failure outcomes were measured by the levels of functioning in terms of physical, social, and emotional well-being among Appalachian patients with heart failure. The research question for this study was: What is the relationship between modifiable risk factors and levels of functioning as measured by physical, social, and emotional well-being for Appalachian patients with heart failure?

Because heart failure is more prevalent among those living in Appalachia than in the US population in general (Casper et al., 2010), it is important to identify the modifiable risk factors of the Appalachian population in order to formulate targeted interventions. According to Neuman's Systems Model, used as the conceptual basis for this study, secondary prevention measures such as nutrition education or a dietician consult, physical activity programs, and/or smoking cessation are essential to decreasing or eliminating stressors inherent to heart failure and strengthening the lines of defense that help to maintain stability of the disease (Narsavage, 1997).

\section{Research Design}

A cross-sectional, convenience sample was used to study 115 people with heart failure who were residents of Sundale Nursing Home, patients of the West Virginia University (WVU) Heart and Vascular Institute or Family Medicine Outpatient Clinic, or who were hospitalized at Ruby Memorial Hospital. 


\section{Population and Sample Size}

The target population was residents of Sundale Nursing Home, patients seen at WVU's Heart and Vascular Institute or Family Medicine Outpatient Clinic, or individuals who were hospitalized at Ruby Memorial Hospital with a primary or secondary diagnosis of heart failure. Sundale Nursing Home is a 100-bed facility in Morgantown, West Virginia, offering 24-hour skilled nursing care, physical and occupational therapy, restorative nursing, dietician consults, and palliative care. WVU's Heart and Vascular Institute is staffed by cardiologists, cardiac surgeons, electrophysiologists, and interventional radiologists who treat heart disease, heart attacks, and heart failure. WVU's Family Medicine Outpatient Clinic provides comprehensive primary care services including behavioral medicine and is centered on helping patients receive managed care provided by physicians, residents, and midlevel providers. Ruby Memorial Hospital in Morgantown, West Virginia, is a tertiary-care teaching hospital with 524 beds and is a Level One Trauma Center with Magnet recognition for nursing. Patients who are residents or patients at these four healthcare facilities come from counties throughout West Virginia, western Maryland, and southwest Pennsylvania, which are all within the Appalachian region. Based on clinical knowledge of the population seen at these facilities, a representative sample of patients with heart failure living in Appalachia was expected, and was obtained, even with convenience sampling.

Inclusion criteria were adults 18 years of age and older who were able to consent and who presented to the study sites for care. Exclusion criteria were persons who were pregnant, incarcerated, had dementia or mental illness that prevented them from answering the surveys accurately, or who had a terminal illness. The patient's healthcare providers were educated about these exclusion criteria and did not refer patients with these conditions for the study. 
G-Power was used to calculate a sample size of 115 for correlation analysis with a moderate effect size (0.3) and an alpha error of .05. Based on the numbers of persons with heart failure at the four study sites, this sample size was determined to be attainable given the fourmonth time frame allotted for subject recruitment and data collection.

\section{Instrumentation}

Risk factors were identified using multiple questionnaires to collect and record selfreported responses during the investigator's sessions with each subject (Supplemental Materials, Table S2). Patient demographics were collected using an investigator-developed form that included age, gender, ethnicity, race, education level, income, comorbidities, and current medications. Nutrition was measured using the American Heart Association Life's Simple 7 Questionnaire (AHA, 2010). Body mass index was used to assess obesity and was obtained from the patient's medical record or the referring provider. The Duke Activity Status Index (DASI) was used to assess physical activity level (Hlatky et al., 1989). The Global Adult Tobacco Survey was used to measure tobacco smoking prevalence (CDC, 2011). The measures included physical functioning, social well-being, and emotional well-being, which were assessed with the Minnesota Living With Heart Failure Questionnaire (MLHFQ) (Garin et al., 2013).

\section{American Heart Association Life's Simple 7 Questionnaire}

The Life's Simple 7 Questionnaire, a dietary questionnaire developed by the AHA (2010), asks questions on the amount of fruit, vegetables, and whole grains consumed on an average day; number of servings of fish and sugary beverages consumed each week; and sodium intake. This six-item questionnaire was adapted from AHA's My Life Check My Life Heart Score Assessment and provides a basic nutritional assessment and in this study assessed whether 
subjects were adhering to the dietary recommendations for heart health (Appendix A). The Dietary Approach to Stop Hypertension (DASH) diet is recommended by the AHA, and it includes a diet rich in fruits, vegetables, whole grains, and fish and low in sodium and sugar. Because healthcare providers should be prescribing the DASH diet for heart failure patients, the Life's Simple 7 Questionnaire allowed for the assessment of dietary habits that may indicate a risk.

\section{Global Adult Tobacco Survey}

Three tobacco smoking prevalence questions from the Global Adult Tobacco Survey (GATS) were used to assess smoking status. This questionnaire was developed in response to the WHO Framework Convention on Tobacco Control calling for an efficient and systematic mechanism to monitor the tobacco epidemic (CDC, 2011). The GATS Core Questionnaire consists of 20 items measuring current and present tobacco use, amount and frequency of use, attempts to quit, physician recommendation to quit, and notice of advertising of tobacco products. Subsets of the GATS questions have been developed that can be used as a stand-alone module or included in other surveys (CDC, 2011). For the purposes of this study, three questions were asked to determine current tobacco use; past use or current less-than-daily smokers; and past use for current nonsmokers (Appendix B).

\section{Duke Activity Status Index}

The Duke Activity Status Index (DASI) is used to determine functional status through a 12-item questionnaire that assesses the respondent's ability to perform activities ranging from eating, dressing, and bathing to participation in strenuous sports including swimming, tennis, and skiing (Hlatky et al., 1989). The responses to each item range from 1, "can perform activity with difficulty," to 4, “cannot perform activity at all” (Wu, Lennie, Frazier, \& Moser, 2016) 
(Appendix C). Responses to each item are weighted based on metabolic equivalency task (MET), a unit that is used to quantify the intensity of physical activity and is commonly used to measure abilities among people with cardiovascular disease including heart failure (Lee et al., 2017). Based on the AHA recommendation of walking for 30 minutes per day for five days per week, a minimum for recommended physical activity is equivalent to a MET score of 495 (Lee et al., 2017).

In a prospective, observational study 313 patients with heart failure were analyzed through secondary analysis of registry data (Wu et al., 2016). Functional status as measured by DASI was independently associated with cardiac events and risk of reduced event-free survival. Similarly, Parissis et al. (2009) also found among 130 patients hospitalized for heart failure exacerbation that event-free survival was significantly lower in patients with elevated B-type Natriuretic Peptide (BNP) levels (>697) and low DASI scores $(<8)$ when compared to those with lower BNP levels $(<697)$ and higher DASI scores $(>8)$. Another study assessing the effects of a home-based exercise program for adults with New York Heart Association (NYHA) class II and class III heart failure revealed that after 12 weeks of exercise, responses on the DASI improved but not at a statistically significant level (Gary, Cress, Higgins, Smith, \& Dunbar, 2011). Thirty African American patients with heart failure were studied to determine the role of physical activity and cardiac rehabilitation in their functional ability to care for themselves as measured by DASI (McCarthy, Katz, Schipper, \& Dickson, 2015). This mixed method study found that $43 \%$ of the subjects reported doing no exercise or less than 30 minutes of exercise in the past week. When participants were asked whether they were told by their provider to exercise, $53 \%$ said they were told to do minimal exercise while $23 \%$ said they were told nothing about exercising. Two themes stemmed from the narratives: "given up" and "still trying." The authors 
point to the need for increased awareness by providers of current physical activity guidelines and the need to educate this minority population with heart failure on the benefits of exercise.

The reliability and validity of DASI has been tested and confirmed in many studies, with Cronbach's $\alpha$ ranging from .82 to .92 (Fan, Lee, Frazier, Lennie, \& Moser, 2015; McCarthy et al., 2015; Nelson et al., 1991; Parissis et al., 2009; Wu et al., 2016). Fan et al. (2015) tested the psychometric properties of the DASI on 297 patients with heart failure and found the internal consistency reliability to be high (Cronbach's $\alpha=.86$ ) when comparing scores between patients with Class I and II and those with Class III and IV NYHA functional classification. Construct validity was also supported when the strength of the relationship of DASI scores was compared with MLHFQ scores, NT-proBNP plasma levels, and Beck Depression Inventory-II and negative correlations on these validation measures were found (Fan et al., 2015). DASI was an appropriate tool for the purposes of this study based on its widespread use in research on heart failure patients.

\section{Minnesota Living With Heart Failure Questionnaire}

The Minnesota Living With Heart Failure Questionnaire (MLHFQ) was designed in 1984 to measure quality of life of individuals with heart failure and receiving treatments for their condition (Appendix D). The questions were designed to measure the ways that heart failure and the associated treatment can affect the major physical, emotional, social, and mental aspects of quality of life. Thomas S. Rector developed the instrument in consultation with physicians and nurses caring for heart failure patients at the University of Minnesota. Responses to the Sickness Impact Profile, which is a comprehensive tool to measure illness in general, were used along with consultation with the aforementioned health professionals to identify appropriate questions for measuring the effects of heart failure on quality of life in these particular patients. The 
resulting questions include measures of physical and psychological symptoms, physical/social functioning, and interactions and relations with family and friends. Physical symptoms questions include those related to shortness of breath, fatigue, peripheral edema, and difficulty sleeping. Physiological symptoms investigated include anxiety and depression. Physical/social functions are assessed through activities such as walking, climbing stairs, household work, need to rest, working to earn a living, going places away from home, doing things with family or friends, recreational activities, sexual activities, eating, and the mental and emotional functions of concentration, memory, loss of self-control, and being a burden to others. The instrument also takes into account the side effects and benefits that treatments might have in alleviating the effects of the heart failure, and thus questions are included on side effects of medications, hospital stays, and cost of care.

The MLHFQ includes 21 questions that respondents are asked to answer on a six-point Likert scale from zero to five, indicating how much each item questioned prevents them from living life as they want to. The total score is used as the best measure of how heart failure and the associated treatments affect the quality of life of afflicted patients.

\section{Reliability of MLHFQ}

The seminal research done on the MLHFQ was conducted in 1987 and revealed a weighted kappa of 0.84 , showing a strong relationship between most individual items and the overall score (Rector, Kubo, \& Cohn, 1987). Several studies have demonstrated the high reliability of the MLHFQ by estimates of repeated baseline assessments and Cronbach's $\alpha$, which ranged from .92 to .94 (S. J. Bennett et al., 2003; Kubo et al., 2004; Riegel et al., 2002). A meta-synthesis done on eight studies from 21 countries that included 3,847 patients with heart failure found Cronbach's $\alpha$ coefficients of $.90, .84, .72$, and .92 for the physical, emotional, 
social environment, and total score, respectively (Garin et al., 2013) (see Supplemental Materials, Table S3).

\section{Validity of MLHFQ}

The correlations of patients' overall rating of how much their heart failure prevented them from living life as they wanted obtained by the MLHFQ $(r=0.80)$ and the NYHA classification $(r=0.60)$ indicated that the MLHFQ is a valid representation of impairment in this population (Rector et al., 1987). The NYHA classifications are based on physicians' subjective assessment of a patient's reported symptoms when carrying out various activities of daily living (Rankin, Briffa, Morton, \& Hung, 1996). A limitation of the NYHA classification is that the method of assigning the classes is not well defined and therefore the interrater reliability has been found to be poor (Holland et al., 2010). It has been suggested that having patients assess their own NYHA class may provide a more accurate measure of their condition (J. A. Bennett, Riegel, Bittner, \& Nichols, 2002; Holland et al., 2010). Because those with heart failure live with symptoms that affect their ability to perform activities of daily living, they may be best suited to assess their own functional status based on the personal, environmental, social, and psychological factors that impact their lives (J. A. Bennett et al., 2002). This study did not include NYHA classes designated by the subjects themselves; however, additional research must be conducted on self-assigned NYHA classes to assure validity and reliability. High internal consistency was found when the MLHFQ was compared to other commonly used measures of quality of life on instruments such as the Chronic Heart Failure questionnaire, Functional Status Scale, Emotional Distress test, SF-12 survey, Six-minute walk test, and ejection fraction (Rector, 2005). 
Exploratory factor analysis was performed on data from the MLHFQ and the three-factor solution with a quartimin rotation revealed better results than the two- and four-factor analysis (Garin et al., 2013). When the structure was fixed in the confirmatory factor analysis, the model resulted in excellent goodness of fit coefficients. Furthermore, the confirmatory factor analysis confirmed a single one-dimensional latent construct for the total score, which included all 21 items.

Construct validity was found in the MLHFQ total score, which discriminated between NYHA classes II and III/IV (Heo et al., 2005). The MLHFQ total score was moderately correlated with symptom status, and with health perception and the Specific Activity Scale, which is a 13-item self-administered questionnaire used to measure functional capacity. Heo et al. (2005) reported a Cronbach's $\alpha$ for the MLHFQ total score of .91, and a Cronbach's $\alpha$ for the MLHFQ physical and emotional scores of .91 and .85 , respectively.

Garin et al. (2014) conducted a systematic evaluation of seven health-related quality-oflife instruments designed for use in heart failure patients and found the MLHFQ and the Kansas City Cardiomyopathy Questionnaire (KCCQ) to be superior to the others considering all the attributes measured. The attributes included conceptual and measurement model, reliability, validity, sensitivity to change, interpretability, burden, and alternative modes of administration.

The MLHFQ was the most highly rated of all seven instruments on reliability and obtained good ratings for validity and ability to detect change over time.

\section{Data Collection}

The data collection process began with referral from the patient's healthcare provider or nurse clinician, followed by informed consent, and administration of the surveys (see Supplemental Materials, Table S4). Patients who met the eligibility criteria were approached 
about participation in the study by their healthcare provider or nurse clinician. Upon completing an informed consent, surveys were administered using the Qualtrics data collection system. The surveys took approximately 20 to 30 minutes of the subject's time. Subjects were asked whether they felt comfortable taking the survey on a tablet; if not, they were given the option of taking it in hardcopy form with the assistance of the researcher. Alternatively, the research nurse asked the questions verbally and recorded the answers in the Qualtrics system. If patients were unable to complete the survey at the time of consent, a hard copy along with a self-addressed stamped envelope was left with them to complete and return at their convenience. A token of appreciation for participation was granted in the form of a $\$ 15$ gift card. Data were cleaned and coded prior to data analysis.

\section{Data Analysis}

Bivariate analyses were used for demographics and basic descriptive analyses, including chi-square $\left(\chi^{2}\right)$ tests on categorical data and t-tests for continuous data. Due to a non-normal distribution of the data, nonparametric analogs were used for analysis. These statistics were used to describe the sample and each risk factor variable, as detailed below. Spearman's rank correlation coefficient $(\rho)$ examined relationships among interval level variables. Continuous data were analyzed using Mann-Whitney U test to compare medians across two groups and Kruskal-Wallis test was used to compare medians across three groups. One-way analysis of variance (ANOVA) was used to compare the variances between the groups with the variability within each group. This analysis allowed for the identification of risk factors related to levels of functioning, which provides insights for clinicians on which interventions might be employed in an attempt to reduce or eliminate these risk factors in order to achieve the greatest impact on improving functioning among Appalachian patients with heart failure. Missing data were 
addressed by following guidance/consultation with a statistician. Analyses were conducted using SPSS version 24 (IBM Corporation, 2016). Model construction using ordinal logistic regression with the NYHA classes as the functional limitation was not possible due to missing NYHA data and the data structure.

1. Among Appalachian patients with heart failure, what is the relationship between nutrition and levels of functioning as measured by physical, social, and emotional well-being? Nutrition habits were measured using the AHA Life's Simple 7 Questionnaire. Responses to each of the six questions were scored from 0, “needs improvement," to 2, "ideal." Descriptive statistics were run on each of the six questions to identify nutritional habits. Chi-square $\left(\chi^{2}\right)$ values were calculated to explore the relationship between nutrition and age, gender, and education. Spearman's Rho was used to compare the continuous data from the MLHFQ with the Life's Simple 7 data to determine the correlation between the variables. The strength of the relationship was determined based on the following criteria: small, $r=.10$ to .29 ; medium, $r=$ .30 to .49 ; large, $r=.50$ to 1.0 . The Kruskal-Wallis test was done to compare physical, social, and emotional well-being scores between groups with different levels of nutritional status. ANOVA was used to compare the mean differences between nutritional status and physical, social, and emotional well-being.

2. Among Appalachian patients with heart failure, what is the relationship between obesity and levels of functioning as measured by physical, social, and emotional well-being? Obesity was measured using the following BMI 
categories: obese $\left(\mathrm{BMI} \geq 30 \mathrm{~kg} / \mathrm{m}^{2}\right.$ ); overweight (BMI 25.0-29.9 kg/m²); normal weight (BMI 18.5-24.9 kg/m²); and underweight (BMI $<18.5 \mathrm{~kg} / \mathrm{m}^{2}$ ). Descriptive statistics were run on the BMI categories to determine the numbers and percentages of people in each category. Chi-square $\left(\chi^{2}\right)$ values were also calculated to determine the relationship between BMI and education. Spearman's Rho was used to compare the continuous data from the MLHFQ with BMI categories to determine the correlation between the variables. The Kruskal-Wallis test was used to compare subjects in different BMI groups in terms of their levels of functioning as measured by physical, social, and emotional well-being domain scores from the MLHFQ. The mean differences between BMI categories and physical, social, and emotional wellbeing were compared using ANOVA.

\section{Among Appalachian patients with heart failure, what is the relationship} between physical activity and levels of functioning as measured by physical, social, and emotional well-being? Physical activity was measured by the DASI, a 12-item questionnaire with "yes" or "no" responses to each question. Each question has weighted response values that can be seen in Appendix C. The DASI score is the sum of weights for "yes" replies. The measured peak oxygen consumption $\left(\mathrm{VO}_{2}\right)$ peak and metabolic equivalency task (MET) values were calculated from the DASI score based on the following equations.

One MET is the amount of oxygen consumed per minute while at rest.

$$
\begin{aligned}
& \mathrm{VO}_{2}\left(\mathrm{~mL}^{*} \mathrm{~kg}^{-1} * \mathrm{~min}^{-1}\right)=0.43 \text { X DASI }+9.6 \\
& 1 \mathrm{MET}=3.5 \mathrm{~mL}^{*} \mathrm{~kg}^{-1} * \mathrm{~min}^{-1} \mathrm{VO}_{2}
\end{aligned}
$$


The MET score was used to determine which subjects were considered to be active and which inactive. Chi-square $\left(\chi^{2}\right)$ values were calculated using these activity classifications and gender and education level. To compare physical activity with levels of functioning, a Mann-Whitney U test was used to determine the differences between active and inactive participants and MLHFQ scores for physical, social, and emotional well-being.

\section{Among Appalachian patients with heart failure, what is the relationship} between smoking and levels of functioning as measured by physical, social, and emotional well-being? Smoking data from the GATS resulted from three questions. The first question asked whether the respondents currently smoke tobacco on a daily basis, less than daily, or not at all. The second question asked whether they have smoked in the past, and the final questions was only asked of those who had smoked in the past to determine whether they had smoked daily or less than daily. Descriptive statistics provided the number and percentages of smoking occurrence past and present among the respondents. Chi-square $\left(\chi^{2}\right)$ values were calculated on smoking status and gender and education level. Spearman's Rho was used to compare smoking status with the MLHFQ scores for physical, social, and emotional well-being. The MannWhitney U test was used to assess differences between smokers and nonsmokers and their levels of physical, social, and emotional well-being. ANOVA was used to compare the mean differences between smoking status and physical, social, and emotional well-being. 


\section{Human Rights and Ethical Considerations}

The study was submitted to WVU's Institutional Review Board for ethical review and protection of human subjects. All subjects meeting the inclusion criteria were provided the opportunity to voluntarily be part of the study. The informed consent was reviewed with the participants by the research nurse or graduate assistant and any questions about the study were answered prior to their signing the consent form. Confidentiality of the participants was maintained by keeping all data coded to participants through a random number and maintaining any connected data in a separate locked file available only to the investigator. A copy of the informed consent was provided to the participant. The benefit of participating was helping others to eliminate risk factors correlated with heart failure, a benefit that outweighed the minimal risks of participation. The risks of participating in the study may have included fatigue and frustration from answering the questions from multiple surveys.

\section{Methods to Assure Rigor}

Several methods were used to assure rigor of the research, including strict adherence to inclusion and exclusion criteria, which have been described above. The large sample size of 115 subjects ensured adequate statistical power. Survey instruments used in the study had a Cronbach's $\alpha$ of greater than .80 to ensure internal consistency (Polit \& Beck, 2012).

\section{Advantages and Limitations of the Design}

The advantages of this cross-sectional descriptive research design were that a convenience sample was used, thereby facilitating recruitment efforts. However, because of this sampling method, selection bias exists, thereby limiting causal inferences (Polit \& Beck, 2012). The cross-sectional design is economical and made this research feasible due to limited external 
funding. However, the design only allowed for data collection at one time point, which eliminated the ability to determine potential changes in risk factors over time. The crosssectional design allowed for the efficient collection of a large amount of data, but selection bias is a limitation. The descriptive design allowed for the relationship between the variables to be explained, but inferences of causality are not possible.

\section{Feasibility of Research}

The study research was feasible because of the investigator's past working relationship with both administrators and providers within Sundale Nursing Home, Ruby Memorial Hospital, the WVU Heart and Vascular Institute, and the WVU Family Medicine Outpatient Clinic. The research entailed the recruitment and collection of data for patients living in Appalachia who were residents or patients within these four study sites. Permission to conduct the proposed research was obtained from administration within each of these facilities and several meetings with providers and nurse researchers were held in advance of data collection to discuss the feasibility of and procedures for the study. A small financial incentive was offered to participants based on the awarding of internal funding from the WVU School of Nursing.

Recruitment rates of heart failure patients in research range between $27 \%$ and $48 \%$ (Bdeir et al., 2015; Pressler et al., 2008; Tsang, Alter, Wijeysundera, Zhang, \& Ko, 2012; Zambroski, Buck, Garrison, \& McMillan, 2014). Bdeir et al. (2015) evaluated the impact of a nurse-led heart failure program on all cause mortality through a retrospective review of 413 patients admitted to the hospital with heart failure exacerbations. All of these patients were invited to participate in the nurse-led program and 199 patients (48\%) agreed and were compared to the 214 patients who chose usual care. Another study recruiting patients at two different sites had a 72\% recruitment rate, and $48 \%$ completed the study at the first site and $74 \%$ completed the study at the second site 
(Pressler et al., 2008). Top reasons that eligible patients refused to participate were lack of interest, lack of time, and being too sick. The authors suggest that investigators need to devote financial and personnel resources to enhance recruitment among heart failure patients. A systematic review of women's enrollment in 328 randomized clinical trials revealed a $27 \%$ successful recruitment rate among women agreeing to participate (Tsang et al., 2012). Zambroski et al. (2014) approached 99 eligible patients for a study of hospice heart failure patients and 32 agreed to participate $(32.3 \%)$.

For this study, considering even the worst-case scenario of a $27 \%$ recruitment rate, only 426 patients would have needed to be available collectively at all four sites over the four-month data collection period. After meetings with administration at the study sites it was evident that the number of patients with heart failure treated at these four sites would far exceed 426 . Upon Institutional Review Board (IRB) approval, subject recruitment and data collection commenced and continued until the sample size was met.

\section{Summary}

Knowing the risk factors that have the largest detrimental effect on levels of functioning allows clinicians to focus on interventions targeted at reducing or eliminating these risk factors, thereby having the greatest impact on improving functioning among those with heart failure in Appalachia. These study results may help identify the secondary prevention interventions aimed at reducing these risk factors in an effort to decrease the disproportionate incidence of heart failure among people living in Appalachia. This information could suggest targeted future interventions aimed at the prevention or earlier identification of heart failure. Studying patients receiving care at four study sites with large patient volumes allowed for successful recruitment of a large sample size that permitted inferences to be made about risk factors related to heart failure 
among this Appalachian population. The internal consistency of all survey instruments assured adequate rigor of the research. The limitation of this research method was convenience sampling, which limits the generalizability of results. 


\section{Chapter 4: Results}

This study was conducted to examine the relationship between modifiable risk factors and levels of functioning in terms of physical, social, and emotional well-being among Appalachian patients with heart failure. A complete description of the data collection process, data cleaning and coding, and analysis results are provided in this chapter. Results are organized according to the four specific study aims outlined in Chapter 1 .

\section{Data Collection}

Data were collected from a convenience sample of 117 subjects recruited from four locations: Sundale Nursing Home, Ruby Memorial Hospital, the WVU Heart and Vascular Institute, and the WVU Family Medicine Outpatient Clinic. A description of each recruitment site can be found in Chapter 3. Recruitment began after IRB approval on January 24, 2017, and was completed on April 25, 2017, after the number of surveys determined to be necessary was collected. Two subjects recruited at different times by the investigator and trained assistants took the survey twice; however, only the initial survey from each of these subjects was included in the data analysis, resulting in the desired sample size of 115.

Permission to recruit subjects from Sundale Nursing Home was granted by the facility's Medical Director and a patient list was generated of all residents with a diagnosis of heart failure using the ICD-10 codes 150.30, Unspecified diastolic (congestive) heart failure; 150.32, Chronic diastolic (congestive) heart failure; 150.40, Unspecified combined systolic and diastolic (congestive) heart failure; 150.43, Acute on chronic combined systolic and diastolic heart failure; and 150.9, Heart failure, unspecified. Of the 21 patients on the list, 11 met the study eligibility criteria and 10 were excluded because of an existing diagnosis of dementia. One of the eligible 
11 patients had speech difficulties and was not approached for the study and two declined to participate, leaving eight patients who participated.

Permission was obtained from the WVU Nursing Research and Evidence-Based Practice Council to recruit inpatients hospitalized with heart failure at Ruby Memorial Hospital and those being seen as outpatients at the WVU Heart and Vascular Institute and Family Medicine Outpatient Clinic.

A total of 72 inpatients were recruited from Ruby Memorial Hospital. Daily inpatient lists of all patients admitted with a primary or secondary diagnosis of heart failure were obtained from the Congestive Heart Failure Nurse Clinician. Assistance with recruitment and data collection among inpatients at Ruby Memorial Hospital was obtained from a Clinical Research Specialist and two students working in the WVU Department of Family Medicine. These three assistants were oriented to the study and trained in recruitment of subjects and survey administration. Detailed training in data collection techniques was done to ensure the fidelity of the survey administration. To ensure uniformity and integrity of data collection, the investigator observed these three assistants the first two times that they recruited subjects and administered the survey. Every third survey of the 15 that they administered was reviewed to ensure no patterns of missing data existed. One of these 15 surveys was not used in data analysis because the patient had been recruited and administered the survey previously by the investigator.

Working with the Heart Failure Program Coordinator at the WVU Heart and Vascular Institute, patients were recruited at their hospitalization follow-up appointment or at a regular outpatient appointment. During the patient's appointment the Heart Failure Program Coordinator gave the patient the study recruitment flyer (Appendix E) and asked whether he or she was 
interested in participating. All 22 patients asked to participate agreed and the investigator proceeded with the consent form and survey administration.

During a monthly meeting of the WVU Family Medicine Department a presentation was made to the physicians and staff to make them aware of this research project. As a result of this meeting, a list of all patients with heart failure who had appointments at the Family Medicine Outpatient Clinic between January and April was provided. Physicians and midlevel providers were given copies of the recruitment flyer to give to their patients during their appointments, and all 13 patients who were asked whether they were interested agreed to participate in the study.

\section{Treatment of Data}

Data were collected either directly into the Qualtrics electronic data collection system (Qualtrics, 2016) or gathered via a hard-copy survey from which responses were subsequently entered into the Qualtrics software. Upon completion of data collection, data from the Qualtrics program were exported into the Statistical Package of Social Sciences (SPSS) program (IBM Corporation, 2016) for data analysis. Data in both Qualtrics and SPSS were stored on devices that are password protected and along with the hard-copy surveys, which are kept in a locked file cabinet, were kept in a locked office when not being used.

Data were cleaned prior to analysis by analyzing frequencies and descriptive statistics to determine the extent of missing data and to identify outliers. Missing data were limited on all variables with the exception of the NYHA class data, which had 17 missing values, representing $14.8 \%$ of the sample. To account for missing data, cases were excluded pairwise during analysis, which eliminates the subject's data only if data required for a specific analysis are missing.

Outliers were found in both the age and BMI data: these were verified as correct by checking the subject's medical chart and thus were included in the analysis. 


\section{Assessment of Statistical Assumptions}

Normality of the data was assessed through analysis-generated histograms and normal QQ plots and the Kolmogorov-Smirnov statistic for all predictor and outcome variables (Pallant, 2010). The distributions displayed in the histograms and normal Q-Q plots were not normally distributed in any of the variables. Kolmogorov-Smirnov statistics for the variables were all significant, suggesting a violation of the assumption of normality. Skewness and kurtosis were also assessed and confirmed the non-normal distribution of the data. When correlation analysis was performed scatterplots were generated and interpreted. Because a linear relationship was not seen between the variables, Pearson correlations could not be used and alternatively the nonparametric Spearman's Rho test was used. Due to the violations of assumptions needed for parametric statistical analysis, nonparametric analyses were utilized, including the Spearman's Rho, Mann-Whitney, and Kruskal-Wallis tests (Pallant, 2010).

A chi-square $\left(\chi^{2}\right)$ test for independence was used to explore the relationship between categorical variables. Cells with an expected frequency of 5 or greater are required for a chisquare test to meet the required assumption.

When ANOVA was used for data analysis, sample size was taken into consideration along with multicollinearity and singularity, outliers, normality, linearity, homoscedasticity, and independence of residuals, which were all assessed. A large sample size is preferable so that results may be generalized to other samples. The formula developed by Tabachnick and Fidell (2007) for calculating required sample size, $N>50+8 m$, where $m$ is the number of independent variables, was applied and the recommended sample size of $74(N>50+8[3]=$ 74) was exceeded in this study $(\mathrm{N}=115)$. 
As discussed earlier the outliers were included in the analysis because the data were verified and deemed to be accurate. Residual scatterplots were generated and checked for normality, linearity, and homoscedasticity. Collinearity statistics were checked to ensure that tolerance was always $>.10$ and variance inflation factors (VIF) were always $<10$. Levene's statistic was assessed for values $>.05$, which indicated that assumptions of homogeneity of variance were not violated.

\section{Results}

Detailed demographic findings and statistical examination of findings among the study population are presented at the beginning of this section. Following that, the findings of this study are reported according to the four specific areas of inquiry, nutrition, obesity, physical activity, and smoking, as outlined in relation to the research questions in Chapter 1.

Table 1 displays the comprehensive data of the subjects' demographic characteristics. Of the 115 people who agreed to participate in the study, $65(57 \%)$ were male and $50(44 \%)$ female. The vast majority were white (93\%). Twenty-six (23\%) of the participants had less than a high school education, 44 (37\%) completed their education through the high school level, and 45 $(40 \%)$ had at least some college. Sixty-four subjects (55\%) reported an income of less than $\$ 24,000$ per year before taxes, $29(25 \%)$ reported an income of between $\$ 25,000$ and $\$ 49,999$, and 20 subjects $(18 \%)$ reported incomes of greater than $\$ 50,000$ annually. Two participants did not report income, one who did not know the answer and one who refused to answer this question. 
Table 1: Demographic Characteristics of Sample

\begin{tabular}{lcc}
\hline \multicolumn{1}{c}{ Demographic Variable } & N & Percent \\
\hline Gender & 65 & 56.5 \\
Male & 50 & 43.5 \\
Female & & \\
Ethnicity & 107 & 93.0 \\
White & 5 & 4.3 \\
Black & 1 & .9 \\
Hispanic & 2 & 1.7 \\
Asian & & \\
Education Level & 1 & .9 \\
No formal education & 6 & 5.2 \\
Completed elementary & 19 & 16.5 \\
Some high school & 43 & 37.4 \\
Completed high school & 24 & 20.9 \\
Some college & 8 & 7.0 \\
Associate's degree & 7 & 6.1 \\
Bachelor's degree & 2 & 1.7 \\
Master's degree & 1 & .9 \\
Other & 4 & 3.5 \\
GED & & \\
Income & 64 & 55.7 \\
< \$24,000 & 29 & 25.2 \\
\$25,000 - \$49,999 & 10 & 8.7 \\
\$50,000 - \$74, 999 & 6 & 5.2 \\
\$75,000 - \$99,999 & 4 & 3.5 \\
\$100,000 or more & &
\end{tabular}

The mean age of the participants was 67 years (range, 23-90) (Table 2). The wide range in ages reflects the diverse patient populations seen at the four sites used in this study. All of these subjects met the preestablished criteria for inclusion in the study. Among the younger participants were a patient with postpartum heart failure, one with a congenital heart condition, and one with a history of substance abuse, which reflects the wide variety of patients seen in the study sites. The mean number of comorbidities was three with a range of zero to seven comorbidities. The number of medications prescribed to participants ranged between one and 12 with the mean number of medications being seven. 
Table 2: Demographic Continuous Variables of Sample

\begin{tabular}{lccc}
\hline \multicolumn{1}{c}{ Demographic } & Mean & Range & $\begin{array}{c}\text { Standard } \\
\text { Deviation }\end{array}$ \\
\hline Age & 67 & $23-90$ & 12.5 \\
Number of comorbidities & 3 & $0-7$ & 1.6 \\
Number of medications & 7 & $1-12$ & 2.1 \\
\hline
\end{tabular}

Table 3 displays the comprehensive clinical characteristics of the study participants. The majority of participants, 66 (57\%), were obese with a BMI $\geq 30.0 ; 28(24 \%)$ were overweight with BMIs between 25.0 and 29.9; 18 (16\%) were normal weight with BMIs between 18.5 and 25.9; and $3(3 \%)$ were underweight with BMIs $<18.5$. While 45 of the subjects reported that they had never smoked (39\%), 12 were current smokers (10\%) and 57 were past smokers (50\%). Data on NYHA class were available for 98 of the participants, with $6(5 \%)$ having NYHA class I disease, 19 (17\%) NYHA class II disease, 52 (45\%) NYHA class III disease, and 21 (18\%) NYHA class IV disease. Using the Charlson Comorbidity Scale to define disease states, data on comorbidities were extracted from each subject's medical records. Sixty-eight participants had lung disease (59\%) and 72 had diabetes (63\%). Nearly half of the participants had a previous myocardial infarction (49\%), while more than a third had chronic kidney disease (34\%), one fourth had cardiovascular disease (24\%), and slightly more than one fifth had peripheral vascular disease $(21 \%)$. Forty-three participants (37\%) had a diagnosis of depression and 23 had a diagnosis of anxiety (20\%); 15 had insomnia (13\%). Twenty-one patients had a diagnosis of cancer (18\%), with most being prostate cancer, and none of the patients were currently receiving treatment for their cancer.

Data on prescription medications were also extracted from the medical records and as expected a majority of the subjects were taking antihypertensive medications (95\%) and a diuretic $(82 \%)$, while more than three fourths were taking an antiplatelet medication $(77 \%)$ and a 
similar number were taking a lipid-lowering agent (73\%). More than half of the subjects were taking gastrointestinal medication $(53 \%)$ and close to half were taking pulmonary medications (41\%) and anticoagulants (42\%). Close to a third of the subjects were taking an antiarrhythmic medication (31\%). More than a third were taking at least oral diabetes medications (34\%) and a slightly greater number were taking insulin (38\%); more than half were taking an oral diabetes medication or insulin, or both (57\%). More than one quarter were on a thyroid medication (26\%). Nearly one third of participants were prescribed a narcotic (30\%). Similarly, nearly one third were taking an antidepressant (30\%), while only $12 \%$ of subjects were prescribed an antianxiety medication. Fewer than one fifth of participants were prescribed medication for insomnia (17\%). Only a few subjects were taking nephrology medication (6\%) and even fewer were taking an antipsychotic medication (3\%). None of the subjects were receiving antineoplastic medications.

Collectively, $63 \%$ of subjects had diabetes and $57 \%$ of all subjects were taking an oral medication, insulin, or both, which suggests that not all those with diabetes were being properly treated; however, it is possible that those not taking medications were being treated with diet and exercise. Similarly, while $37 \%$ of participants had a diagnosis of depression, fewer than $30 \%$ had been prescribed an antidepressant medication, but again, those not treated with medication could have been receiving treatment in the form of counseling. Anxiety was also diagnosed in $20 \%$ of subjects in this study and only $12 \%$ were receiving an antianxiety medication. Interestingly, nearly $17 \%$ of study participants were prescribed insomnia medication but only $13 \%$ had a diagnosis of insomnia. 
Table 3: Sample Characteristics: Clinical Variables

\begin{tabular}{|c|c|c|}
\hline Clinical Variable & $\mathbf{N}$ & Percent \\
\hline \multicolumn{3}{|l|}{ BMI Categories } \\
\hline < 18.5 Underweight & 3 & 2.6 \\
\hline 18.5-24.9 Normal weight & 18 & 15.7 \\
\hline 25.0-29.9 Overweight & 28 & 24.3 \\
\hline$\geq 30.0$ Obese & 66 & 57.4 \\
\hline \multicolumn{3}{|l|}{ Smoking Status } \\
\hline Current smoker & 45 & 10.4 \\
\hline Past smoker & 57 & 49.6 \\
\hline Never smoked & 12 & 39.1 \\
\hline \multicolumn{3}{|l|}{ NYHA Class } \\
\hline 1 & 6 & 5.2 \\
\hline II & 19 & 16.5 \\
\hline III & 52 & 45.2 \\
\hline IV & 21 & 18.3 \\
\hline \multicolumn{3}{|l|}{ Comorbidity } \\
\hline Myocardial infarction & 56 & 48.7 \\
\hline Peripheral vascular disease & 24 & 20.9 \\
\hline Cardiovascular disease & 27 & 23.5 \\
\hline Lung disease & 68 & 59.1 \\
\hline Diabetes & 72 & 62.6 \\
\hline Chronic kidney disease & 39 & 33.9 \\
\hline Cancer & 21 & 18.3 \\
\hline Depression & 43 & 37.4 \\
\hline Anxiety & 23 & 20.0 \\
\hline Insomnia & 15 & 13.0 \\
\hline \multicolumn{3}{|l|}{ Medications } \\
\hline Narcotic & 35 & 30.4 \\
\hline Antihypertensive & 109 & 94.8 \\
\hline Anticoagulation & 48 & 41.7 \\
\hline Antiplatelet & 88 & 76.5 \\
\hline Antiarrhythmic & 36 & 31.3 \\
\hline Diuretic & 94 & 81.7 \\
\hline Lipid lowering & 84 & 73.0 \\
\hline Insulin & 44 & 38.3 \\
\hline Oral DM agent & 39 & 33.9 \\
\hline Insulin or oral DM agent & 66 & 57.4 \\
\hline Thyroid & 30 & 26.1 \\
\hline Nephrology & 7 & 6.1 \\
\hline Pulmonary & 47 & 40.9 \\
\hline Antidepressant & 34 & 29.6 \\
\hline Antianxiety & 14 & 12.2 \\
\hline Antipsychotic & 3 & 2.6 \\
\hline Insomnia & 19 & 16.5 \\
\hline Gastrointestinal & 61 & 53.0 \\
\hline Antineoplastics & 0 & 0.0 \\
\hline
\end{tabular}


Dietary rank was determined by responses to the AHA Life's Simple 7 Questionnaire (Appendix A). A score of 1 was given for each affirmative response to the questions that asked whether the person ate five servings of fruits and vegetables per day; ate two servings or more of fish weekly; ate whole grains daily; drank less than 36 ounces of sugary beverages; avoided prepackaged processed foods or ate the low-sodium version; avoided eating out or asked for the low-sodium preparation; and cooked at home without adding salt. Cumulative scores ranged from 0 to 7 , and dietary rank was assigned as poor for scores $\leq 2$; scores $\geq 3$ and $\leq 5$ were ranked as good; and scores $\geq 6$ were assigned a rank of excellent.

Table 4 displays chi-square test results for independence between gender in relation to the predictor variables of the four study aims (nutrition, obesity, physical activity, and smoking) as well as education, comorbidities, and medications, and between education and these same variables. A significant association was revealed between dietary rank (poor, good, and excellent $)$ and gender $\left(\chi^{2}=6.415, \mathrm{p}<0.05\right)$ and between comorbidities $(\leq 3$ comorbidities and $>$ 3 comorbidities $)$ and gender $\left(\chi^{2}=4.613, \mathrm{p}<0.05\right)$. A significant association was also found between education (less than high school, completed high school, and some college and higher) and smoking status (never smoked, past smoker, and current smoker) $\left(\chi^{2}=12.559, \mathrm{p}<0.01\right)$. Similarly, a significant association was found between education and comorbidities $\left(\chi^{2}=6.234, p\right.$ $<0.05)$. There were no significant associations found between gender and BMI, physical activity, or smoking status. No significant associations were found between levels of education and dietary rank, BMI, or physical activity. 
Table 4: Results of Chi-square ( $\left.\chi^{2}\right)$ Test for Independence

\begin{tabular}{|c|c|c|c|c|}
\hline Characteristic & $\mathbf{N}$ & $\%$ & $x^{2}$ & Significance \\
\hline \multicolumn{5}{|c|}{ GENDER } \\
\hline \multicolumn{5}{|l|}{ Dietary Rank } \\
\hline \multicolumn{5}{|l|}{ Poor } \\
\hline Male & 18 & 15.7 & 6.415 & 0.040 \\
\hline Female & 9 & 7.8 & & \\
\hline \multicolumn{5}{|l|}{ Good } \\
\hline Male & 42 & 36.5 & & \\
\hline Female & 29 & 25.2 & & \\
\hline \multicolumn{5}{|l|}{ Excellent } \\
\hline Male & 5 & 4.3 & & \\
\hline Female & 12 & 10.4 & & \\
\hline \multicolumn{5}{|l|}{ BMI } \\
\hline \multicolumn{5}{|l|}{ Normal weight } \\
\hline Male & 10 & 8.6 & 5.241 & 0.073 \\
\hline Female & 11 & 9.6 & & \\
\hline \multicolumn{5}{|l|}{ Overweight } \\
\hline Male & 21 & 18.3 & & \\
\hline Female & 7 & 6.1 & & \\
\hline \multicolumn{5}{|l|}{ Obese } \\
\hline Male & 34 & 29.6 & & \\
\hline Female & 32 & 27.8 & & \\
\hline \multicolumn{5}{|l|}{ Physical Activity } \\
\hline \multicolumn{5}{|l|}{ Inactive } \\
\hline Male & 9 & 7.8 & .122 & 0.727 \\
\hline Female & 10 & 7.8 & & \\
\hline \multicolumn{5}{|l|}{ Active } \\
\hline Male & 56 & 48.7 & & \\
\hline Female & 40 & 35.7 & & \\
\hline \multicolumn{5}{|l|}{ Smoking Status } \\
\hline \multicolumn{5}{|l|}{ Never smoked } \\
\hline Male & 23 & 20.2 & 1.074 & 0.585 \\
\hline Female & 22 & 19.1 & & \\
\hline \multicolumn{5}{|l|}{ Past smoker } \\
\hline Male & 33 & 28.9 & & \\
\hline Female & 24 & 20.9 & & \\
\hline \multicolumn{5}{|l|}{ Current smoker } \\
\hline Male & 8 & 7.0 & & \\
\hline Female & 4 & 3.5 & & \\
\hline
\end{tabular}




\begin{tabular}{|c|c|c|c|c|}
\hline \multicolumn{5}{|c|}{ Comorbidities } \\
\hline \multicolumn{5}{|c|}{$\leq 3$ Comorbidities } \\
\hline Male & 44 & 38.3 & 4.613 & 0.032 \\
\hline Female & 23 & 20.0 & & \\
\hline \multicolumn{5}{|c|}{ > 3 Comorbidities } \\
\hline Male & 21 & 18.3 & & \\
\hline Female & 27 & 23.5 & & \\
\hline \multicolumn{5}{|c|}{ Medications } \\
\hline \multicolumn{5}{|c|}{$\leq 7$ Medications } \\
\hline Male & 40 & 34.8 & 0.037 & 0.848 \\
\hline Female & 29 & 25.2 & & \\
\hline \multicolumn{5}{|c|}{ > 7 Medications } \\
\hline Male & 25 & 21.7 & & \\
\hline Female & 21 & 18.3 & & \\
\hline
\end{tabular}

\section{Dietary Rank}

Poor

Less than high school Completed high school Some college \& higher Good

Less than high school Completed high school Some college \& higher Excellent Less than high school Completed high school Some college $\&$ higher

\section{6}

11

10

15

28

28

5

8

4
5.2

1.567

9.6

8.7

13.0

24.3

24.3

4.3

7.0

3.5

BMI

Normal weight

Less than high school Completed high school Some college \& higher

Overweight

Less than high school Completed high school Some college $\&$ higher Obese

Less than high school Completed high school Some college \& higher

7

8

6

12

10

14

28

24
5.2

.782

6.1

7.0

5.2

10.4

8.7

12.2

24.3

20.9 


\begin{tabular}{|c|c|c|c|c|}
\hline \multicolumn{5}{|l|}{$\begin{array}{l}\text { Physical Activity } \\
\text { Inactive }\end{array}$} \\
\hline Less than high school & 6 & 5.2 & 1.553 & 0.460 \\
\hline Completed high school & 7 & 6.1 & & \\
\hline Some college \& higher & 5 & 4.3 & & \\
\hline \multicolumn{5}{|l|}{ Active } \\
\hline Less than high school & 20 & 17.4 & & \\
\hline Completed high school & 40 & 34.8 & & \\
\hline Some college $\&$ higher & 37 & 32.2 & & \\
\hline \multicolumn{5}{|l|}{ Smoking Status } \\
\hline \multicolumn{5}{|l|}{ Never smoked } \\
\hline Less than high school & 5 & 4.4 & 12.559 & 0.014 \\
\hline Completed high school & 20 & 17.5 & & \\
\hline Some college \& higher & 20 & 17.5 & & \\
\hline \multicolumn{5}{|l|}{ Past smoker } \\
\hline Less than high school & 14 & 12.3 & & \\
\hline Completed high school & 24 & 21.1 & & \\
\hline Some college \& higher & 19 & 16.7 & & \\
\hline \multicolumn{5}{|l|}{ Current smoker } \\
\hline Less than high school & 7 & 6.1 & & \\
\hline Completed high school & 3 & 2.6 & & \\
\hline Some college $\&$ higher & 2 & 1.8 & & \\
\hline \multicolumn{5}{|l|}{ Comorbidities } \\
\hline \multicolumn{5}{|l|}{$\leq 3$ comorbidities } \\
\hline Less than high school & 10 & 8.7 & 6.234 & 0.040 \\
\hline Completed high school & 28 & 24.3 & & \\
\hline Some college \& higher & 29 & 25.2 & & \\
\hline \multicolumn{5}{|l|}{$>3$ comorbidities } \\
\hline Less than high school & 16 & 13.9 & & \\
\hline Completed high school & 19 & 16.5 & & \\
\hline Some college \& higher & 13 & 11.3 & & \\
\hline \multicolumn{5}{|l|}{ Medications } \\
\hline \multicolumn{5}{|l|}{$\leq 7$ medications } \\
\hline Less than high school & 13 & 11.3 & 1.461 & 0.482 \\
\hline Completed high school & 29 & 25.2 & & \\
\hline Some college \& higher & 27 & 23.5 & & \\
\hline \multicolumn{5}{|l|}{$>7$ medications } \\
\hline Less than high school & 13 & 11.3 & & \\
\hline Completed high school & 18 & 15.7 & & \\
\hline Some college \& higher & 15 & 13.0 & & \\
\hline
\end{tabular}


The nonparametric Mann-Whitney U test was performed on independent groups and the continuous outcome measures to determine whether male subjects and female subjects differed in terms of physical, social, and emotional well-being. Similarly, the test was used to determine whether smokers and nonsmokers differed in terms of physical, social, and emotional well-being. Physical, social, and emotional well-being were measured using the Minnesota Living With Heart Failure Questionnaire (MLHFQ; Appendix D), in which higher scores indicate poorer quality of life in each of these domains. Tables 5, 6, and 7 display the results, which revealed a significant statistical difference with a small effect size only in social well-being between males $($ median $=14, \mathrm{n}=65)$ and females $($ median $=10, \mathrm{n}=50): \mathrm{U}=1155, \mathrm{z}=-2.654, \mathrm{p}<.01, \mathrm{r}=.24$ This significant finding shows that male study subjects had significantly higher scores for social well-being than the female subjects; that is, they had lower levels of social well-being than the female subjects. Despite there being no significant differences between male and female subjects in terms of physical and emotional well-being and no significant differences between smokers and nonsmokers for any of the physical, social, and emotional outcome variables, the differences in median scores are notable. Male subjects had higher median values (median $=39$ and 19, respectively) than did female subjects (median $=37$ and 19, respectively) for both physical and emotional well-being, indicating that men with heart failure had worse (lower states of) physical and emotional well-being than did their female counterparts. When comparing smokers to nonsmokers, the participants who reported being current smokers had slightly higher median scores for physical $($ median $=38.5)$, social $($ median $=16)$, and emotional $($ median $=21.5)$ wellbeing than did nonsmokers (median $=37.5,12$, and 19, respectively), indicating that smokers have lower levels of physical, social, and emotional well-being than do nonsmokers. 
Table 5: Differences in Physical Well-being Scores by Gender and Smoking Status: MannWhitney Test

\begin{tabular}{lcccccc}
\hline & N & Median & $\begin{array}{c}\text { Mann- } \\
\text { Whitney U }\end{array}$ & Z & $\begin{array}{c}\text { Significance } \\
\text { (2-tailed) }\end{array}$ & r \\
\hline Gender & 65 & 39.00 & 1398.50 & -1.279 & 0.201 & .12 \\
$\quad \begin{array}{l}\text { Male } \\
\quad \text { Female }\end{array}$ & 50 & 37.00 & & & & \\
$\quad \begin{array}{l}\text { Current Smoking Status } \\
\quad \text { Smoker }\end{array}$ & 12 & 38.50 & 589.50 & -.208 & 0.835 & .02 \\
$\quad$ Nonsmoker & 102 & 37.50 & & & & \\
\hline
\end{tabular}

Table 6: Differences in Emotional Well-being Scores by Gender and Smoking Status: MannWhitney Test

\begin{tabular}{lcccccc}
\hline & N & Median & $\begin{array}{c}\text { Mann- } \\
\text { Whitney U }\end{array}$ & Z & $\begin{array}{c}\text { Significance } \\
\text { (2-tailed) }\end{array}$ & r \\
\hline $\begin{array}{l}\text { Gender } \\
\quad \text { Male }\end{array}$ & 65 & 19.00 & 1536.50 & -.500 & 0.617 & .05 \\
$\quad$ Female & 50 & 19.00 & & & & \\
$\quad \begin{array}{l}\text { Current Smoking Status } \\
\quad \text { Smoker }\end{array}$ & 12 & 21.50 & 1464.50 & -.511 & 0.610 & .05 \\
$\quad$ Nonsmoker & 102 & 19.00 & & & & \\
\hline
\end{tabular}

Table 7: Differences in Social Well-being Scores by Gender and Smoking Status: MannWhitney Test

\begin{tabular}{lcccccc}
\hline & N & Median & $\begin{array}{c}\text { Mann- } \\
\text { Whitney U }\end{array}$ & Z & $\begin{array}{c}\text { Significance } \\
\text { (2-tailed) }\end{array}$ & r \\
\hline Gender & 65 & 14.00 & 1155.50 & -2.654 & 0.008 & .24 \\
$\quad \begin{array}{l}\text { Male } \\
\text { Female }\end{array}$ & 50 & 10.00 & & & & \\
$\quad \begin{array}{l}\text { Current Smoking Status } \\
\quad \text { Smoker }\end{array}$ & 12 & 16.00 & 523.50 & -.819 & 0.413 & .08 \\
$\quad$ Nonsmoker & 102 & 12.00 & & & & \\
\hline
\end{tabular}

Tables 8, 9, and 10 display the analyses from the nonparametric Kruskal-Wallis test. This test determined whether there was a difference in physical, social, and emotional well-being across BMI groups and nutritional status levels. Although there were no statistically significant differences found, it is interesting to note that higher median scores were found among the overweight and obese subjects than among those with normal weight BMIs for all three of the 
physical, social, and emotional well-being outcome variables. This suggests that those subjects who are overweight or obese have lower levels of physical, social, and emotional well-being than those who have BMIs in the normal weight range. Similarly, those with poor nutritional status had higher emotional and social well-being scores than those with good or excellent status. This suggests that subjects with better nutritional status had higher levels of emotional and social well-being. 
Table 8: Differences in Physical Well-being Scores by BMI and Nutritional Status: KruskalWallis Test

\begin{tabular}{lccccc}
\hline & N & Median & X2 & Significance & df \\
\hline BMI & & & & & \\
$\quad$ Normal weight & 21 & 36.00 & 1.162 & 0.559 & 2 \\
Overweight & 28 & 37.00 & & & \\
$\quad$ Obese & 66 & 39.50 & & & \\
$\quad$ Nutritional Status & & & & & \\
$\quad$ Poor & 27 & 37.00 & .010 & & \\
$\quad$ Good & 71 & 38.00 & & & \\
Excellent & 17 & 37.00 & & & \\
\hline
\end{tabular}

Table 9: Differences in Emotional Well-being Scores by BMI and Nutritional Status: KruskalWallis Test

\begin{tabular}{lccccc}
\hline & N & Median & $\mathbf{X 2}$ & Significance & df \\
\hline BMI & & & & & \\
$\quad$ Normal weight & 21 & 12.00 & 2.174 & 0.337 & 2 \\
Overweight & 28 & 19.00 & & & \\
Obese & 66 & 19.00 & & & \\
$\quad$ Nutritional Status & & & & & \\
$\quad$ Poor & 27 & 22.00 & 3.037 & 0.219 & 2 \\
$\quad$ Good & 71 & 18.00 & & & \\
$\quad$ Excellent & 17 & 21.00 & & & \\
\hline
\end{tabular}

Table 10: Differences in Social Well-being Scores by BMI and Nutritional Status: KruskalWallis Test

\begin{tabular}{lccccc}
\hline & N & Median & $\mathbf{\chi 2}$ & Significance & df \\
\hline BMI & & & & & \\
$\quad$ Normal weight & 21 & 10.00 & 2.118 & 0.347 & 2 \\
Overweight & 28 & 11.00 & & & \\
$\quad$ Obese & 66 & 13.50 & & & \\
$\quad$ Nutritional Status & & & & & \\
$\quad$ Poor & 27 & 18.00 & 4.567 & & \\
$\quad$ Good & 71 & 11.00 & & & \\
Excellent & 17 & 12.00 & & & \\
\hline
\end{tabular}

Spearman Rank Order Correlation (rho) was used to determine whether there was a relationship between the predictor variables of nutrition, obesity (BMI), physical activity (METs), and smoking and the outcome variables of physical, social, and emotional well-being 
(Table 11). A higher score for nutritional status indicated better dietary habits including eating more fruits and vegetables, eating whole grains, and limiting sodium and sugar intake. Similarly, a higher metabolic equivalency task (MET) score (calculated from the DASI score; see Chapter 2) indicated a better, more active lifestyle. Smoking status was coded as never smoked (0), past smoker (1), and current smoker (2), with a higher score indicating a potential detrimental impact on health due to smoking. Education was coded into three groups: less than high school (1); completed high school/GED (2); and some college/bachelor's or master's (3). Age was analyzed as a continuous variable using the actual age of the subject. Physical, social, and emotional wellbeing were measured using the MLHFQ, in which higher scores indicate poorer quality of life in each of these domains. Significant findings included a small, negative correlation between nutritional status and social well-being, indicating that better nutritional status is associated with increased levels (better) of social well-being $(\mathrm{r}=-.200, \mathrm{p}<.05)$. MET scores also had a statistically significant, small, negative correlation to social well-being, indicating that the more physically active subjects were, the better their state of social well-being $(r=-.248, p<.01)$. MET scores had a medium, negative correlation to both physical well-being $(r=-.485, \mathrm{p}<.01)$ and emotional well-being $(\mathrm{r}=-.468, \mathrm{p}<.01)$. The more physically active a subject was, the better levels of physical and emotional well-being were. A small, negative correlation between age and social well-being was also found $(\mathrm{r}=-.212, \mathrm{p}<.05)$, indicating that the older a subject was, the better his/her social well-being. There were no significant correlations found between BMI or smoking status and physical, social, and emotional well-being. 
Table 11: Correlations between Predictor Variables and Outcomes: Spearman's Rho

\begin{tabular}{lccc}
\hline & Physical Well-being & Social Well-being & Emotional Well-being \\
\hline Nutritional Status & -.009 & -.200 & -.077 \\
BMI & .098 & .135 & .089 \\
MET & -.485 & -.248 & -.468 \\
Smoking Status & .118 & .109 & .082 \\
Age & -.068 & -.212 & -.074 \\
\hline
\end{tabular}

Correlation analyses using Spearman's Rho were also run to determine whether there was an association between demographic and predictor variables (Table 12). Education had a small, negative correlation with both current smoking $(\mathrm{r}=-.240, \mathrm{p}<.05)$ and past smoking $(\mathrm{r}=-.210$, $\mathrm{p}<.05)$. Thus the less educated subjects were, the more likely they were to have been past smokers or to be current smokers. There were no significant correlations between education and nutritional status, obesity, or physical activity. Age was found to have a small, negative correlation to both obesity $(\mathrm{r}=-.203, \mathrm{p}<.05)$ and physical activity $(\mathrm{r}=-.193, \mathrm{p}<.05)$. This indicates that an increase in age was associated with lower BMI. Similarly, increasing age was associated with lower amounts of physical activity.

Table 12: Correlations between Demographic Variables and Predictor Variables: Spearman's Rho

\begin{tabular}{lccccc}
\hline & $\begin{array}{c}\text { Nutritional } \\
\text { Status }\end{array}$ & Obesity (BMI) & $\begin{array}{c}\text { Physical } \\
\text { Activity (MET) }\end{array}$ & $\begin{array}{c}\text { Current } \\
\text { Smoker }\end{array}$ & $\begin{array}{c}\text { Past } \\
\text { Smoker }\end{array}$ \\
\hline Education & -.065 & -.182 & .127 & -.240 & -.210 \\
Age & .009 & -.203 & -.193 & -.086 & -.064 \\
\hline
\end{tabular}

A histogram of nutritional status scores revealed a normal distribution with limited skewness (-.20) and kurtosis (-4.26), which allowed for an independent samples t-test to be done to compare the nutritional status score for male subjects and female subjects (Table 13). There was a significant difference in nutritional status scores between males $(\mathrm{M}=3.44, \mathrm{SD}=1.49)$ and females $(\mathrm{M}=4.06, \mathrm{SD}=1.75 ; t[112]=4.19, \mathrm{p}<.05$, two tailed $)$. The magnitude of the differences in mean scores had a small effect size (eta squared $=.03$ ); however, women had 
higher mean nutritional status scores than did men, indicating that, overall, female subjects had better nutritional habits than did male subjects.

Table 13: Independent Samples T-test: Differences in Nutrition Status Score between Male and Female Subjects

\begin{tabular}{lccccc}
\hline & \multicolumn{5}{c}{ Nutritional Status Score } \\
\cline { 2 - 6 } & $\mathbf{N}$ & Mean & SD & df & t \\
\hline Male & 64 & 3.44 & 1.489 & 112 & -2.048 \\
Female & 50 & 4.06 & 1.754 & & \\
\hline
\end{tabular}

Aim 1: Among Appalachian patients with heart failure, what is the relationship between nutrition and levels of functioning as measured by physical, social, and emotional well-being?

A one-way between-group analysis of variance (ANOVA) was conducted to explore the impact of nutritional status on levels of physical, social, and emotional well-being (Polit \& Beck, 2012) (Table 14). Nutritional status was coded as poor, good, or excellent based on responses to the AHA Life's Simple 7 Questionnaire. Physical, social, and emotional well-being were measured using the MLHFQ, with higher scores indicating poorer quality of life in each of these domains. Although there were no statistically significant differences found, the mean difference between the groups shows that those with poor or good nutritional status had higher (worse) scores for physical well-being than those with excellent nutritional status. This indicates that subjects who had excellent nutritional status had higher levels of physical well-being than those with either poor or good nutritional status.

The mean difference between nutritional status and social well-being is also worth noting. Study subjects with the poorest nutrition status had the lowest levels of social well-being, followed by those with good nutrition status, who had slightly better levels of social well-being. Those subjects with excellent nutrition status had the highest levels of social well-being. The 
mean difference between those with poor nutritional status $(M=15.19)$ and excellent nutritional status $(\mathrm{M}=11.06)$ was 4.13 .

For emotional well-being, those with good nutritional habits had the highest levels of emotional well-being, followed by those with excellent nutritional habits, while those with poor nutritional habits had the lowest levels of emotional well-being.

Table 14: ANOVA: Impact of Nutritional Status on Physical, Social, and Emotional Wellbeing

\begin{tabular}{|c|c|c|c|c|c|c|c|}
\hline Nutritional Status & $\mathbf{N}$ & Mean & Mean Differences* & df & $\mathbf{F}$ & $\begin{array}{c}\text { Significance } \\
\text { Between } \\
\text { Groups }\end{array}$ & $\begin{array}{l}\text { Significance } \\
\text { Scheffe }\end{array}$ \\
\hline \multicolumn{8}{|l|}{ Physical Well-being } \\
\hline Poor & 27 & 34.96 & $\begin{array}{l}-.206 \text { (good) } \\
.786 \text { (excellent) }\end{array}$ & 2 & .055 & 0.947 & 0.947 \\
\hline Good & 71 & 35.17 & $\begin{array}{l}.206 \text { (poor) } \\
.993 \text { (excellent) }\end{array}$ & & & & \\
\hline Excellent & 17 & 34.18 & $\begin{array}{l}-.786 \text { (poor) } \\
-.993 \text { (good) }\end{array}$ & & & & \\
\hline \multicolumn{8}{|l|}{ Social Well-being } \\
\hline Poor & 27 & 15.19 & $\begin{array}{l}2.38 \text { (good) } \\
4.13 \text { (excellent) }\end{array}$ & 2 & 2.743 & 0.069 & 0.339 \\
\hline Good & 71 & 12.80 & $\begin{array}{l}-2.38 \text { (poor) } \\
1.74 \text { (excellent) }\end{array}$ & & & & \\
\hline Excellent & 17 & 11.06 & $\begin{array}{l}-4.13 \text { (poor) } \\
-1.74 \text { (good) }\end{array}$ & & & & \\
\hline \multicolumn{8}{|l|}{$\begin{array}{l}\text { Emotional Well-being } \\
\text { Poor }\end{array}$} \\
\hline & 27 & 20.00 & 2.73 (good) & 2 & 1.362 & 0.260 & 0.423 \\
\hline Good & & & 1.00 (excellent) & & & & \\
\hline Excellent & 71 & 17.27 & $\begin{array}{l}-2.73 \text { (poor) } \\
-1.73 \text { (excellent) }\end{array}$ & & & & \\
\hline & 17 & 19.00 & $\begin{array}{r}-1.00 \text { (poor) } \\
1.73 \text { (good) }\end{array}$ & & & & \\
\hline
\end{tabular}

*Mean differences are displayed for variable groups (poor, good, excellent) in the leftmost column to groups in parentheses. 
Aim 2: Among Appalachian patients with heart failure, what is the relationship between obesity and levels of functioning as measured by physical, social, and emotional well-being?

To explore the impact of obesity as measured by BMI on levels of physical, social, and emotional well-being, an ANOVA was conducted and although there were no statistically significant differences found, the mean differences between BMI categories are noteworthy (Table 15). BMI levels were collapsed into three categories with all BMIs $\leq 24.9$ classified as normal, BMIs between 25.0 and 29.9 as overweight, and BMIs $\geq 30.0$ as obese. As BMI increases, there is a decrease in the levels of physical, social, and emotional well-being. Subjects with BMIs in the normal weight range had the lowest mean scores for each of the domains, indicating higher levels of physical $(M=32.90)$, social $(M=11.67)$, and emotional $(M=15.86)$ well-being. All subjects with BMIs in the overweight range had higher mean scores than those with normal weight but lower than those with BMIs in the obese category for physical wellbeing $(M=34.93$ and 35.65, respectively) and social well-being $(M=12.43$ and 13.85, respectively). Subjects who were obese had a slightly lower mean score $(M=18.59)$ than those who were overweight $(M=18.89)$, with a small mean difference of .30 for emotional well-being, indicating that obese subjects had higher levels of emotional well-being than did those who were overweight. 
Table 15: ANOVA: Impact of Obesity on Physical, Social, and Emotional Well-being

\begin{tabular}{|c|c|c|c|c|c|c|c|}
\hline BMI & $\mathbf{N}$ & Mean & Mean Differences* & df & $\mathbf{F}$ & $\begin{array}{c}\text { Significance } \\
\text { Between } \\
\text { Groups }\end{array}$ & $\begin{array}{l}\text { Significance } \\
\text { Scheffe }\end{array}$ \\
\hline \multicolumn{8}{|c|}{ Physical Well-being } \\
\hline Normal weight & 21 & 32.90 & $\begin{array}{l}-2.02 \text { (overweight) } \\
-2.75 \text { (obese) }\end{array}$ & 2 & .492 & 0.613 & 0.626 \\
\hline Overweight & 28 & 34.93 & $\begin{array}{l}2.02 \text { (normal wt) } \\
-.72 \text { (obese) }\end{array}$ & & & & \\
\hline Obese & 66 & 35.65 & $\begin{array}{l}2.75 \text { (normal wt) } \\
.72 \text { (overweight) }\end{array}$ & & & & \\
\hline \multicolumn{8}{|l|}{ Social Well-being } \\
\hline Normal weight & 21 & 11.67 & $\begin{array}{l}-.762 \text { (overweight) } \\
-2.18 \text { (obese) }\end{array}$ & 2 & 1.275 & 0.283 & 0.372 \\
\hline Overweight & 28 & 12.43 & $\begin{array}{l}.762 \text { (normal wt) } \\
-1.42 \text { (obese) }\end{array}$ & & & & \\
\hline Obese & 66 & 13.85 & $\begin{array}{l}2.18 \text { (normal wt) } \\
1.42 \text { (overweight) }\end{array}$ & & & & \\
\hline \multicolumn{8}{|c|}{ Emotional Well-being } \\
\hline Normal weight & 21 & 15.86 & $\begin{array}{l}-3.04 \text { (overweight) } \\
-2.73 \text { (obese) }\end{array}$ & 2 & 1.177 & 0.312 & 0.307 \\
\hline Overweight & 28 & 18.89 & $\begin{array}{l}3.04 \text { (normal wt) } \\
.30 \text { (obese) }\end{array}$ & & & & \\
\hline Obese & 66 & 18.59 & $\begin{array}{l}2.73 \text { (normal wt) } \\
-.30 \text { (overweight) }\end{array}$ & & & & \\
\hline
\end{tabular}

*Mean differences are displayed for variable groups (normal weight, overweight, obese) in the leftmost column to groups in parentheses.

Aim 3: Among Appalachian patients with heart failure, what is the relationship between physical activity and levels of functioning as measured by physical, social, and emotional wellbeing?

A Mann-Whitney U test was performed on the independent groups and the continuous outcome measures to determine whether active and inactive subjects differed in terms of their physical, social, and emotional well-being (Table 16). Subjects were grouped into active or inactive categories based on the recommendation by the American College of Sports Medicine (ACSM) that moderate-intensity physical activity be based on metabolic equivalency task (MET) according to age (Furlanetto, Pinto, Sant'Anna, Hernandes, \& Pitta, 2016). The ACSM 
recommends > 4 METs for individuals between 40 and 64 years of age and > 3.2 METs for individuals $\geq 65$ years of age. Subjects meeting these minimum recommendations were classified as active and those who did not were classified as inactive. A majority of the subjects (84\%) were found to be active $(\mathrm{N}=96)$ and only 19 were classified as inactive $(16 \%)$, which is surprising due to the older age distribution of the sample.

Physical, social, and emotional well-being were measured using the MLHFQ, with higher scores indicating poorer quality of life in each of these domains. A statistically significant difference with a small effect size was found between active (median $=18, \mathrm{n}=96)$ and inactive $($ median $=23, \mathrm{n}=19)$ subjects for emotional well-being $(\mathrm{U}=579.5, \mathrm{z}=-2.507, \mathrm{p}<.01, \mathrm{r}=.23)$. This difference suggests that those individuals who were more active had higher levels of emotional well-being than those who were inactive. The differences between active (median = $37, \mathrm{n}=96$ ) and inactive (median $=41, \mathrm{n}=19$ ) approached statistical significance for physical well-being with a small effect size $(U=671.5, z=-1.813, p=.07, r=.17)$. Despite the difference not being statistically significant, subjects who were active had higher levels of physical well-being than those who were inactive. Similarly, although not statistically significant, there were differences between active $($ median $=12, \mathrm{n}=96)$ and inactive $($ median $=$ $14, \mathrm{n}=19)$ subjects in terms of social well-being, with those who were active having better levels of social well-being than their inactive counterparts. 
Table 16: Differences in Physical, Social, and Emotional Well-being Scores by Level of Physical Activity: Mann-Whitney Test

\begin{tabular}{|c|c|c|c|c|c|c|}
\hline Physical Activity Status & $\mathbf{N}$ & Median & $\begin{array}{c}\text { Mann- } \\
\text { Whitney } \\
\text { U }\end{array}$ & $\mathbf{Z}$ & $\begin{array}{c}\text { Significance } \\
\text { (2-tailed) }\end{array}$ & $r$ \\
\hline \multicolumn{7}{|l|}{ Physical Well-being } \\
\hline Inactive & 19 & 41.00 & 671.50 & -1.813 & 0.07 & .17 \\
\hline Active & 96 & 37.00 & & & & \\
\hline \multicolumn{7}{|l|}{ Social Well-being } \\
\hline Inactive & 19 & 14.00 & 801.00 & -.838 & 0.402 & .04 \\
\hline Active & 96 & 12.00 & & & & \\
\hline \multicolumn{7}{|l|}{ Emotional Well-being } \\
\hline Inactive & 19 & 23.00 & 579.50 & -2.507 & 0.012 & .23 \\
\hline Active & 96 & 18.00 & & & & \\
\hline
\end{tabular}

Aim 4: Among Appalachian patients with heart failure, what is the relationship between smoking and levels of functioning as measured by physical, social, and emotional well-being?

To explore the impact of smoking status on physical, social and emotional well-being, an ANOVA was conducted (Table 17). Smoking status was categorized into three groups, subjects who had never smoked, past smokers, and current smokers. No statistically significant differences were detected, but the mean difference among past smokers and current smokers in the physical well-being domain was small (.55), with current smokers having a lower mean score on the MLHFQ physical domain questions $(M=35.83)$ than past smokers $(M=36.39)$, indicating that current smokers had higher levels of physical well-being than did their counterparts who were past smokers. The lowest mean score for physical well-being was for subjects who had never smoked ( $M=33.18)$, which suggests that those who had never smoked had higher levels of physical well-being than both past and current smokers. The mean differences in scores reveals that scores for social and emotional well-being were the highest among current smokers followed by past smokers and the lowest scores were those of subjects who had never smoked. This indicates that those participants who were currently smokers had the lowest levels of social $(M=14.33)$ and emotional $(M=20.92)$ well-being, while past 
smokers had the next lowest levels $\left(\mathrm{M}_{\text {social }}=13.37, \mathrm{M}_{\text {emotional }}=18.14\right)$ followed by those who never smoked $\left(\mathrm{M}_{\text {social }}=12.47, \mathrm{M}_{\mathrm{emotional}}=17.62\right)$.

Table 17: ANOVA: Impact of Smoking Status on Physical, Social, and Emotional Well-being

\begin{tabular}{|c|c|c|c|c|c|c|c|}
\hline Smoking Status & $\mathbf{N}$ & Mean & $\begin{array}{c}\text { Mean } \\
\text { Differences* }\end{array}$ & df & $\mathbf{F}$ & $\begin{array}{c}\text { Significance } \\
\text { Between } \\
\text { Groups }\end{array}$ & $\begin{array}{l}\text { Significance } \\
\text { Scheffe }\end{array}$ \\
\hline \multicolumn{8}{|l|}{ Physical Well-being } \\
\hline Never Smoked & 45 & 33.18 & $\begin{array}{l}-3.21 \text { (past) } \\
-2.66 \text { (current) }\end{array}$ & 2 & 1.102 & 0.336 & 0.597 \\
\hline Past Smoker & 57 & 36.39 & $\begin{array}{l}3.21 \text { (never) } \\
.55 \text { (current) }\end{array}$ & & & & \\
\hline Current Smoker & 12 & 35.83 & $\begin{array}{l}2.66 \text { (never) } \\
-.55 \text { (past) }\end{array}$ & & & & \\
\hline \multicolumn{8}{|l|}{ Social Well-being } \\
\hline Never Smoked & 45 & 12.47 & $\begin{array}{l}-.902 \text { (past) } \\
-1.87 \text { (current) }\end{array}$ & 2 & .544 & 0.582 & 0.566 \\
\hline Past Smoker & 57 & 13.37 & $\begin{array}{c}.902 \text { (never) } \\
-.965 \text { (current) }\end{array}$ & & & & \\
\hline Current Smoker & 12 & 14.33 & $\begin{array}{l}1.87 \text { (never) } \\
.97 \text { (past) }\end{array}$ & & & & \\
\hline \multicolumn{8}{|l|}{ Emotional Well-being } \\
\hline Never Smoked & 45 & 17.62 & $\begin{array}{c}-.52 \text { (past) } \\
-3.29 \text { (current) }\end{array}$ & 2 & .875 & 0.420 & 0.331 \\
\hline Past Smoker & 57 & 18.14 & $\begin{array}{c}.52 \text { (never) } \\
-2.78 \text { (current) }\end{array}$ & & & & \\
\hline Current Smoker & 12 & 20.92 & $\begin{array}{l}3.29 \text { (never) } \\
2.78 \text { (past) }\end{array}$ & & & & \\
\hline
\end{tabular}

*Mean differences are displayed for variable groups (never smoked, past smoker, current smoker) in the leftmost column to groups in parentheses.

\section{Summary}

This quantitative study using a cross-sectional, convenience sample of patients with heart failure was conducted at healthcare facilities in West Virginia. The majority of the patients were older, male, white, obese or overweight, with NYHA class III or IV disease, a high school education or less, and an income less than $\$ 25,000$ per year. Social well-being was significantly associated with better nutritional status and significant differences were found in nutritional status and gender, with female subjects having better nutritional status than male subjects. There 
was also a statistically significant association between higher levels of physical activity and physical, social, and emotional well-being.

Although not statistically significant, data trends showed that as BMI increased, levels of physical, social, and emotional well-being decreased. Similar nonsignificant trends were also found between those subjects with better nutritional status and physical and social well-being. There were also no significant findings for smoking status, but those who had never smoked had higher levels of physical well-being and current smokers had the lowest levels of social and emotional well-being. 


\section{Chapter 5: Findings}

The purpose of this study was to examine the relationship between modifiable risk factors and levels of functioning in terms of physical, social, and emotional well-being among Appalachian patients with heart failure. The results of the study showed that higher levels of physical activity were found to be positively correlated with physical, social, and emotional wellbeing among heart failure patients seen in healthcare facilities in the northern Appalachia region. In addition, nutritional status, which differed by gender, was also significantly correlated with social well-being. This chapter includes implications of the study in relation to the theoretical framework and the relevance of the study findings to prior research. Also included are a discussion of implications for practice, possibilities for future research to build upon the findings, and limitations of the study.

\section{Theoretical Framework}

Neuman's Systems Model was used as the theoretical basis for this study. The philosophical basis for the model is "helping each other live" and the main concept is the client/client system, comprised of the individual, family, community, and social issues (Fawcett, 2005a). Physiological, psychological, sociocultural, developmental, and spiritual aspects of the patient are components of the theory. The central core of the model is made up of basic survival factors, which include body organ strengths and weaknesses and which in the context of this study is the failure of the heart to function effectively. Attainment and retention of wellness in the client is the optimal goal of the model and is measured by the patient's ability to deal with intrapersonal, interpersonal, and extrapersonal stressors from both internal and external sources despite reactions in the client system. Intrapersonal stressors are conditioned responses and 
behaviors that encompass nutritional habits, levels of physical activity, and smoking status, which are the predictor variables in this study. Anxiety and depression are also intrapersonal stressors that were measured in this study both through comorbidity data and the Minnesota Living With Heart Failure Questionnaire (MLHFQ) emotional domain questions about worrying and feeling depressed. Interpersonal stressors include things such as interactions with family and friends, ability to maintain hobbies, and whether or not the patient feels that he/she is a burden to others, which are outcomes measured by the emotional and social domains of the MLHFQ.

Extrapersonal stressors are made up of social policy or financial concerns, measured here by the MLHFQ questions that constitute the social domain.

Prevention as Intervention is a concept of Neuman's Systems Model that includes primary, secondary, and tertiary prevention. Secondary prevention is the most pertinent in this study because the subjects already had heart failure so the goal for their treatment must include educating them about their disease and treatment, likely including dietary modifications, weight loss, increased exercise, and/or smoking cessation. The goal of secondary prevention would be to prevent further complications from heart failure and to decrease stressors in order to strengthen the lines of resistance that protect the basic core: body organ strength, which in this instance is optimal functioning of the heart in patients with heart failure.

\section{Relation to Previous Studies}

Aim 1: Among Appalachian patients with heart failure, what is the relationship between nutrition and levels of functioning as measured by physical, social, and emotional well-being?

High salt intake can be detrimental to patients with heart failure (He et al., 2011) and nearly a quarter of participants in this study had poor nutritional habits according to the ranking method used, which included an assessment of sodium consumption. The Behavioral Risk Factor 
Surveillance System (BRFSS) estimates that more than $90 \%$ of West Virginia residents eat fewer than five servings of fruits and vegetables per day and although this estimate is not specific to people with heart failure the results of the current study show that even when a patient is diagnosed with heart failure the AHA recommendation for fruits and vegetables is not always followed (WV Health Statistics Center, 2015). People with heart failure are inadequately treated for risk factors including hypertension, hyperlipidemia, and diabetes (Lama Tamang et al., 2014) and findings of this study partially corroborate this prior research. Although nearly all the participants were receiving antihypertensives (95\%) and nearly three fourths were taking lipidlowering agents, only $57 \%$ of the subjects were taking a diabetes medication, either insulin or an oral agent, even though $63 \%$ of all subjects were diagnosed with diabetes. It was beyond the scope of this study to collect information on blood pressure values or laboratory values for cholesterol, triglycerides, glucose, or $\mathrm{HgA}_{1} \mathrm{c}$, so it is not clear whether the subjects were being properly treated for these aforementioned risk factors. Secondary prevention measures are paramount for patients with heart failure to ensure medication adherence, minimize risk factors, and promote lifestyle modifications including decreasing salt intake and consumption of low-fat food and fruits and vegetables. Study findings suggest that social and emotional well-being as measured by the MLHFQ were negatively affected by poor nutritional habits.

Aim 2: Among Appalachian patients with heart failure, what is the relationship between obesity and levels of functioning as measured by physical, social, and emotional well-being?

Obesity is a risk factor for heart failure (Alpert et al., 2014; Ebong et al., 2014) and well over half of the participants in this study were obese (57\%). Narumi et al. (2014) studied the effects of metabolic syndrome among heart failure patients and obesity in terms of prognosis including death due to heart failure, myocardial infarction, stroke, and other vascular problems. 
Metabolic syndrome was not directly measured in this study; however, many of the subjects had diabetes (63\%) and were taking lipid-lowering agents (73\%). In addition, the risk factors for morbidity were present in many of the participants: myocardial infarction (49\%), stroke (24\%), and peripheral vascular disease $(21 \%)$.

The obesity paradox has been studied extensively in relation to morbidity and mortality among patients with heart failure (Ebong et al., 2014; Lavie et al., 2014; Zapatero et al., 2012) and although a majority of the patients in this study were obese $(57 \%)$ or overweight $(24 \%)$, this study did not collect data on these outcome indicators. The recommendations from previous studies included the need for weight loss guidelines for heart failure management; weight loss being reserved for those with BMIs $>35 \mathrm{~kg} / \mathrm{m}^{2}$; and improving cardiorespiratory fitness, increasing lean muscle mass, and muscle strengthening to lead to improvements in prognosis. All these recommendations have implications for secondary prevention in this population. Conversely, primary prevention is needed to avert epidemic levels of heart failure since diabetes, obesity, and metabolic syndrome are all risk factors and increasingly prevalent in this Appalachian population (Horwich \& Fonarow, 2010; Mamudu et al., 2015; Schmidt et al., 2014). Detrimental effects of obesity on cognitive function point to a need for weight loss among patients with heart failure (Alosco et al., 2015). Again, cognitive function was not directly assessed in this study but one of the MLHFQ emotional domain questions was, "did your heart failure prevent you from living as you wanted during the past month by making it difficult for you to concentrate or remember things?” Results from this study suggest that as BMI increases, the level of emotional well-being decreases. Although N-terminal pro-brain natriuretic peptide (NT-proBNP) and plasma leptin levels were also not measured in this study, these lab 
values may be useful indicators for heart failure incidence among obese patients (Ndumele et al., 2016; Wannamethee et al., 2011).

Aim 3: Among Appalachian patients with heart failure, what is the relationship between physical activity and levels of functioning as measured by physical, social, and emotional wellbeing?

In addition to using NT-proBNP as an indicator of heart failure in the obese, this biomarker has also been shown to have an inverse relationship with physical activity (deFilippi et al., 2012). Data on NT-proBNP were not collected in this study, but screening for it in regard to heart failure in individuals with sedentary lifestyles warrants consideration for future initiatives. The inverse relationship between regular exercise and increased levels of physical fitness and the incidence of heart failure has been shown in studies done throughout the world (Andersen et al., 2014; Echouffo-Tcheugui et al., 2015; Kraigher-Krainer et al., 2013; Nayor \& Vasan, 2015). Likewise, physical activity is an important component of the treatment of heart failure and self-efficacy seems to be an important factor in promoting participation and adherence to physical activity interventions for patients with heart failure (Du et al., 2012). Selfefficacy is the degree of confidence that a person has in his or her ability to perform a behavior under specific circumstances, that is, exercise. The MLHFQ measures a person's physical wellbeing by including questions about one's ability to walk and climb stairs; working around the house and yard; being tired, fatigued, or low on energy; and being short of breath, all of which would likely impact self-efficacy for exercise. Study findings suggest that lower levels of physical well-being as measured by these indicators are associated with lower levels of physical activity. Lee et al. (2017) stressed the importance of exercise self-efficacy in improving physical functioning and physical activity to improve patient outcomes and recommended patient 
education on the importance of physical activity despite the debility inherent to their heart failure. Therefore, secondary prevention aimed at improving self-efficacy in regular physical activity has the potential to improve physical well-being and ultimately patient outcomes.

A relationship between physical activity and cognition in older adults with heart failure has been shown to exist (Miller \& Gunstad, 2016). One of the indicators of emotional well-being as measured by the MLHFQ is "difficulty concentrating or remembering things." Statistically significant findings from this study support this previously documented relationship by suggesting that individuals who were more active had higher levels of emotional well-being than those who were inactive.

Aim 4: Among Appalachian patients with heart failure, what is the relationship between smoking and levels of functioning as measured by physical, social, and emotional well-being?

Smoking is a risk factor for heart failure and increased morbidity and mortality among those with heart failure (Gopal et al., 2012; Javaheri et al., 2012; Plank et al., 2014; Shah et al., 2010). The majority of the participants in this study were past or current smokers (61\%); a similar number had lung disease (59\%), which was usually chronic obstructive pulmonary disease (COPD). Although mortality data were not collected in this cross-sectional study, it has been shown that current smokers with heart failure are at significantly higher risk of ventricular tachyarrhythmia or death than past or nonsmokers (Plank et al., 2014); thus a need is demonstrated for secondary prevention measures to include smoking cessation programs for individuals diagnosed with heart failure. Current smokers and those with sleep apnea were also found to have higher rates of nocturnal ventricular tachyarrhythmia (Javaheri et al., 2012). In the present study the physical well-being questions on the MLHFQ included one asking about difficulty sleeping and another about being tired, fatigued, and low on energy. While these 
questions are not diagnostic indicators of sleep apnea, these symptoms are similar to those of untreated sleep apnea and merit further investigation among those with heart failure. Findings in this study, although not statistically significant, show that lower levels of physical well-being were found among smokers and past smokers as compared to participants who had never smoked.

\section{Heart Failure in Rural Populations}

People living in rural areas who have heart failure face unique challenges in caring for their health. Perceived needs, rural values, health disparities, lack of convenient healthcare providers, and low literacy are all factors that need to be taken into account when treating heart failure patients from rural areas (Goetz-Perry, 2010; Muus et al., 2010; Verdejo et al., 2015). The participants in this study were from rural Appalachia and possessed many of these characteristics and challenges. Although addresses were not tracked in this study many of the patients receiving care at Ruby Memorial Hospital and WVU's Heart and Vascular Institute and Family Medicine Outpatient Clinic often travel long distances because there are few cardiologists practicing in rural communities throughout the state. Lower literacy and income levels were also prevalent in this study, with a majority of participants having a high school education or less $(60 \%)$. When asked whether their heart failure prevented them from living life as they wanted to by costing them money for medical care more than $40 \%$ responded "no" or "very little," which may be attributable to their being on Medicaid and not having direct medical expenses.

People from rural areas tend to have limited social support systems, which was reinforced in the results of this study. The emotional well-being domain was measured through questions on the MLHFQ about feelings of a loss of self-control, feelings of being a burden to family and friends, worrying, and feeling depressed. Previous research shows that the prevalence of 
depression (26\%) and anxiety (20.5\%) is high in those with heart failure (Vanhoof et al., 2014). In the present study, higher rates of depression were found (37\%) and a similar percentage of subjects had a diagnosis of anxiety (20\%); however, both of these conditions were undertreated in this Appalachian population. Depression and anxiety both negatively affect emotional wellbeing, yet results from this study revealed that not all study participants with these diagnoses were being treated with antidepressant and/or antianxiety medications. Emotional well-being was also negatively affected as BMI increased and among current smokers.

Work is an integral part of life in rural settings and is viewed as pleasurable (Stevenson et al., 2015) and this was measured in this study for both physical and emotional well-being in the questions about whether the subject's disease made working around the house and yard difficult and made earning a living difficult, respectively. Statistically significant findings between levels of physical activity and physical and emotional well-being support previous research by showing that the ability to work either through gainful employment or just around the house was important to participants in this study. Although the mean age of the participants in this study was 67 , more than a third of respondents stated that their heart failure affected their life in the past month by making it difficult to earn a living.

Heart transplants are a rarity and are generally done on younger patients. Implantation of left ventricular assistive devices (LVAD) is an option for older patients with heart failure (Khazanie \& Rogers, 2011). Unfortunately, at the present time surgery for LVAD implantations is not being done in the catchment area of this study and therefore any patient eligible for the procedure would be referred to hospitals in more metropolitan areas. Insurance, costs, and travel constraints may obstruct successful referrals in this Appalachian population. 


\section{Implications for Practice}

Findings from this study shed light on the modifiable risk factors that have an impact on the physical, social, and emotional well-being of individuals living with heart failure in rural Appalachia. The most significant risk factor was lack of physical activity. Inactivity leads to lower levels of well-being in these three domains and indicates a need for exercise programs either through physical or occupational therapy or through established community exercise programs or facilities. Self-efficacy in exercise programs is important in improving patient outcomes, physical functioning, and activity (Lee et al., 2017). Patient education is paramount to emphasize the importance of exercise despite the challenges intrinsic to heart failure. Moderateintensity physical activity of 150 minutes per week is recommended for those with heart failure (Andersen et al., 2014). Cognitive dysfunction is associated with lower levels of physical activity, further supporting the need for exercise programs (Miller \& Gunstad, 2016). Because higher levels of physical activity are associated with lower levels of NT-proBNP over time (deFilippi et al., 2012), consideration should be given to testing NT-proBNP levels in patients with sedentary lifestyles.

Nutritional status was significantly associated with enhanced social well-being. Referrals to dietician consults, support groups for healthy eating and/or weight loss, and cooking classes and promotion of farmer's markets are all possibilities for positively impacting the dietary habits of those with heart failure. Patients with heart failure need to be educated about using no more than the recommended level of $<5-6$ grams of salt per day (He et al., 2011). Interdisciplinary models of care are essential, as the provider would be responsible for the referral for a dietary consult, and the dietician, in addition to developing a dietary plan for the patient, would likely recommend support groups, cooking classes, and farmer's markets as tools to assist in adherence 
to the dietary plan. Care managers may need to assist in this process of linking patients to resources available in their communities.

Additionally, weight loss for those who are obese with BMIs > 35 is indicated both in previous research (Lavie et al., 2014) and in this current study. In clinical practice areas, this should begin with the recommendation from the provider and should be supported by nurses, dieticians, and exercise physiologists treating the patients. Weight Watchers and similar weight loss programs should be recommended and promoted among the obese living with heart failure. In rural areas these weight loss programs are not always offered, but Weight Watchers is available online with coaching from leaders who have lost weight through the program and a number of digital tools that help to keep people motivated in an online community (Weight Watchers, 2017).

Smoking was also negatively associated with social and emotional well-being, and those who had never smoked had the highest levels of physical well-being. This finding supports the need for smoking cessation among those living with heart failure. Because the risk of heart failure and death for former smokers who quit more than 15 years ago becomes similar to those who have never smoked (Ahmed et al., 2015), smoking cessation is warranted for those with heart failure as well as those with risk factors for heart failure. Providers need to offer nicotine replacement therapies or medications that promotion cessation such as varenicline and bupropion hydrochloride. Referrals to smoking cessation programs, where available, should be made. Additionally, information on West Virginia's Department of Health and Human Resources Quitline should be given to patients (WV Department of Health and Human Services, 2017). This Quitline provides individual phone counseling by certified phone coaches to help participants quit tobacco and also offers free nicotine replacement. 
If the aforementioned implications for practice are implemented, the philosophical basis for Neuman's Systems Model is supported in "helping each other live." Through treatment of a smoking addiction; referrals to dieticians for nutritional counseling and weight loss; and referrals to physical and/or occupational therapy and exercise programs, the attainment of wellness in the client/patient is possible. This state is achievable through such secondary prevention measures; furthermore, these preventive measures may avert further complications from heart failure thereby strengthening the lines of resistance in the model that are imperative to improving the functioning of patients with heart failure, which should lead to enhanced levels of physical, emotional, and social well-being. Nurses are a vital part of the interdisciplinary care team and are ideally suited to provide the education patients need to ensure that they have a full understanding of the importance of following all aspects of their treatment plan from each member of the healthcare team. Heart failure patients in rural areas are influenced by perceived needs, rural values, contextual issues, and external factors when deciding to access support for health promotion (Goetz-Perry, 2010), which precipitates that need for specialized, complex nursing interventions aimed at treating multiple comorbidities in a population faced with health disparities. Interventions must be tailored to the unique needs of those living in Appalachia.

Participants in this study were from a rural area and of lower socioeconomic status, and the majority had a high school education or less. Such patients often require additional resources, education, and services to manage their heart failure. Because health literacy is a predictor of allcause mortality and rehospitalization among heart failure patients in rural areas, individualized education must be presented with appropriate literacy levels taken into consideration (Moser et al., 2015). Nurses engaged in care management should be sensitive to the financial concerns that many in the Appalachian region are faced with if they are to be able to adhere to treatment plans 
that likely include multiple medications and treatment regimens. Telehealth can be a service ideally suited for people with heart failure in Appalachia because of the lack of healthcare providers in rural communities and travel distances to major healthcare centers. Monitoring technologies either through daily telephone calls or electronically transmitted vital signs can optimize treatment, resulting in improvements in self-management and adherence to therapeutic guidelines (Verdejo et al., 2015).

In order to improve modifiable risk factors, education of both providers and patients is necessary to achieve lifestyle modifications and improve adherence to pharmacological protocols (Lama Tamang et al., 2014). Providers need to be educated on the current American College of Cardiology and American Heart Association's Guidelines for Management of Heart Failure (Yancy et al., 2017). These guidelines include the measurement of B-type natriuretic peptide (BNP) or of NT-proBNP for establishing prognosis and disease severity, and appropriate use of angiotensin-converting enzyme (ACE) inhibitors, angiotensin II receptor blockers (ARBs), or angiotensin-receptor/neprilysin inhibitors (ARNIs), ivabradine, and intravenous iron replacement for patients with anemia to improve functional status and improve quality of life. Because there are high prevalence rates of coronary artery disease, diabetes, hypertension, and chronic kidney disease in this population, there are likely to be individuals with Stage A heart failure who are undiagnosed since symptoms are not yet present (Kovell et al., 2015). This further indicates the need for diagnostic measures in this Appalachian population, which should include natriuretic peptide biomarker testing (Yancy et al., 2017). One of the questions measuring physical wellbeing on the MLHFQ asked whether "heart failure prevented them from living life as they wanted to by making it difficult to sleep at night" and a statistically significant correlation was found between levels of physical activity and physical well-being. This finding lends support to 
the ACC/AHA guideline recommending a formal sleep assessment for patients suspected to have sleep apnea due to excessive daytime sleepiness. If such patients are found to have sleep apnea, continuous positive airway pressure (CPAP) therapy should be ordered. The guidelines suggest that all patients receive further coaching by a nurse specialist who is able to emphasize individual risk factors and stress the importance of adherence to medications and healthy lifestyle behaviors (Ledwidge et al., 2013). Collectively, proper medical treatment of heart failure along with optimizing healthy lifestyles to decrease risk factors should allow patients to manage their disease, which may result in improvements in their physical, social, and emotional well-being.

\section{Future Research}

Additional research is needed to determine whether patients with heart failure in this rural, Appalachian population differ significantly from demographically similar patients living in more urban areas in terms of the modifiable risk factors associated with physical, social, and emotional well-being. A mixed design study with a larger sample from this Appalachian region and a corresponding urban cohort would allow for comparisons to be made between these groups. If the samples are found to be similar in terms of modifiable risk factors and well-being, the same interventions aimed at reducing these risk factors could be used uniformly in these populations (Polit \& Beck, 2012). A randomized controlled trial needs to be done to determine which interventions are most effective among patients with heart failure in improving nutrition, reducing obesity, promoting active lifestyles, and helping people to stop smoking. Additional data need to be collected on disease states and whether the patients are being treated effectively according to current guidelines. For example, examining data on $\mathrm{HgA}_{1} \mathrm{c}$ level, treatment for sleep apnea, and cognitive behavioral therapy for depression and anxiety could be useful. More robust 
data on smoking history such as pack-years and how long ago former smokers quit smoking would add to the body of knowledge about the relationship between smoking and the onset of heart failure. The participant's support systems and community resources available to them should be known. Demographic information including marital status and number of children and grandchildren, who often comprise the social support system for an individual with heart failure, also should be collected.

A longitudinal study on heart failure patients in rural Appalachia would allow for a more in-depth understanding of why heart failure rates in this population are higher than in the US as a whole. Such a study should include additional clinical data, travel distances to cardiologists and hospitals, types of grocery stores and food available in rural areas, measures of health literacy, and willingness to make changes based on Prochaska's stages of change (Suppan, 2001). It is possible to stop the progression of heart failure with interventions aimed at improved nutrition, limiting sodium intake when indicated; limiting alcohol consumption; engaging in appropriate amounts of exercise; medication adherence; managing hypertension, diabetes, and hyperlipidemia; and smoking cessation. Depending on how many of these risk factors individuals have, the secondary prevention measures including lifestyle modifications may be daunting and therefore it is necessary to work closely with the patients to determine which changes will have the biggest impact on their heart failure and which ones they are ready to make. Generally, $40 \%$ of people will be in the precontemplation stage, $40 \%$ in the contemplation stage, and $20 \%$ in the preparation stage. If an individual is in the precontemplation stage the nurse's role would be to educate the patient about the benefits of the behavior change and the negative consequences of not making the change. For those in the contemplation phase, the nurse should emphasize the benefits of the behavior change and make referrals to resources available 
to facilitate the desired change. Once an individual is in the preparation phase the nurse's role is to help the patient identify a date for the behavior change and develop a plan for making the change as easy and burden-free as possible. The nurse-patient relationship at this stage of behavior modification is vital and must address the intrapersonal, interpersonal, and extrapersonal issues that are impacted by this change. These factors must be taken into consideration so that patients have the strong personal motivation to make the change, the support from family and friends that is necessary to provide the daily encouragement needed to sustain the change, and the ability to afford any of the resources essential for the behavior change. When these intrapersonal, interpersonal, and extrapersonal stressors are reduced, the lines of resistance in Neuman's Systems Model will be strengthened, protecting the basic core and minimizing further damage to the heart thereby slowing the progression of the heart failure.

Finally, because social domain, as a third factor in addition to the physical and emotional domains, has recently been identified by researchers using the MLHFQ, a larger study on this Appalachian population using the MLHFQ should be done to confirm the existence of this factor (Bilbao, Escobar, Garcia-Perez, Navarro, \& Quiros, 2016; Garin et al., 2013; Munyombwe et al., 2014). The studies identifying this third factor vary in which questions should be included for this social domain and a factor analysis of data from a study in this unique rural population would add to the research in solidifying agreement on the particular question set that best identifies social well-being.

\section{Limitations}

This study had a number of limitations. The cross-sectional study was based on a convenience sample collected during a three-month period between January and April 2017. Because part of this time frame was during the winter months there were many cancelled 
appointments at the WVU Heart and Vascular Institute and Family Medicine Outpatient Clinic and this likely influenced the sample, as those who live in the most isolated, rural areas may have been unable to travel to appointments during inclement weather. Demographic data on patient addresses was not collected, so access to care issues could not be addressed. Despite the fact that the majority of subjects had low income, data on the number of people living in the patient's household was not collected and therefore household income could not be used to assess poverty levels. Insurance information was also not collected and insurance is important in this rural Appalachian population because ability to pay for medications and treatments is often a deterrent to patient compliance. Because of the homogeneity of the sample with participants being predominantly white and of lower socioeconomic status, the results are not generalizable to Appalachian regions outside the region from which subjects were recruited.

Clinical data on laboratory values were also beyond the scope of this study but certainly could have provided vital information on the current health status of patients. Lab values including a basic metabolic panel, $\mathrm{HgA}_{1} \mathrm{c}, \mathrm{BNP}$, and NT-proBNP would have allowed for a more comprehensive picture of the subject's health, particularly among those with the comorbidities of diabetes, COPD, and chronic kidney disease. Additionally, this study did not identify whether patients were receiving CPAP therapy and/or dialysis, which might have had an impact on outcome data.

The AHA Life's Simple 7 Questionnaire has been widely used as a patient assessment tool to determine heart disease risk; however, its validity and reliability have not been tested or confirmed. As with most dietary assessments, this provides self-reported data, which were not verified with further interviews to determine accuracy. A more widely used 24-hour dietary recall would have added strength to this nutrition predictor variable. Moreover, when analyzing 
the data from this questionnaire a carefully developed but arbitrary distinction was made by the investigator about what scores on the questionnaire indicated excellent, good, and poor nutritional status.

Another limitation of this study was that comparisons between participants in the inpatient $(\mathrm{N}=72)$, outpatient $(\mathrm{N}=35)$, and community dwelling $(\mathrm{N}=8)$ sites were not made. The majority of subjects were from the inpatient setting and were likely more incapacitated than those in the outpatient or community setting. Furthermore, subjects being followed up at the WVU Heart and Vascular Institute may have differed in disease severity from those seen at the Family Medicine Outpatient Clinic. The care in these two outpatient settings may also have differed because of the type of providers seen: cardiology specialists versus family medicine practitioners.

Missing data was a further limitation of the study with the most problematic being the NYHA classes, which were missing for nearly $15 \%$ of the sample. Most of the missing NYHA data were among the subjects drawn from the Family Medicine Outpatient Clinic $(\mathrm{N}=13)$, which may be a reflection of the manner in which patients with heart failure are assessed in this setting. Missing NYHA class data limited any comparisons that might have been made in physical, social, and emotional well-being based on disease severity. In addition, because previous research suggests that self-reported NYHA classes may be more accurate than providerassessed stages, measuring individuals' own assessment of their NYHA class may have provided additional insights into their functional status (J. A. Bennett et al., 2002; Holland et al., 2010).

A larger sample size likely would have resulted in data that were more normally distributed, allowing for parametric statistics to be used for analyses. Confounding variables were not accounted for by performing partial or semipartial correlations, so the results are 
limited because it is not known whether the variables analyzed had a relationship without the influence of other factors (variables) that were not controlled for. Therefore the statistically significant relationships that were found may have been influenced by another factor that was not taken into consideration.

\section{Conclusions}

Among patients in the rural Appalachian setting of this study, the more physically active an individual living with heart failure was, the higher the levels of physical, social, and emotional well-being as measured by the MLHFQ. Many of the subjects in this study live on farms or have large properties that they take pride in, and a frequent complaint heard during data collection was that they could no longer properly take care of their homes, mow the lawn, garden, or tend to livestock due to their symptoms. The inability to be physically active likely has a detrimental impact on quality of life in this study population. Nutritional status of the study participants was also significantly correlated to social well-being.

Nurses are uniquely qualified to provide secondary prevention to those with heart failure by assessing readiness for change, providing education, identifying resources, and encouraging behavior modification to reduce risk factors in an effort to minimize disease progression. Additional research is needed to determine the causal effect of nutrition, BMI, physical activity, and smoking on physical, social, and emotional well-being in patients with heart disease who have lower levels of education and lower socioeconomic status in the northern Appalachian region. Interventions aimed at eliminating modifiable risk factors among those with heart failure need to be tested in this population to determine the most effective strategies for evoking positive changes that may reduce morbidity and mortality due to heart failure. 


\section{Appendixes}

\section{Appendix A: American Heart Association Life's Simple 7 Dietary Questionnaire}

Dietary questionnaire adapted from the AHA Life's Simple 7 questionnaire.

1. How many cups of fruit do you eat in an average day?

I eat __ number of cups of fruit per day

1 large orange or banana

1 medium pear or grapefruit

1 small apple

8 large strawberries

15 grapes or $1 / 2$ cup of raisins
1 cup equals any one of these options

2. How many cups of vegetables do you eat in an average day?

I eat number of cups of vegetables per day

1 large bell pepper or ear of corn

1 medium potato or large sweet potato

1 cup cooked greens

1 cup equals any one of these options

2 cups raw greens

2 medium carrots or 12 baby carrots

2 large stalks of celery

3. Do you eat two servings or more of fish weekly? ( 1 serving $=3.5$ ounces $)$

o Yes

O No

4. Do you eat 4 ounces or more of whole grains daily?

O Yes

○ No

5. Do you drink less than 36 ounces (450 calories) of beverages with added sugar (sugars added to beverages during processing) weekly?

O Yes

O No

6. Please check all boxes that apply to your sodium intake.

$\circ$ I avoid eating prepackaged processed food or I eat low-sodium version

O I avoid eating out or ask for the low-sodium preparation

O I cook at home without adding salt

$\circ$ I do none of the above 


\section{Appendix B: Global Adult Tobacco Survey}

1. Current Tobacco Smoking Status

Do you currently smoke tobacco on a daily basis, less than daily, or not at all?

Daily

Less than daily

Not at all

Don't know

2a. Past Daily Smoking Status

Have you smoked tobacco daily in the past?

Yes

No

2b. Past Smoking Status

In the past, have you smoked tobacco on a daily basis, less than daily, or not at all?

(Interviewer: if respondent has done both "daily" and "less than daily" in the past, check "daily")

Daily

Less than daily

Not at all

Don't know 


\section{Appendix C: Duke Activity Status Index}

\begin{tabular}{|c|c|c|c|}
\hline & & Yes & No \\
\hline 1. & $\begin{array}{l}\text { Are you able to take care of yourself, that is, eating, dressing, } \\
\text { bathing, or using the toilet? }\end{array}$ & & \\
\hline 2. & Are you able to walk indoors, such as around the house? & & \\
\hline 3. & Are you able to walk a block or two on level ground? & & \\
\hline 4. & $\begin{array}{l}\text { Are you able to climb a flight of stairs or walk up a hill without } \\
\text { stopping? }\end{array}$ & & \\
\hline 5. & Are you able to run a short distance? & & \\
\hline 6. & $\begin{array}{l}\text { Are you able to do light work around the house like dusting or } \\
\text { washing dishes? }\end{array}$ & & \\
\hline 7. & $\begin{array}{l}\text { Are you able to do moderate work around the house like } \\
\text { vacuuming, sweeping floors, or carrying in the groceries? }\end{array}$ & & \\
\hline 8. & $\begin{array}{l}\text { Are you able to do heavy work around the house like scrubbing } \\
\text { floors, or lifting or moving heavy furniture? }\end{array}$ & & \\
\hline 9. & $\begin{array}{l}\text { Are you able to do yard work like raking leaves, weeding, or } \\
\text { pushing a power mower yet? }\end{array}$ & & \\
\hline 10. & Are you having sexual relations? & & \\
\hline 11. & $\begin{array}{l}\text { Are you able to participate in moderate recreational activities like } \\
\text { golf, bowling, dancing, doubles tennis, or throwing a baseball or } \\
\text { football? }\end{array}$ & & \\
\hline 12. & $\begin{array}{l}\text { Are you able to participate in strenuous sports like swimming, } \\
\text { singles tennis, football, basketball, or skiing? }\end{array}$ & & \\
\hline
\end{tabular}




\section{Appendix D: Minnesota Living With Heart Failure Questionnaire}

\section{MINNESOTA LIVING WITH HEART FAILURE® QUESTIONNAIRE}

The following questions ask how much your heart failure (heart condition) affected your life during the past month (4 weeks). After each question, circle the $0,1,2,3,4$, or 5 to show how much your life was affected. If a question does not apply to you, circle the 0 after that question.

Did your heart failure prevent you from living as you wanted during the past month (4 weeks) by -

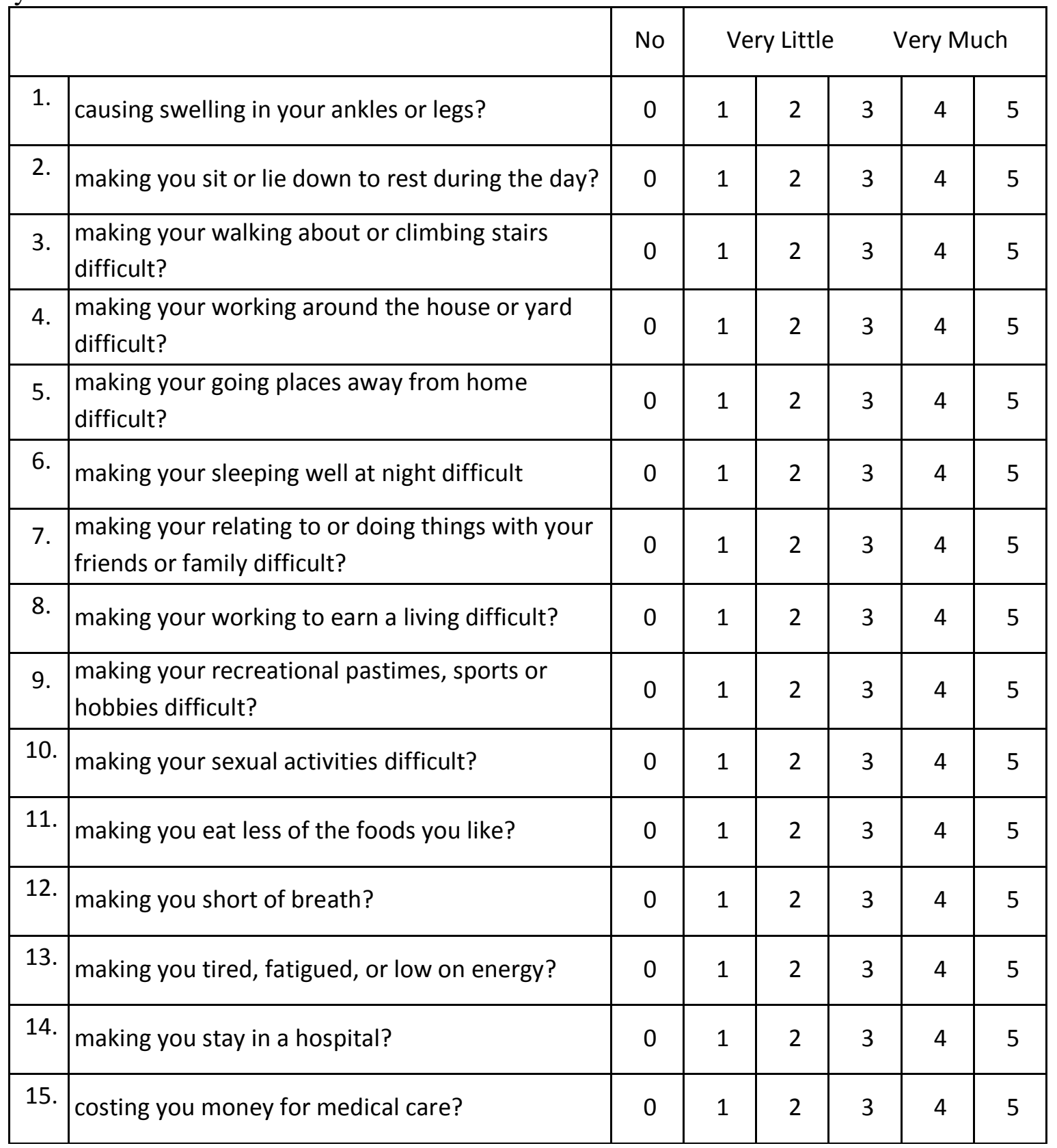




\begin{tabular}{|c|l|c|c|c|c|c|c|}
\hline 16. & giving you side effects from treatments? & 0 & 1 & 2 & 3 & 4 & 5 \\
\hline 17. & $\begin{array}{l}\text { making you feel you are a burden to your family } \\
\text { or friends? }\end{array}$ & 0 & 1 & 2 & 3 & 4 & 5 \\
\hline 18. & making you feel a loss of self-control in your life? & 0 & 1 & 2 & 3 & 4 & 5 \\
\hline 19. & making you worry? & 0 & 1 & 2 & 3 & 4 & 5 \\
\hline 20. & $\begin{array}{l}\text { making it difficult for you to concentrate or } \\
\text { remember things? }\end{array}$ & 0 & 1 & 2 & 3 & 4 & 5 \\
\hline 21. & making you feel depressed? & 0 & 1 & 2 & 3 & 4 & 5 \\
\hline
\end{tabular}

(C1986 Regents of the University of Minnesota, All rights reserved. Do not copy or reproduce without permission. LIVING WITH HEART FAILURE® is a registered trademark of the Regents of the University of Minnesota. 
Appendix E: Recruitment Flyer

\section{Complete a Survey about living with Heart Failure}

- People 18 years of age and older with heart failure are eligible to participate

- This will take about 15-20 minutes in the clinic today

- All information will be kept private

- You will be provided with a $\$ 15$ gift card for your participation after completing the questionnaires

Would you like to participate in a research study about risk factors for heart failure and how they affect your life?

The information from this study will be used to see how risk factors affect daily activities you normally do like dressing, bathing, cooking, cleaning, and other household chores; spending time with your family and friends; and how you are feeling: happy, sad, depressed, or anxious.

This is a research study through the Department of Nursing at West Virginia University. The West Virginia University Institutional Review Board has approved this project. For more information, please contact:

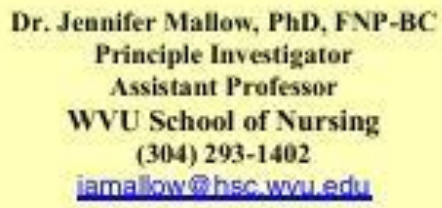




\section{Supplemental Materials}

In addition to the literature review matrix (Table S1, Chapter 2), this section contains five tables compiled before data collection for the purposes of study design development (Chapter 3): a list of risk factor measures by variable studied, with source listings (Table S2); source listings for the MLHFQ (Table S3); an explication of the data collection process (Table S4); and the dissertation project timeline (Table S5).

\section{Table S1: Literature review matrix}

\begin{tabular}{|c|c|c|c|c|c|}
\hline $\begin{array}{c}\text { Authors/Year/ } \\
\text { Location }\end{array}$ & Aim & Design & Sample Size & Data Collection & Results \\
\hline \multicolumn{6}{|c|}{ NUTRITION } \\
\hline $\begin{array}{l}\text { (Esch \& Hendryx, } \\
\text { 2011) } \\
\text { United Kingdom }\end{array}$ & $\begin{array}{l}\text { Examine the } \\
\text { relationship } \\
\text { between salt } \\
\text { intake and the } \\
\text { development of } \\
\text { HF }\end{array}$ & $\begin{array}{l}\text { Literature } \\
\text { synthesis }\end{array}$ & $\mathrm{N} / \mathrm{A}$ & $\begin{array}{l}97 \text { articles } \\
\text { included in review }\end{array}$ & $\begin{array}{l}\text { High salt intake is related to left ventricular } \\
\text { hypertrophy (LVH) independent of blood } \\
\text { pressure. High blood pressure and LVH are risk } \\
\text { factors for HF. Patients with HF who have high } \\
\text { salt intake are at risk for retention of salt and } \\
\text { water leading to exacerbation of HF symptoms } \\
\text { and disease progression. A reduction in salt } \\
\text { intake from } 9-12 \mathrm{~g} / \text { day to the recommended } \\
\text { level of }<5-6 \mathrm{~g} / \text { day will have a beneficial effect. }\end{array}$ \\
\hline
\end{tabular}




\begin{tabular}{|c|c|c|c|c|c|}
\hline $\begin{array}{l}\text { (Kovell et al., } \\
\text { 2015)) } \\
\text { United States }\end{array}$ & $\begin{array}{l}\text { Evaluate whether } \\
\text { nationally } \\
\text { accepted } \\
\text { guidelines for risk } \\
\text { factor control } \\
\text { were achieved in } \\
\text { Stage A HF }\end{array}$ & $\begin{array}{l}\text { Secondary data } \\
\text { analysis of } \\
\text { NHANES data on } \\
\text { Stage A HF, } \\
\text { which is defined } \\
\text { by ACC/AHA as } \\
\text { people w/o HF } \\
\text { symptoms but } \\
\text { with diseases } \\
\text { leading to HF: } \\
\text { CHD, DM, HTN, } \\
\text { or CKD }\end{array}$ & $\begin{array}{l}\text { Data were } \\
\text { weighted to } \\
\text { evaluate the } \\
\text { number of US } \\
\text { adults with } \\
\text { Stage A HF }\end{array}$ & $\begin{array}{l}\text { NHANES data are } \\
\text { cross-sectional, } \\
\text { collected using a } \\
\text { complex, } \\
\text { multistage } \\
\text { sampling design. } \\
\text { Interviews, } \\
\text { physical exams, } \\
\text { and laboratory } \\
\text { measurements } \\
\text { were continuously } \\
\text { gathered (2007- } \\
\text { 2010) from } \\
\text { participants } 20 \\
\text { years of age and } \\
\text { older }\end{array}$ & $\begin{array}{l}\text { A high prevalence of Stage A HF exists in adults } \\
\text { in the US and many are not being properly } \\
\text { treated for the risk factors. Over } 75 \text { million } \\
\text { people are at risk of developing HF and patients } \\
\text { and primary care providers need to assess risk } \\
\text { factors and aggressively treat comorbid } \\
\text { conditions to prevent progression to } \\
\text { symptomatic HF. }\end{array}$ \\
\hline $\begin{array}{l}\text { Pfister et al. } \\
\text { (2014) } \\
\text { United Kingdom }\end{array}$ & $\begin{array}{l}\text { Examine the } \\
\text { association } \\
\text { between bone } \\
\text { mineral density } \\
\text { and the } \\
\text { development of } \\
\text { HF }\end{array}$ & $\begin{array}{l}\text { Secondary data } \\
\text { analysis of bone } \\
\text { mineral density } \\
\text { among patients } \\
\text { with HF }\end{array}$ & $\begin{array}{l}\mathrm{N}=25,639 \text { from } \\
\text { EPIC-Norfolk } \\
\text { Study } \\
\mathrm{N}=13,666 \text { with } \\
\text { bone-density } \\
\text { test included in } \\
\text { study } \\
\mathrm{N}=380 \text { cases of } \\
\mathrm{HF}\end{array}$ & $\begin{array}{l}\text { European } \\
\text { Prospective } \\
\text { Investigation into } \\
\text { Cancer and } \\
\text { Nutrition (EPIC) } \\
\text { study of men and } \\
\text { women, } 39 \text { \& } 79 \\
\text { years of age, } \\
\text { recruited between } \\
1993 \text { \& } 1997 \text { in } \\
\text { Norfolk, UK. } \\
\text { Health and } \\
\text { lifestyle } \\
\text { questionnaires and } \\
\text { quantitative } \\
\text { ultrasound of the } \\
\text { calcaneum }\end{array}$ & $\begin{array}{l}\text { During the follow-up period of } 9 \text { years, } 380 \text { cases } \\
\text { of HF occurred. An inverse association between } \\
\text { bone mineral density and the risk of HF was } \\
\text { found. Findings support the need for cardiac } \\
\text { assessment in those with reduced bone mineral } \\
\text { density. }\end{array}$ \\
\hline
\end{tabular}




\begin{tabular}{|c|c|c|c|c|c|}
\hline $\begin{array}{l}\text { Pfister et al. } \\
\text { (2011) } \\
\text { United Kingdom }\end{array}$ & $\begin{array}{l}\text { Determine the } \\
\text { association } \\
\text { between plasma } \\
\text { vitamin C and HF }\end{array}$ & $\begin{array}{l}\text { Secondary data } \\
\text { analysis of } \\
\text { plasma vitamin C } \\
\text { among patients } \\
\text { with HF }\end{array}$ & $\begin{array}{l}\mathrm{N}=25,639 \text { from } \\
\text { EPIC-Norfolk } \\
\text { Study } \\
\mathrm{N}=20,299 \text { with } \\
\text { plasma vitamin C } \\
\\
\end{array}$ & $\begin{array}{l}\text { European } \\
\text { Prospective } \\
\text { Investigation into } \\
\text { Cancer and } \\
\text { Nutrition (EPIC) } \\
\text { study of men and } \\
\text { women, } 39 \& 79 \\
\text { years of age, } \\
\text { recruited between } \\
1993 \text { \& } 1997 \text { in } \\
\text { Norfolk, UK. } \\
\text { Health and } \\
\text { lifestyle } \\
\text { questionnaires and } \\
\text { plasma vitamin C } \\
\text { measurements } \\
\end{array}$ & $\begin{array}{l}\text { During the follow-up period of nearly } 13 \text { years, } \\
1,258 \text { cases of HF occurred. An inverse } \\
\text { association between plasma vitamin C and the } \\
\text { risk of HF was found. The intake of fruits and } \\
\text { vegetables is associated with higher plasma } \\
\text { vitamin C levels, which may be preventive for HF. } \\
\text { Randomized controlled trials are needed to } \\
\text { examine the effect of a fruit- and vegetable-rich } \\
\text { diet in the prevention of HF. }\end{array}$ \\
\hline $\begin{array}{l}\text { Lama Tamang et } \\
\text { al. (2014) } \\
\text { United States }\end{array}$ & $\begin{array}{l}\text { Evaluate the } \\
\text { adequacy of risk } \\
\text { factor control } \\
\text { among patients } \\
\text { with HF and } \\
\text { adherence to } \\
\text { medication } \\
\text { therapy }\end{array}$ & $\begin{array}{l}\text { Secondary data } \\
\text { analysis of } \\
\text { NHANES data of } \\
\text { people with HF }\end{array}$ & $N=371$ & $\begin{array}{l}\text { NHANES data are } \\
\text { cross-sectional, } \\
\text { collected using a } \\
\text { complex, } \\
\text { multistage } \\
\text { sampling design. } \\
\text { Interviews, } \\
\text { physical exams, } \\
\text { and laboratory } \\
\text { measurements } \\
\text { were continuously } \\
\text { gathered (2007- } \\
\text { 2010) from } \\
\text { participants } 20 \\
\text { years of age and } \\
\text { older }\end{array}$ & $\begin{array}{l}\text { People with HF are inadequately treated for risk } \\
\text { factors including HTN, hyperlipidemia, and DM. } \\
\text { Adherence to lifestyle modifications including } \\
\text { physical activity, smoking, alcohol consumption, } \\
\text { sodium intake, and BMI is poor. Secondary } \\
\text { prevention is needed to minimize risk factors } \\
\text { and increase adherence to lifestyle modification } \\
\text { guidelines. }\end{array}$ \\
\hline
\end{tabular}




\begin{tabular}{|c|c|c|c|c|c|}
\hline \multicolumn{6}{|c|}{ OBESITY } \\
\hline $\begin{array}{l}\text { Alosco, et al. } \\
\text { (2015) } \\
\text { United States }\end{array}$ & $\begin{array}{l}\text { Determine the } \\
\text { relationship } \\
\text { between the } \\
\text { combination of } \\
\text { HTN, DM2, and } \\
\text { reduced fitness } \\
\text { and obesity and } \\
\text { cognitive } \\
\text { dysfunction }\end{array}$ & $\begin{array}{l}\text { Correlational } \\
\text { case-control } \\
\text { study }\end{array}$ & $N=200$ & $\begin{array}{l}\text { Patients were } \\
\text { recruited from a } \\
\text { larger NIH funded } \\
\text { study and } \\
\text { completed a } \\
\text { neuropsychologica } \\
\text { I test and physical } \\
\text { fitness assessment }\end{array}$ & $\begin{array}{l}\text { Reduced physical fitness levels along with } \\
\text { increased risk for comorbidities explain the } \\
\text { detrimental effects of obesity on cognitive } \\
\text { dysfunction in patients with HF. Prospective } \\
\text { studies of HF patients are needed to verify this } \\
\text { association and determine the pathophysiology } \\
\text { of weight loss and potential improvements in } \\
\text { cognitive function. }\end{array}$ \\
\hline $\begin{array}{l}\text { Alpert, M. A, } \\
\text { Lavie, C. J., } \\
\text { Agrawal, H., } \\
\text { Aggarwal, K. B., \& } \\
\text { Kumar, S. A. } \\
\text { (2014) } \\
\text { United States }\end{array}$ & \begin{tabular}{|l} 
Review of the \\
literature to \\
explore the \\
epidemiology, \\
pathophysiology, \\
and clinical \\
manifestations of \\
HF in adults who \\
are obese
\end{tabular} & $\begin{array}{l}\text { Literature } \\
\text { synthesis }\end{array}$ & N/A & $\begin{array}{l}109 \text { articles } \\
\text { included in review }\end{array}$ & $\begin{array}{l}\text { Severe obesity produces hemodynamic } \\
\text { alterations that possibly lead to cardiac } \\
\text { remodeling and changes in ventricular function } \\
\text { that can lead to left ventricular and right } \\
\text { ventricular failure. Weight loss is an effective } \\
\text { method of reversing abnormalities of cardiac } \\
\text { performance and morphology, leading to } \\
\text { improving the clinical manifestations of HF in } \\
\text { patients with cardiomyopathy. }\end{array}$ \\
\hline $\begin{array}{l}\text { Ebong, I. A., Goff, } \\
\text { D.C., Rodriguez, } \\
\text { C. J., Chen, H., \& } \\
\text { Bertoni, A. G. } \\
\text { (2014) } \\
\text { United States }\end{array}$ & $\begin{array}{l}\text { Overview of the } \\
\text { literature to } \\
\text { explore the } \\
\text { pathophysiologic } \\
\text { al mechanisms } \\
\text { leading to HF in } \\
\text { obesity and } \\
\text { enumerations of } \\
\text { premises for the } \\
\text { obesity paradox }\end{array}$ & $\begin{array}{l}\text { Literature } \\
\text { synthesis }\end{array}$ & N/A & $\begin{array}{l}71 \text { articles } \\
\text { included in review }\end{array}$ & $\begin{array}{l}\text { Obesity induces changes in cardiac } \\
\text { hemodynamics, structure, function, and } \\
\text { conduction leading to endothelial dysfunction } \\
\text { and vascular changes. These changes contribute } \\
\text { to metabolic derangements involving insulin } \\
\text { resistance, secretion of adipokines, inflammatory } \\
\text { markers and cardiac lipotoxicity and also } \\
\text { increases incidence of obstructive sleep apnea } \\
\text { (OSA) and Obesity Hypoventilation Syndrome } \\
\text { (OHS), which are risk factors for HF. Further } \\
\text { understanding of the obesity paradox is needed } \\
\text { prior to the development of weight-loss } \\
\text { guidelines for HF management. }\end{array}$ \\
\hline
\end{tabular}




\begin{tabular}{|c|c|c|c|c|c|}
\hline $\begin{array}{l}\text { Horwich, T.B. \& } \\
\text { Fonarow, G. C. } \\
\text { (2010) } \\
\text { United States }\end{array}$ & $\begin{array}{l}\text { Highlight the link } \\
\text { between HF and } \\
\text { metabolic risk } \\
\text { factors: diabetes, } \\
\text { obesity, and } \\
\text { metabolic } \\
\text { syndrome }\end{array}$ & $\begin{array}{l}\text { Literature } \\
\text { synthesis }\end{array}$ & N/A & $\begin{array}{l}70 \text { articles } \\
\text { included in } \\
\text { synthesis }\end{array}$ & $\begin{array}{l}\text { Urgency to identify modifiable risk factors } \\
\text { leading to HF. Additional focus on the } \\
\text { interrelated epidemics of diabetes, obesity, and } \\
\text { metabolic syndrome is needed. Lifestyle } \\
\text { interventions can decrease the risk of these } \\
\text { syndromes. Medical treatment of hypertension, } \\
\text { dyslipidemia, and hyperglycemia in those at risk } \\
\text { is needed in the prevention of HF. }\end{array}$ \\
\hline $\begin{array}{l}\text { Jindal, A., } \\
\text { Whaley-Connell, } \\
\text { A., \& Sowers, J. R. } \\
\text { (2013) } \\
\text { United States }\end{array}$ & $\begin{array}{l}\text { Overview of the } \\
\text { literature on the } \\
\text { relationship } \\
\text { between obesity } \\
\text { and HF and risk } \\
\text { for chronic kidney } \\
\text { disease and } \\
\text { stroke }\end{array}$ & $\begin{array}{l}\text { Literature } \\
\text { synthesis }\end{array}$ & N/A & $\begin{array}{l}38 \text { articles } \\
\text { included in review }\end{array}$ & $\begin{array}{l}\text { Obesity contributes to a } \\
\text { prooxidative/inflammatory milieu that leads to } \\
\text { alterations in fatty acid, lipid, and glucose } \\
\text { metabolism that leads to HF due to diastolic and } \\
\text { systolic failure. Progressive HF is associated with } \\
\text { CKD and is a significant risk factor for } \\
\text { cerebrovascular disease (CVD). }\end{array}$ \\
\hline $\begin{array}{l}\text { Lavie, C.J., et al. } \\
\text { (2013) } \\
\text { United States }\end{array}$ & $\begin{array}{l}\text { Review of obesity } \\
\text { and HF in the } \\
\text { context of } \\
\text { cardiopulmonary } \\
\text { exercise testing }\end{array}$ & $\begin{array}{l}\text { Literature } \\
\text { synthesis }\end{array}$ & N/A & $\begin{array}{l}70 \text { articles } \\
\text { included in review }\end{array}$ & $\begin{array}{l}\text { Obese patients with HF have a better prognosis } \\
\text { than leaner patients with HF due to a } \\
\text { phenomenon known as the obesity paradox. } \\
\text { Weight reduction has beneficial effects on } \\
\text { cardiac structure but only limited data are } \\
\text { available on which to base recommendations for } \\
\text { intentional weight loss in patients with HF. }\end{array}$ \\
\hline $\begin{array}{l}\text { Lavie, C. J., et al. } \\
\text { (2014) } \\
\text { United States }\end{array}$ & $\begin{array}{l}\text { Review of the } \\
\text { obesity paradox, } \\
\text { cachexia, and } \\
\text { frailty among } \\
\text { persons with HF }\end{array}$ & $\begin{array}{l}\text { Literature } \\
\text { synthesis }\end{array}$ & N/A & $\begin{array}{l}45 \text { articles } \\
\text { included in review }\end{array}$ & $\begin{array}{l}\text { The obesity paradox exists among patients with } \\
\text { HF, and those who are mildly obese or } \\
\text { overweight have a better prognosis than patients } \\
\text { with normal weight. Conversely, frailty and } \\
\text { cardiac cachexia are associated with poor } \\
\text { prognosis in persons with HF. Weight loss in HF } \\
\text { patients should be reserved for those with BMI } \\
>35 \mathrm{~kg} / \mathrm{m} 2 \text {. Improving cardiorespiratory fitness } \\
\text { (CRF) and lean muscle mass and muscle } \\
\text { strengthening should lead to improvements in } \\
\text { prognosis. }\end{array}$ \\
\hline
\end{tabular}




\begin{tabular}{|c|c|c|c|c|c|}
\hline $\begin{array}{l}\text { Nagarajan et al. } \\
\text { (2013) } \\
\text { United States }\end{array}$ & $\begin{array}{l}\text { Examine the } \\
\text { obesity paradox } \\
\text { in patients with } \\
\text { advanced HF }\end{array}$ & $\begin{array}{l}\text { Secondary data } \\
\text { analysis of a } \\
\text { large data set of } \\
\text { patients referred } \\
\text { to the Cleveland } \\
\text { Clinic with end- } \\
\text { stage HF for } \\
\text { cardiac } \\
\text { transplant } \\
\text { evaluation }\end{array}$ & $N=501$ & $\begin{array}{l}\text { A data set was } \\
\text { used to compare } \\
\text { BMI scores and } \\
\text { prognoses of } \\
\text { patients with } \\
\text { advanced HF. Data } \\
\text { were categorized } \\
\text { into } 3 \text { groups } \\
\text { based on BMI: } \\
\text { non-obese, obese, } \\
\text { and morbidly } \\
\text { obese }\end{array}$ & $\begin{array}{l}\text { Among patients with end-stage HF, obese } \\
\text { patients had a more favorable outcome than } \\
\text { non-obese patients. HF is a cachectic disease and } \\
\text { it is theorized that the high metabolic reserve in } \\
\text { obese patients allows for tolerance of the } \\
\text { catabolic effects of HF. Lower B-type natriuretic } \\
\text { peptide (BNP) levels are seen in obese patients, } \\
\text { but very high BNP levels were found in the } \\
\text { morbidly obese patients. The obesity paradox } \\
\text { has been confirmed in many studies, but results } \\
\text { from this study show that this paradox may not } \\
\text { extend to the morbidly obese. }\end{array}$ \\
\hline $\begin{array}{l}\text { Narumi et al. } \\
(2014) \\
\text { Japan }\end{array}$ & $\begin{array}{l}\text { Investigate the } \\
\text { impact of obesity } \\
\text { on prognosis in } \\
\text { patients with HF } \\
\text { with or without } \\
\text { metabolic } \\
\text { syndrome }\end{array}$ & $\begin{array}{l}\text { Prospective } \\
\text { cohort study of } \\
\text { patients with HF } \\
\text { divided into } \\
\text { obese and non- } \\
\text { obese groups; } \\
\text { the effect of } \\
\text { metabolic } \\
\text { syndrome on } \\
\text { prognosis was } \\
\text { measured }\end{array}$ & $\mathrm{N}=374$ & $\begin{array}{l}\text { Patients admitted } \\
\text { to a hospital in } \\
\text { Japan for } \\
\text { treatment of } \\
\text { worsening HF. } \\
\text { Patients were } \\
\text { followed } \\
\text { prospectively for } 2 \\
\text { years with } \\
\text { outcomes } \\
\text { including death } \\
\text { due to HF, } \\
\text { myocardial } \\
\text { infarction, stroke, } \\
\text { other vascular } \\
\text { causes, sudden } \\
\text { cardiac death, or } \\
\text { rehospitalization } \\
\text { for HF } \\
\text { exacerbation }\end{array}$ & $\begin{array}{l}\text { Favorable HF outcomes were found among } \\
\text { obese patients without metabolic syndrome but } \\
\text { this favorable impact did not extend to those } \\
\text { obese patients with metabolic syndrome. } \\
\text { Metabolic syndrome was defined as follows: } \\
\mathrm{BMI} \geq 25 \mathrm{~kg} / \mathrm{m} 2 \\
\text { Triglycerides } \geq 150 \mathrm{ml} / \mathrm{dL} \\
\mathrm{HDL}<40 \mathrm{mg} / \mathrm{dL} \text { in } \mathrm{men} \text { and }<50 \mathrm{mg} / \mathrm{dL} \text { in women } \\
\text { Fasting blood sugar } \geq 110 \mathrm{mg} / \mathrm{dL} \text { or DM diagnosis } \\
\text { Blood pressure } \geq 130 \mathrm{mmHg} \text { systolic and/or } \geq 85 \\
\mathrm{mmHg} \text { diastolic or antihypertensive medication }\end{array}$ \\
\hline
\end{tabular}




\begin{tabular}{|c|c|c|c|c|c|}
\hline $\begin{array}{l}\text { Ndumele et al. } \\
\text { (2016) } \\
\text { United States }\end{array}$ & $\begin{array}{l}\text { Determine the } \\
\text { prognostic value } \\
\text { of N-terminal } \\
\text { pro-brain } \\
\text { natriuretic } \\
\text { peptide (NT- } \\
\text { proBNP) levels for } \\
\text { HF risk across } \\
\text { BMl categories }\end{array}$ & $\begin{array}{l}\text { Secondary data } \\
\text { analysis from the } \\
\text { Atherosclerosis } \\
\text { Risk in } \\
\text { Communities } \\
\text { Study (ARIC), } \\
\text { which was a } \\
\text { study of } \\
\text { community- } \\
\text { based, middle- } \\
\text { aged individuals }\end{array}$ & $N=12,230$ & $\begin{array}{l}\text { Recruitment \& } \\
\text { baseline data } \\
\text { collection } \\
\text { occurred between } \\
1987 \text { \& } 1989 \text { in } 4 \\
\text { US communities in } \\
\text { MD, MS, NC, \& } \\
\text { MN. Followed up } \\
\text { at 3-year intervals } \\
\text { with the last } \\
\text { follow-up visit } \\
\text { completed } \\
\text { between } 2011 \text { \& } \\
2013\end{array}$ & $\begin{array}{l}\text { An inverse relationship exists between BMI and } \\
\text { NT-proBNP levels. NT-proBNP is independently } \\
\text { associated with HF and improves HF risk } \\
\text { prediction beyond traditional risk factors even } \\
\text { among patients with obesity. Because obesity is } \\
\text { a risk factor for HF, even modest NT-proBNP } \\
\text { levels may be a useful clinical indicator of HF } \\
\text { incidence in patients with BMI } \geq 30 \text {. }\end{array}$ \\
\hline $\begin{array}{l}\text { Schmidt et al. } \\
\text { (2014) } \\
\text { Denmark }\end{array}$ & $\begin{array}{l}\text { Examine the } \\
\text { relationship } \\
\text { between young } \\
\text { adulthood } \\
\text { obesity and long- } \\
\text { term risk of HF }\end{array}$ & $\begin{array}{l}\text { Population- } \\
\text { based cohort } \\
\text { study using data } \\
\text { from the Draft } \\
\text { Board in } \\
\text { Northern } \\
\text { Denmark and } \\
\text { the Danish } \\
\text { National Patient } \\
\text { Registry }\end{array}$ & $\begin{array}{l}\mathrm{N}=12,850 \text { from } \\
\text { the Draft Board } \\
\mathrm{N}=107 \text { with } \mathrm{HF} \\
\text { from the } \\
\text { National Patient } \\
\text { Registry }\end{array}$ & $\begin{array}{l}\text { Draft Board data } \\
\text { collected from } \\
\text { men in the } 1955 \text { \& } \\
1965 \text { birth cohorts. } \\
\text { Follow-up data } \\
\text { from up to } 36 \\
\text { years on } 107 \\
\text { patients with HF }\end{array}$ & $\begin{array}{l}\text { Men with obesity in early adulthood were at } \\
\text { increased risk for both ischemic heart disease } \\
\text { (IHD) and HF. The absolute risk was highest for } \\
\text { IHD, but the relative risk was even higher for HF. } \\
\text { Hypertension was the most influential mediator } \\
\text { of BMI-associated risk of IHD and HF. }\end{array}$ \\
\hline $\begin{array}{l}\text { Wannamethee et } \\
\text { al. (2011) } \\
\text { United Kingdom }\end{array}$ & \begin{tabular}{|l|} 
Examine the \\
relationship \\
between risk \\
factors of BMI, \\
waist \\
circumference, \\
and the incidence \\
of HF and assess \\
the contribution \\
of plasma leptin \\
concentration to \\
these factors
\end{tabular} & $\begin{array}{l}\text { Prospective } \\
\text { cohort study } \\
\text { using data from } \\
\text { the British Heart } \\
\text { Study, which } \\
\text { was a study of } \\
\text { men from } 24 \\
\text { British towns }\end{array}$ & $\begin{array}{l}\mathrm{N}=7,735 \text { from } \\
\text { the British Heart } \\
\text { Study } \\
\mathrm{N}=228 \text { with HF } \\
\text { in the mean } \\
\text { follow-up period } \\
\text { of } 9 \text { years }\end{array}$ & $\begin{array}{l}\text { Data collected on } \\
\text { men aged } 40 \text { to } 59 \\
\text { years between } \\
1978 \& 1980.20- \\
\text { year follow-up on } \\
\text { surviving men } \\
\text { (aged } 60 \text { to } 79 \\
\text { years) from } 1998 \\
\text { to } 2000\end{array}$ & $\begin{array}{l}\text { Leptin regulates alterations in myocardial } \\
\text { metabolism leading to cardiac hypertrophy and } \\
\text { possibly cardiac remodeling and is normally } \\
\text { increased in patients with HF. Leptin may be the } \\
\text { mechanism linking obesity to HF. In those with } \\
\text { no preexisting CHD, obesity and HF may be } \\
\text { mediated by leptin. In patients with CHD, leptin } \\
\text { is not a factor in the association between BMI } \\
\text { and HF. }\end{array}$ \\
\hline
\end{tabular}




\begin{tabular}{|c|c|c|c|c|c|}
\hline $\begin{array}{l}\text { Zapatero et al. } \\
\text { (2012) } \\
\text { Spain }\end{array}$ & $\begin{array}{l}\text { Determine the } \\
\text { association of } \\
\text { obesity and } \\
\text { malnutrition on } \\
\text { acute HF }\end{array}$ & $\begin{array}{l}\text { Secondary } \\
\text { analysis of the } \\
\text { Minimum Basic } \\
\text { Data Set of } \\
\text { patients } \\
\text { discharged from } \\
\text { internal } \\
\text { medicine } \\
\text { services in } \\
\text { hospitals of the } \\
\text { Spanish National } \\
\text { Health System } \\
\end{array}$ & $N=370,983$ & $\begin{array}{l}\text { Patients } \\
\text { discharged from } \\
\text { internal medicine } \\
\text { departments } \\
\text { within the Spanish } \\
\text { National Health } \\
\text { System between } \\
2006 \& 2008 \text { with } \\
\text { a primary or } \\
\text { secondary } \\
\text { diagnosis of HF }\end{array}$ & $\begin{array}{l}\text { Among patients admitted to the hospital for HF, } \\
\text { obesity was associated with reduced in-hospital } \\
\text { mortality risk and reduced possibility of early } \\
\text { readmission. Patients with malnutrition had } \\
\text { increased in-hospital mortality and increased risk } \\
\text { of readmission within } 30 \text { days of discharge. } \\
\text { Findings support the "obesity paradox." }\end{array}$ \\
\hline \multicolumn{6}{|c|}{ PHYSICAL ACTIVITY } \\
\hline $\begin{array}{l}\text { Andersen, K., et } \\
\text { al. (2014) } \\
\text { Sweden }\end{array}$ & $\begin{array}{l}\text { Investigate } \\
\text { nonlinear } \\
\text { associations of } \\
\text { total and leisure } \\
\text { time activity with } \\
\text { the risk of HF }\end{array}$ & $\begin{array}{l}\text { Secondary data } \\
\text { analysis from the } \\
\text { National March } \\
\text { Cohort, which } \\
\text { was a Swedish } \\
\text { Cancer Society } \\
\text { fundraising } \\
\text { event in 3,600 } \\
\text { cities and } \\
\text { villages in } \\
\text { Sweden }\end{array}$ & $\begin{array}{l}\mathrm{N}=43,880 \\
\mathrm{~N}=39,805 \\
\text { included in the } \\
\text { study, } \\
\text { comprising those } \\
\text { w/o previously } \\
\text { diagnosed HF }\end{array}$ & $\begin{array}{l}\text { Data collected } \\
\text { from volunteer } \\
\text { participants } \\
\text { through a 32-page } \\
\text { questionnaire with } \\
\text { questions about } \\
\text { physical activity, } \\
\text { diet, medical } \\
\text { history, and } \\
\text { lifestyle factors. } \\
\text { Study sample } \\
\text { included only } \\
\text { those who were } \\
\text { not previously } \\
\text { diagnosed with HF }\end{array}$ & $\begin{array}{l}\text { Both total physical activity and leisure time } \\
\text { physical activity were inversely related to the risk } \\
\text { of developing HF. It is recommended that people } \\
\text { get } \geq 150 \text { minutes of moderate-intensity physical } \\
\text { activity per week. }\end{array}$ \\
\hline
\end{tabular}




\begin{tabular}{|c|c|c|c|c|c|}
\hline $\begin{array}{l}\text { deFilippi, C. R., et } \\
\text { al. (2012) } \\
\text { United States }\end{array}$ & $\begin{array}{l}\text { Evaluate the } \\
\text { association } \\
\text { between physical } \\
\text { activity and cTNT } \\
\text { and NT-proBNP } \\
\text { and the risk of HF }\end{array}$ & $\begin{array}{l}\text { Secondary data } \\
\text { analysis from the } \\
\text { Cardiovascular } \\
\text { Heart Study } \\
\text { (CHS), which is a } \\
\text { multicenter, } \\
\text { prospective, } \\
\text { observational } \\
\text { cohort study of } \\
\text { CVD in older } \\
\text { adults }\end{array}$ & $\begin{array}{l}\mathrm{N}=5,888 \mathrm{CHS} \\
\mathrm{N}=1,757 \\
\text { included in the } \\
\text { study, } \\
\text { comprising those } \\
\text { w/o previously } \\
\text { diagnosed HF }\end{array}$ & $\begin{array}{l}\text { Data collected on } \\
\text { older adults from } \\
1989 \text { to } 1990 \text { for } \\
\text { the main cohort } \\
\text { and } 1992 \text { to } 1993 \\
\text { for the African- } \\
\text { American cohort. } \\
\text { Physical activity } \\
\text { measures and } \\
\text { changes in } \\
\text { troponin T (cTnT) } \\
\text { and N-terminal } \\
\text { pro-B-type } \\
\text { natriuretic peptide } \\
\text { (NT-proBNP) } \\
\text { serum samples }\end{array}$ & $\begin{array}{l}\text { New onset of HF is inversely associated with the } \\
\text { extent of physical activity. A strong inverse } \\
\text { relationship exists between higher levels of } \\
\text { physical activity in ambulatory older adults and a } \\
\text { lower probability of increases in cTnT and NT- } \\
\text { proBNP over time. Regular monitoring of these } \\
\text { biomarkers may provide an early indication of } \\
\text { the pathophysiology associated with sedentary } \\
\text { lifestyle and the risk of developing HF. }\end{array}$ \\
\hline $\begin{array}{l}\text { Du, H., Everett, } \\
\text { B., Newton, P. J., } \\
\text { Salamonson, Y., \& } \\
\text { Davidson, P. M. } \\
\text { (2012) } \\
\text { Australia }\end{array}$ & $\begin{array}{l}\text { Explore the } \\
\text { conceptual } \\
\text { underpinnings of } \\
\text { self-efficacy to } \\
\text { the barriers to } \\
\text { being physically } \\
\text { active }\end{array}$ & $\begin{array}{l}\text { Literature } \\
\text { synthesis }\end{array}$ & N/A & $\begin{array}{l}78 \text { articles } \\
\text { included in review }\end{array}$ & $\begin{array}{l}\text { Low adherence to physical activity } \\
\text { recommendations is found among persons with } \\
\text { HF. Physical activity is an important component } \\
\text { of HF management and self-efficacy is known to } \\
\text { be the strongest predictor of adherence. The } \\
\text { theoretical foundation of self-efficacy could } \\
\text { provide the basis for community-based exercise } \\
\text { programs, which may be superior to traditional } \\
\text { exercise programs in terms of reaching larger } \\
\text { groups of people in addition to promoting long- } \\
\text { term adherence to physical activity } \\
\text { recommendations. }\end{array}$ \\
\hline
\end{tabular}




\begin{tabular}{|c|c|c|c|c|c|}
\hline $\begin{array}{l}\text { Echouffo- } \\
\text { Tcheugui et al. } \\
\text { (2015) } \\
\text { United States }\end{array}$ & $\begin{array}{l}\text { Determine the } \\
\text { effects of physical } \\
\text { activity or fitness } \\
\text { on the incidence } \\
\text { of HF }\end{array}$ & $\begin{array}{l}\text { Systematic } \\
\text { review and } \\
\text { meta-analysis }\end{array}$ & $\begin{array}{l}\mathrm{N}=282,889 \text { in } \\
10 \text { cohort } \\
\text { studies followed } \\
\text { for } 7-30 \text { years } \\
\mathrm{N}=165,695 \text { in } \\
\text { studies of max. } \\
\text { vs min. physical } \\
\text { activity }\end{array}$ & $\begin{array}{l}\text { MEDLINE and } \\
\text { EMBASE search of } \\
\text { prospective cohort } \\
\text { studies on the } \\
\text { association of } \\
\text { physical activity ( } \mathrm{n} \\
=10 \text { ) or fitness ( } \mathrm{n} \\
=2 \text { ) with incidence } \\
\text { of HF }\end{array}$ & $\begin{array}{l}\text { An association exists between regular physical } \\
\text { activity and lower incidence of HF. A similar } \\
\text { association exists between level of physical } \\
\text { fitness and the incidence of HF. This inverse } \\
\text { relationship between physical activity and fitness } \\
\text { and risk of HF was found in both men and } \\
\text { women and in cohorts from the US and Northern } \\
\text { Europe. Significant effects of physical activity on } \\
\text { HF exist in the elderly. }\end{array}$ \\
\hline $\begin{array}{l}\text { Kraigher-Krainer, } \\
\text { E. (2013) } \\
\text { United States }\end{array}$ & $\begin{array}{l}\text { Examine the } \\
\text { relationship } \\
\text { between } \\
\text { inactivity in the } \\
\text { elderly and HF } \\
\text { risk }\end{array}$ & $\begin{array}{l}\text { Secondary data } \\
\text { analysis from the } \\
\text { Framingham } \\
\text { Heart Study, } \\
\text { which was a } \\
\text { prospective } \\
\text { cohort study of a } \\
\text { community- } \\
\text { based sample; } \\
\text { baseline data } \\
\text { from } 1948 \text { with } \\
\text { follow-up every } \\
2 \text { years }\end{array}$ & $\begin{array}{l}\mathrm{N}=1,402 \text { in } 20 \text { th } \\
\text { biannual } \\
\text { evaluation } \\
\mathrm{N}=1,142 \text { for } \\
\text { this study }\end{array}$ & $\begin{array}{l}\text { Data collected } \\
\text { beginning in } 1948 \\
\text { with follow-up } \\
\text { every } 2 \text { years. } \\
\text { Study data were } \\
\text { from the 20th } \\
\text { biannual } \\
\text { examination } \\
\text { (1986-1990) and } \\
\text { excluded those } \\
\text { with HF, MI, renal } \\
\text { disease, and lack } \\
\text { of recorded } \\
\text { physical activity } \\
\text { index }\end{array}$ & $\begin{array}{l}\text { Lower physical activity was found to be } \\
\text { associated with higher incidence of HF. This } \\
\text { association existed in both HF with preserved } \\
\text { ejection fraction (HFPEF) and HF with reduced } \\
\text { ejection fraction (HFREF). Greater physical } \\
\text { activity among the elderly was associated with a } \\
\text { lower risk of HFPEF. }\end{array}$ \\
\hline $\begin{array}{l}\text { Lee et al. (2017) } \\
\text { Korea }\end{array}$ & $\begin{array}{l}\text { Examine the } \\
\text { impact of } \\
\text { exercise self- } \\
\text { efficacy, physical } \\
\text { functioning, and } \\
\text { physical activity } \\
\text { on quality of life }\end{array}$ & $\begin{array}{l}\text { Cross-sectional } \\
\text { descriptive }\end{array}$ & $\begin{array}{l}\mathrm{N}=116 \\
\text { outpatients }\end{array}$ & $\begin{array}{l}\text { Data collected } \\
\text { from patients at } \\
\text { outpatient clinics } \\
\text { of } 3 \text { academic- } \\
\text { affiliated hospitals. } \\
\text { Subjects had a HF } \\
\text { diagnosis with a } \\
\text { LVEF } \leq 45 \% \text { and } \\
\text { were between the } \\
\text { ages of } 40 \text { and } 80 \\
\text { years }\end{array}$ & $\begin{array}{l}\text { Exercise self-efficacy is important in improving } \\
\text { patient-centered outcomes, physical functioning, } \\
\text { physical activity, and quality of life. Nurses need } \\
\text { to be proactive in promoting exercise self- } \\
\text { efficacy through patient education aimed at } \\
\text { teaching patients with HF the importance of } \\
\text { physical activity despite challenges inherent to } \\
\text { their chronic condition. }\end{array}$ \\
\hline
\end{tabular}




\begin{tabular}{|c|c|c|c|c|c|}
\hline $\begin{array}{l}\text { Miller and } \\
\text { Gunstad (2016) } \\
\text { United States }\end{array}$ & \begin{tabular}{|l|} 
Describe the \\
relationship \\
between physical \\
activity and \\
cognition in older \\
adults with HF
\end{tabular} & $\begin{array}{l}\text { Literature } \\
\text { synthesis }\end{array}$ & N/A & $\begin{array}{l}72 \text { articles } \\
\text { included in } \\
\text { synthesis }\end{array}$ & $\begin{array}{l}\text { Lower levels of functional capacity have } \\
\text { consistently been linked to poorer cognitive } \\
\text { outcomes among patients with HF. Cognitive } \\
\text { dysfunction is associated with adverse outcome } \\
\text { and increased disability and mortality. As HF } \\
\text { progresses there is an increased risk of cognitive } \\
\text { dysfunction and an associated decline in physical } \\
\text { activity due to functional limitations. High- } \\
\text { intensity exercise has a positive effect on } \\
\text { cognitive functioning and there does not appear } \\
\text { to be an increased risk of adverse events when } \\
\text { patients with HF engage in this level of exercise. }\end{array}$ \\
\hline $\begin{array}{l}\text { Nayor and Vasan } \\
\text { (2015) } \\
\text { United States }\end{array}$ & $\begin{array}{l}\text { Describe the } \\
\text { importance of } \\
\text { public health } \\
\text { initiatives for HF } \\
\text { prevention }\end{array}$ & $\begin{array}{l}\text { Literature } \\
\text { synthesis }\end{array}$ & N/A & $\begin{array}{l}50 \text { articles } \\
\text { included in } \\
\text { synthesis }\end{array}$ & $\begin{array}{l}\text { Increased levels of physical activity and } \\
\text { decreased levels of sedentary time along with } \\
\text { improved cardiorespiratory fitness are } \\
\text { associated with a lower risk of HF. Mechanisms } \\
\text { that may explain these findings include reducing } \\
\text { the prevalence of cardiovascular risk factors, } \\
\text { preventing cardiac remodeling, enhancing } \\
\text { physiologic remodeling, and improving vascular, } \\
\text { renal, pulmonary, skeletal muscle, } \\
\text { neurohormonal, and cardiac functioning. } \\
\text { Additional research is needed to determine the } \\
\text { type of physical activity and optimal time and } \\
\text { duration of exercise necessary to prevent HF. }\end{array}$ \\
\hline \multicolumn{6}{|c|}{ SMOKING } \\
\hline $\begin{array}{l}\text { Ahmed, A. A., et } \\
\text { al. (2015) } \\
\text { United States }\end{array}$ & \begin{tabular}{|l|} 
Determine the \\
health \\
consequences of \\
smoking after $>15$ \\
years of \\
abstinence
\end{tabular} & $\begin{array}{l}\text { Secondary data } \\
\text { analysis from the } \\
\text { Cardiovascular } \\
\text { Health Study } \\
\text { (CHS) }\end{array}$ & $\begin{array}{l}N=4,482 \text { adults } \\
\geq 65 \text { years old }\end{array}$ & $\begin{array}{l}\text { CHS is an ongoing, } \\
\text { prospective, } \\
\text { population-based } \\
\text { study of CV risk } \\
\text { factors among } \\
\text { community- } \\
\text { dwelling adults }\end{array}$ & $\begin{array}{l}\text { The risk of HF and death for former smokers who } \\
\text { have quit for }>15 \text { years becomes similar to those } \\
\text { who have never smoked. Former heavy smokers } \\
\text { ( } \geq 32 \text { pack-years of former smoking) had similar } \\
\text { risk of HF to that of current smokers but have a } \\
\text { lower risk of mortality. }\end{array}$ \\
\hline
\end{tabular}




\begin{tabular}{|c|c|c|c|c|c|}
\hline $\begin{array}{l}\text { Gopal, D. M., et } \\
\text { al. (2012) } \\
\text { United States }\end{array}$ & $\begin{array}{l}\text { Determine the } \\
\text { link between } \\
\text { former and } \\
\text { current smokers } \\
\text { and HF and the } \\
\text { strength of this } \\
\text { association }\end{array}$ & $\begin{array}{l}\text { Secondary data } \\
\text { analysis from the } \\
\text { Healthy Aging } \\
\text { and Body } \\
\text { Composition } \\
\text { (Healthy ABC) } \\
\text { study }\end{array}$ & $\begin{array}{l}\mathrm{N}=2,125 \\
1,165 \\
\text { nonsmokers } \\
738 \text { past } \\
\text { smokers } \\
221 \text { current } \\
\text { smokers }\end{array}$ & $\begin{array}{l}\text { Community- } \\
\text { dwelling men and } \\
\text { women living in } \\
\text { Pittsburgh, PA, and } \\
\text { Memphis, TN. } \\
\text { Physiological } \\
\text { measures, blood } \\
\text { samples, } \\
\text { performance } \\
\text { measures, and } \\
\text { questionnaires } \\
\text { were obtained at } \\
\text { baseline, follow-up } \\
\text { was done in } \\
\text { person alternating } \\
\text { with telephone } \\
\text { interviews every } 6 \\
\text { months }\end{array}$ & $\begin{array}{l}\text { Current and past cigarette smoking increases HF } \\
\text { risk. Among current smokers the risk is high } \\
\text { regardless of pack-years of exposure. In past } \\
\text { smokers, the higher the pack-years of exposure } \\
\text { the greater the risk of HF. }\end{array}$ \\
\hline $\begin{array}{l}\text { Javaheri, S., } \\
\text { Shukla, R., \& } \\
\text { Wexler, L. (2012) } \\
\text { United States }\end{array}$ & $\begin{array}{l}\text { Determine the } \\
\text { association of } \\
\text { nocturnal } \\
\text { ventricular } \\
\text { arrhythmias in HF } \\
\text { patients }\end{array}$ & $\begin{array}{l}\text { Observational } \\
\text { study }\end{array}$ & $\begin{array}{l}\mathrm{N}=86 \text { men } \text { with } \\
\mathrm{HF}\end{array}$ & $\begin{array}{l}\text { Patients were } \\
\text { admitted to the } \\
\text { hospital for } 2 \\
\text { consecutive nights } \\
\text { of attended } \\
\text { polysomnography. } \\
\text { Detailed physical } \\
\text { exam, lab work, } \\
\text { and sleep history } \\
\text { and pulmonary } \\
\text { function exam }\end{array}$ & $\begin{array}{l}\text { The incidence of nocturnal ventricular } \\
\text { tachyarrhythmias is higher among current } \\
\text { smokers and those with sleep apnea and plasma } \\
\text { alkalosis. }\end{array}$ \\
\hline
\end{tabular}




\begin{tabular}{|c|c|c|c|c|c|}
\hline $\begin{array}{l}\text { Plank et al. (2014) } \\
\text { United States }\end{array}$ & $\begin{array}{l}\text { Evaluate the } \\
\text { relationship } \\
\text { between smoking } \\
\text { and the risk of } \\
\text { ventricular } \\
\text { tachyarrhythmias } \\
\text { in HF patients }\end{array}$ & $\begin{array}{l}\text { Secondary data } \\
\text { analysis from the } \\
\text { Multicenter } \\
\text { Automatic } \\
\text { Defibrillator } \\
\text { Implantation } \\
\text { Trial-Cardiac } \\
\text { Resynchronizatio } \\
\text { n Therapy Study } \\
\text { (MADIT-CRT) }\end{array}$ & $\begin{array}{l}\mathrm{N}=1,820 \\
\text { patients in the } \\
\mathrm{MADIT}-\mathrm{CRT} \\
\mathrm{N}=1,442 \\
\text { included in this } \\
\text { analysis }\end{array}$ & $\begin{array}{l}\text { Patients enrolled } \\
\text { at } 110 \text { hospitals in } \\
\text { US, Canada, \& } \\
\text { Europe. Exclusion } \\
\text { criteria were }>75 \\
\text { years of age (331 } \\
\text { patients), no } \\
\text { device } \\
\text { implantation (19 } \\
\text { patients), lack of } \\
\text { smoking data ( } 25 \\
\text { patients), and no } \\
\text { smoking or device } \\
\text { data ( } 3 \text { patients) }\end{array}$ & $\begin{array}{l}\text { Current smokers with mild HF and left } \\
\text { ventricular dysfunction are at significantly higher } \\
\text { risk of ventricular tachyarrhythmias or death } \\
\text { than past smokers or nonsmokers. }\end{array}$ \\
\hline $\begin{array}{l}\text { Shah et al. (2010) } \\
\text { United States }\end{array}$ & $\begin{array}{l}\text { Determine the } \\
\text { risk decrease } \\
\text { associated with } \\
\text { smoking } \\
\text { cessation in } \\
\text { patients with left } \\
\text { ventricular } \\
\text { systolic } \\
\text { dysfunction after } \\
\text { myocardial } \\
\text { infarction (MI) }\end{array}$ & $\begin{array}{l}\text { Secondary data } \\
\text { analysis from the } \\
\text { Survival and } \\
\text { Ventricular } \\
\text { Enlargement } \\
\text { (SAVE) trial, a } \\
\text { randomized } \\
\text { controlled trial } \\
\text { of the efficacy } \\
\text { and safety of } \\
\text { captopril (ACE) } \\
\text { inhibitor after a } \\
\text { high-risk MI with } \\
\text { left ventricular } \\
\text { ejection fraction } \\
<40 \%\end{array}$ & $\mathrm{~N}=2,231$ & $\begin{array}{l}\text { Patients enrolled } 3 \\
\text { to } 16 \text { days after an } \\
\text { MI. Smoking status } \\
\text { was assessed at } \\
\text { randomization, } 2 \\
\text { weeks after } \\
\text { randomization, } \\
\text { and } 3 \text { months after } \\
\text { randomization for } \\
\text { the first year and } \\
\text { every } 4 \text { months } \\
\text { after } \\
\text { randomization for } \\
5 \text { years }\end{array}$ & $\begin{array}{l}\text { Among patients with left ventricular dysfunction } \\
\text { after an MI, smoking cessation is associated with } \\
\text { a } 40 \% \text { lower risk of all-cause mortality and a } 30 \% \\
\text { lower risk of death or recurrent MI or death or } \\
\text { HF hospitalization. }\end{array}$ \\
\hline
\end{tabular}


Table S2: Risk factor measures

\begin{tabular}{|l|l|l|}
\hline \multicolumn{1}{|c|}{ Variable } & \multicolumn{1}{c|}{ Instrument } & \multicolumn{1}{c|}{ Source/Reliability } \\
\hline Nutrition & AHA Life's Simple 7 Questionnaire & American Heart Association (AHA) (2010) \\
\hline Obesity & weight (Ib)/[height (in)]2 x 703 & Medical record or referring provider \\
\hline Physical activity & Duke Activity Status Index (DASI) & Hlatky et al. (1989) \\
\hline Smoking & $\begin{array}{l}\text { Global Adult Tobacco Survey } \\
\text { (GATS) }\end{array}$ & $\begin{array}{l}\text { Centers for Disease Control and } \\
\text { Prevention (2011) }\end{array}$ \\
\hline
\end{tabular}

Table S3: Outcome measure instrument

\begin{tabular}{|l|l|}
\hline \multicolumn{1}{|c|}{ Instrument } & \multicolumn{1}{|c|}{ Source/Reliability } \\
\hline Minnesota Living With Heart & Cronbach's $\alpha$ of .92 to .94 (S. J. Bennett et al., 2003; Kubo et al., \\
Failure Questionnaire (MLHFQ) & $\begin{array}{l}\text { 2004; Riegel et al., 2002). The correlations between the MLHFQ } \\
(r=0.80) \text { \& NYHA classification ( } r=0.60) \text { indicate that the } \\
\text { MLHFQ is a valid instrument for HF impairment (Rector et al., } \\
\text { 1987). }\end{array}$ \\
\hline
\end{tabular}

Table S4: Data collection process

\begin{tabular}{|l|l|l|l|}
\hline \multicolumn{1}{|c|}{ Steps } & \multicolumn{1}{|c|}{ Rationale } & \multicolumn{1}{c|}{ Strengths } & \multicolumn{1}{c|}{ Limitations } \\
\hline $\begin{array}{l}\text { 1. Healthcare } \\
\text { provider } \\
\text { recruited/referred } \\
\text { subjects for study }\end{array}$ & $\begin{array}{l}\text { Healthcare provider had } \\
\text { established relationship } \\
\text { with patients, which } \\
\text { enhanced subject } \\
\text { recruitment }\end{array}$ & $\begin{array}{l}\text { Enrollment was enhanced } \\
\text { due to healthcare } \\
\text { provider /patient } \\
\text { relationship and trust. }\end{array}$ & Possible Hawthorne Effect \\
\hline $\begin{array}{l}\text { 2. Informed } \\
\text { consent }\end{array}$ & $\begin{array}{l}\text { Subjects must } \\
\text { understand fully the } \\
\text { study and what it entails } \\
\text { and must sign consent } \\
\text { form }\end{array}$ & Participation is voluntary & $\begin{array}{l}\text { Time required for study } \\
\text { may deter potential } \\
\text { subjects }\end{array}$ \\
\hline $\begin{array}{l}\text { 3. Survey } \\
\text { administration }\end{array}$ & Collection of data & $\begin{array}{l}\text { Data collected directly } \\
\text { into database }\end{array}$ & $\begin{array}{l}\text { Length of survey } \\
\text { administration and } \\
\text { possible data entry errors }\end{array}$ \\
\hline
\end{tabular}


Table S5: Dissertation project timeline

\begin{tabular}{|l|c|c|c|c|}
\hline \multicolumn{1}{|c|}{ Tasks } & $\begin{array}{c}\mathbf{0 - 3} \\
\text { Months }\end{array}$ & $\begin{array}{c}3-6 \\
\text { Months }\end{array}$ & $\begin{array}{c}6-9 \\
\text { Months }\end{array}$ & $\begin{array}{c}\mathbf{9 - 1 2} \\
\text { Months }\end{array}$ \\
\hline Proposal defense & $\mathrm{X}$ & & & \\
\hline IRB protocol development, submission, approval & $\mathrm{X}$ & $\mathrm{X}$ & & \\
\hline Data collection, entry, cleaning & & $\mathrm{X}$ & $\mathrm{X}$ & \\
\hline Analysis of data & & & $\mathrm{X}$ & \\
\hline Writing results: chapters 4 and 5 & & & $\mathrm{X}$ & $\mathrm{X}$ \\
\hline Presentation of study results: dissertation defense & & & & $\mathrm{X}$ \\
\hline
\end{tabular}




\section{References}

Ahmed, A. A., Patel, K., Nyaku, M. A., Kheirbek, R. E., Bittner, V., Fonarow, G. C., . . .

Ahmed, A. (2015). Risk of Heart Failure and Death After Prolonged Smoking Cessation:

Role of Amount and Duration of Prior Smoking. Circ Heart Fail, 8(4), 694-701. doi:10.1161/circheartfailure.114.001885

Alosco, M. L., Spitznagel, M. B., Cohen, R., Sweet, L. H., Josephson, R., Hughes, J., . . . Gunstad, J. (2015). Obesity and cognitive dysfunction in heart failure: the role of hypertension, type 2 diabetes, and physical fitness. Eur J Cardiovasc Nurs, 14(4), 334341. doi:10.1177/1474515114535331

Alpert, M. A., Lavie, C. J., Agrawal, H., Aggarwal, K. B., \& Kumar, S. A. (2014). Obesity and heart failure: epidemiology, pathophysiology, clinical manifestations, and management. Transl Res, 164(4), 345-356. doi:10.1016/j.trs1.2014.04.010

American Heart Association (AHA). (2010). Life's Simple 7 Questionnaire. Retrieved from http://www.heart.org/HEARTORG/Conditions/My-Life-Check---Lifes-Simple7_UCM 471453 Article.jsp\#.WUqc3evys1I

American Heart Association (AHA). (2016). Understanding your risks to prevent heart attack. Retrieved from http://www.heart.org/HEARTORG/Conditions/HeartAttack/UnderstandYourRiskstoPrev entaHeartAttack/Understand-Your-Risks-to-Prevent-a-HeartAttack_UCM_002040_Article.jsp\#.V6OnxphTGUk

American Heart Association Criteria Committee. (1994). Nomenclature and criteria for diagnosis of diseases of the heart and great vessels. In (9th ed., pp. 253-256). Boston, MA: Little, Brown \& Co. Retrieved from 
http://professional.heart.org/professional/General/UCM_423811_Classification-ofFunctional-Capacity-and-Objective-Assessment.jsp.

Andersen, K., Mariosa, D., Adami, H. O., Held, C., Ingelsson, E., Lagerros, Y. T., . . . Sundstrom, J. (2014). Dose-response relationship of total and leisure time physical activity to risk of heart failure: a prospective cohort study. Circ Heart Fail, 7(5), 701708. doi:10.1161/circheartfailure.113.001010

Bdeir, B., Conboy, T., Mukhtar, A., Omer, H., Odeh, R., Farah, I., . . Al Mallah, M. (2015). Impact of a nurse-led heart failure program on all-cause mortality. J Cardiovasc Nurs, 30(2), E7-e14. doi:10.1097/jen.0000000000000133

Bennett, J. A., Riegel, B., Bittner, V., \& Nichols, J. (2002). Validity and reliability of the NYHA classes for measuring research outcomes in patients with cardiac disease. Heart Lung, 31(4), 262-270.

Bennett, S. J., Oldridge, N. B., Eckert, G. J., Embree, J. L., Browning, S., Hou, N., . . Murray, M. D. (2003). Comparison of quality of life measures in heart failure. Nurs Res, 52(4), 207-216.

Bilbao, A., Escobar, A., Garcia-Perez, L., Navarro, G., \& Quiros, R. (2016). The Minnesota living with heart failure questionnaire: comparison of different factor structures. Health Qual Life Outcomes, 14, 23. doi:10.1186/s12955-016-0425-7

Bui, A. L., Horwich, T. B., \& Fonarow, G. C. (2011). Epidemiology and risk profile of heart failure. Nat Rev Cardiol, 8(1), 30-41. doi:10.1038/nrcardio.2010.165

Casper, M., Nwaise, I., Croft, J. B., Hong, Y., Fang, J., \& Greer, S. (2010). Geographic disparities in heart failure hospitalization rates among Medicare beneficiaries. $J$ Am Coll Cardiol, 55(4), 294-299. doi:10.1016/j.jacc.2009.10.021 
Center for Medicare and Medicaid Services. (2014). Conditions prevalence trends: 2007-2014. Retrieved from http://medicare-usage.healthgrove.com/l/3149/Monongalia-County

Centers for Disease Control and Prevention. (2011). Global Adult Survey collaborative group tobacco questions for surveys: A subset of key questions from the Global Adult Tobacco Survey (GATS). Atlanta, GA: CDC.

Centers for Disease Control and Prevention. (2014). Current cigarette smoking among U.S. adults aged 18 years and older. Atlanta, GA: CDC Retrieved from http://www.cdc.gov/tobacco/data_statistics/fact_sheets/adult_data/cig_smoking/.

Centers for Disease Control and Prevention [CDC]. (2015). Nutrition, physical activity and obesity data, trends and maps. Retrieved from National Center for Chronic Disease Prevention and Health Promotion, Division of Nutrition, Physical Activity and Obesity website: http://www.cdc.gov/nccdphp/DNPAO/index.html

Chung, M. L., Moser, D. K., Lennie, T. A., \& Frazier, S. K. (2013). Perceived social support predicted quality of life in patients with heart failure, but the effect is mediated by depressive symptoms. Qual Life Res, 22(7), 1555-1563. doi:10.1007/s11136-012-0294-4

Dalusung-Angosta, A. (2013). CHD knowledge and risk factors among Filipino-Americans connected to primary care services. J Am Assoc Nurse Pract, 25(9), 503-512. doi:10.1002/2327-6924.12039

deFilippi, C. R., de Lemos, J. A., Tkaczuk, A. T., Christenson, R. H., Carnethon, M. R., Siscovick, D. S., . . Seliger, S. L. (2012). Physical activity, change in biomarkers of myocardial stress and injury, and subsequent heart failure risk in older adults. J Am Coll Cardiol, 60(24), 2539-2547. doi:10.1016/j.jacc.2012.08.1006 
Djousse, L., Driver, J. A., \& Gaziano, J. M. (2009). Relation between modifiable lifestyle factors and lifetime risk of heart failure. Jama, 302(4), 394-400. doi:10.1001/jama.2009.1062

Du, H., Everett, B., Newton, P. J., Salamonson, Y., \& Davidson, P. M. (2012). Self-efficacy: a useful construct to promote physical activity in people with stable chronic heart failure. $J$ Clin Nurs, 21(3-4), 301-310. doi:10.1111/j.1365-2702.2011.03983.x

Ebong, I. A., Goff, D. C., Jr., Rodriguez, C. J., Chen, H., \& Bertoni, A. G. (2014). Mechanisms of heart failure in obesity. Obes Res Clin Pract, 8(6), e540-548. doi:10.1016/j.orcp.2013.12.005

Echouffo-Tcheugui, J. B., Butler, J., Yancy, C. W., \& Fonarow, G. C. (2015). Association of Physical Activity or Fitness With Incident Heart Failure: A Systematic Review and MetaAnalysis. Circ Heart Fail, 8(5), 853-861. doi:10.1161/circheartfailure.115.002070

Esch, L., \& Hendryx, M. (2011). Chronic cardiovascular disease mortality in mountaintop mining areas of central Appalachian states. J Rural Health, 27(4), 350-357. doi:10.1111/j.1748-0361.2011.00361.x

Fan, X., Lee, K. S., Frazier, S. K., Lennie, T. A., \& Moser, D. K. (2015). Psychometric testing of the Duke Activity Status Index in patients with heart failure. Eur J Cardiovasc Nurs, 14(3), 214-221. doi:10.1177/1474515114523354

Fawcett, J. (2005a). Contemporary nursing knowledge: Analysis and evaluation of nursing models and theories (2nd ed.). Philadelphia, PA F. A. Davis Co.

Fawcett, J. (2005b). Neuman's systems model. In J. Fawcett (Ed.), Contemporary nursing knowledge: analysis and evaluation of nursing models and theories (2nd ed., pp. 166222). Philadelphia, PA: F. A. Davis Co. 
Freydberg, N., Strain, L., Tsuyuki, R. T., McAlister, F. A., \& Clark, A. M. (2010). "If he gives in, he will be gone...": the influence of work and place on experiences, reactions and selfcare of heart failure in rural Canada. Soc Sci Med, 70(7), 1077-1083. doi:10.1016/j.socscimed.2009.11.026

Furlanetto, K. C., Pinto, I. F., Sant'Anna, T., Hernandes, N. A., \& Pitta, F. (2016). Profile of patients with chronic obstructive pulmonary disease classified as physically active and inactive according to different thresholds of physical activity in daily life. Braz J Phys Ther, 20(6), 517-524. doi:10.1590/bjpt-rbf.2014.0185

Garin, O., Ferrer, M., Pont, A., Wiklund, I., Van Ganse, E., Vilagut, G., . . Alonso, J. (2013). Evidence on the global measurement model of the Minnesota Living with Heart Failure Questionnaire. Qual Life Res, 22(10), 2675-2684. doi:10.1007/s11136-013-0383-z

Garin, O., Herdman, M., Vilagut, G., Ferrer, M., Ribera, A., Rajmil, L., . . Alonso, J. (2014). Assessing health-related quality of life in patients with heart failure: a systematic, standardized comparison of available measures. Heart Fail Rev, 19(3), 359-367. doi:10.1007/s10741-013-9394-7

Gary, R. A., Cress, M. E., Higgins, M. K., Smith, A. L., \& Dunbar, S. B. (2011). Combined aerobic and resistance exercise program improves task performance in patients with heart failure. Arch Phys Med Rehabil, 92(9), 1371-1381. doi:10.1016/j.apmr.2011.02.022

Gheorghiade, M., Sopko, G., De Luca, L., Velazquez, E. J., Parker, J. D., Binkley, P. F., .. . Bonow, R. O. (2006). Navigating the crossroads of coronary artery disease and heart failure. Circulation, 114(11), 1202-1213. doi:10.1161/circulationaha.106.623199 
Goetz-Perry, C. (2010). Supporting health promotion behaviours in rural older adults: A mixed methods study (Unpublished doctoral dissertation). Michigan State University, East Lansing,

Gopal, D. M., Kalogeropoulos, A. P., Georgiopoulou, V. V., Smith, A. L., Bauer, D. C., Newman, A. B., . . Butler, J. (2012). Cigarette smoking exposure and heart failure risk in older adults: the Health, Aging, and Body Composition Study. Am Heart J, 164(2), 236-242. doi:10.1016/j.ahj.2012.05.013

Gromoske, A. N., Oldridge, N., \& Brondino, M. J. (2011). Readability of 3 Heart Disease Health-Related Quality of Life Questionnaires. Journal of Cardiopulmonary Rehabilitation and Prevention, 31(4), 245-248. doi:10.1097/HCR.0b013e31821c13c6

He, F. J., Burnier, M., \& Macgregor, G. A. (2011). Nutrition in cardiovascular disease: salt in hypertension and heart failure. Eur Heart J, 32(24), 3073-3080. doi:10.1093/eurheartj/ehr194

Heo, S., Moser, D. K., Riegel, B., Hall, L. A., \& Christman, N. (2005). Testing the psychometric properties of the Minnesota Living with Heart Failure questionnaire. Nurs Res, 54(4), 265-272.

Hlatky, M. A., Boineau, R. E., Higginbotham, M. B., Lee, K. L., Mark, D. B., Califf, R. M., . . Pryor, D. B. (1989). A brief self-administered questionnaire to determine functional capacity (the Duke Activity Status Index). Am J Cardiol, 64(10), 651-654.

Holland, R., Rechel, B., Stepien, K., Harvey, I., \& Brooksby, I. (2010). Patients' self-assessed functional status in heart failure by New York Heart Association class: a prognostic predictor of hospitalizations, quality of life and death. J Card Fail, 16(2), 150-156. doi:10.1016/j.cardfail.2009.08.010 
Horwich, T. B., \& Fonarow, G. C. (2010). Glucose, obesity, metabolic syndrome, and diabetes relevance to incidence of heart failure. J Am Coll Cardiol, 55(4), 283-293. doi:10.1016/j.jacc.2009.07.029

IBM Corporation. (2016). IBM SPSS Statistics for Windows (Version 24.0). Armonk, NY: IBM Corp.

Javaheri, S., Shukla, R., \& Wexler, L. (2012). Association of smoking, sleep apnea, and plasma alkalosis with nocturnal ventricular arrhythmias in men with systolic heart failure. Chest, 141(6), 1449-1456. doi:10.1378/chest.11-1724

Jindal, A., Whaley-Connell, A., \& Sowers, J. R. (2013). Obesity and heart failure as a mediator of the cerebrorenal interaction. Contrib Nephrol, 179, 15-23. doi:10.1159/000346718

Kenchaiah, S., Evans, J. C., Levy, D., Wilson, P. W., Benjamin, E. J., Larson, M. G., .. . Vasan, R. S. (2002). Obesity and the risk of heart failure. N Engl J Med, 347(5), 305-313. doi:10.1056/NEJMoa020245

Khazanie, P., \& Rogers, J. G. (2011). Patient selection for left ventricular assist devices. Congest Heart Fail, 17(5), 227-234. doi:10.1111/j.1751-7133.2011.00236.x

Kovell, L. C., Juraschek, S. P., \& Russell, S. D. (2015). Stage A Heart Failure Is Not Adequately Recognized in US Adults: Analysis of the National Health and Nutrition Examination Surveys, 2007-2010. PLoS One, 10(7), e0132228. doi:10.1371/journal.pone.0132228

Kraigher-Krainer, E., Lyass, A., Massaro, J. M., Lee, D. S., Ho, J. E., Levy, D., . . Vasan, R. S. (2013). Association of physical activity and heart failure with preserved vs. reduced ejection fraction in the elderly: the Framingham Heart Study. Eur J Heart Fail, 15(7), 742-746. doi:10.1093/eurjhf/hft025 
Kubo, S. H., Schulman, S., Starling, R. C., Jessup, M., Wentworth, D., \& Burkhoff, D. (2004). Development and validation of a patient questionnaire to determine New York Heart Association classification. J Card Fail, 10(3), 228-235.

Lama Tamang, T. G., Tang, L., Chuang, J., Patel, R. J., \& Wong, N. D. (2014). Examining risk factor goal attainment and adherence to treatment among US heart failure patients: the National Health and Nutrition Examination Survey 2007-2010. Am J Cardiovasc Drugs, 14(1), 41-49. doi:10.1007/s40256-013-0046-z

Lavie, C. J., Alpert, M. A., Arena, R., Mehra, M. R., Milani, R. V., \& Ventura, H. O. (2013). Impact of obesity and the obesity paradox on prevalence and prognosis in heart failure. JACC Heart Fail, 1(2), 93-102. doi:10.1016/j.jchf.2013.01.006

Lavie, C. J., De Schutter, A., Alpert, M. A., Mehra, M. R., Milani, R. V., \& Ventura, H. O. (2014). Obesity paradox, cachexia, frailty, and heart failure. Heart Fail Clin, 10(2), 319326. doi:10.1016/j.hfc.2013.12.002

Ledwidge, M., Gallagher, J., Conlon, C., Tallon, E., O'Connell, E., Dawkins, I., .. . McDonald, K. (2013). Natriuretic peptide-based screening and collaborative care for heart failure: the STOP-HF randomized trial. Jama, 310(1), 66-74. doi:10.1001/jama.2013.7588

Lee, H., Boo, S., Yu, J., Suh, S. R., Chun, K. J., \& Kim, J. H. (2017). Physical Functioning, Physical Activity, Exercise Self-Efficacy, and Quality of Life Among Individuals With Chronic Heart Failure in Korea: A Cross-Sectional Descriptive Study. J Nurs Res, 25(2), 131-139. doi:10.1097/jnr.0000000000000150

Mamudu, H. M., Paul, T., Veeranki, S. P., Wang, L., Panchal, H. B., \& Budoff, M. (2015). Subclinical Atherosclerosis and Relationship With Risk Factors of Coronary Artery 
Disease in a Rural Population. Am J Med Sci, 350(4), 257-262. doi:10.1097/maj.0000000000000548

McCarthy, M., Katz, S. D., Schipper, J., \& Dickson, V. V. (2015). "I Just Can't Do It Anymore" Patterns of Physical Activity and Cardiac Rehabilitation in African Americans with Heart Failure: A Mixed Method Study. Healthcare (Basel), 3(4), 973-986.

doi:10.3390/healthcare3040973

Meyer, K., \& Laederach-Hofmann, K. (2003). Effects of a comprehensive rehabilitation program on quality of life in patients with chronic heart failure. Prog Cardiovasc Nurs, 18(4), 169-176.

Miller, L., \& Gunstad, J. (2016). Physical activity and cognition in older adults with heart failure. In T. McMorris (Ed.), Exercise-cognition interaction: Neuroscience perspectives (pp. 421-433): Elsevier Science.

Moser, D. K., Robinson, S., Biddle, M. J., Pelter, M. M., Nesbitt, T. S., Southard, J., . . Dracup, K. (2015). Health Literacy Predicts Morbidity and Mortality in Rural Patients With Heart Failure. J Card Fail, 21(8), 612-618. doi:10.1016/j.cardfail.2015.04.004

Mozaffarian, D., Benjamin, E. J., Go, A. S., Arnett, D. K., Blaha, M. J., Cushman, M., . . . Turner, M. B. (2016). Heart Disease and Stroke Statistics-2016 Update: A Report From the American Heart Association. Circulation, 133(4), e38-360. doi:10.1161/cir.0000000000000350

Mudd-Martin, G., Biddle, M. J., Chung, M. L., Lennie, T. A., Bailey, A. L., Casey, B. R., . . Moser, D. K. (2014). Rural Appalachian perspectives on heart health: social ecological contexts. Am J Health Behav, 38(1), 134-143. doi:10.5993/ajhb.38.1.14 
Munyombwe, T., Hofer, S., Fitzsimons, D., Thompson, D. R., Lane, D., Smith, K., \& Astin, F. (2014). An evaluation of the Minnesota Living with Heart Failure Questionnaire using Rasch analysis. Qual Life Res, 23(6), 1753-1765. doi:10.1007/s11136-013-0617-0

Muus, K. J., Knudson, A., Klug, M. G., Gokun, J., Sarrazin, M., \& Kaboli, P. (2010). Effect of post-discharge follow-up care on re-admissions among US veterans with congestive heart failure: a rural-urban comparison. Rural Remote Health, 10(2), 1447.

Nagarajan, V., Cauthen, C. A., Starling, R. C., \& Tang, W. H. (2013). Prognosis of morbid obesity patients with advanced heart failure. Congest Heart Fail, 19(4), 160-164. doi:10.1111/chf.12038

Narsavage, G. L. (1997). Promoting function in clients with chronic lung disease by increasing their perception of control. Holist Nurs Pract, 12(1), 17-26.

Narumi, T., Watanabe, T., Kadowaki, S., Otaki, Y., Honda, Y., Nishiyama, S., . . Kubota, I. (2014). The obesity paradox is not observed in chronic heart failure patients with metabolic syndrome. Excli j, 13, 516-525.

Nayor, M., \& Vasan, R. S. (2015). Preventing heart failure: the role of physical activity. Curr Opin Cardiol, 30(5), 543-550. doi:10.1097/hco.0000000000000206

Ndumele, C. E., Matsushita, K., Sang, Y., Lazo, M., Agarwal, S. K., Nambi, V., . . Selvin, E. (2016). N-Terminal Pro-Brain Natriuretic Peptide and Heart Failure Risk Among Individuals With and Without Obesity: The Atherosclerosis Risk in Communities (ARIC) Study. Circulation, 133(7), 631-638. doi:10.1161/circulationaha.115.017298

Nelson, C. L., Herndon, J. E., Mark, D. B., Pryor, D. B., Califf, R. M., \& Hlatky, M. A. (1991). Relation of clinical and angiographic factors to functional capacity as measured by the Duke Activity Status Index. Am J Cardiol, 68(9), 973-975. 
Neuman, B. M., \& Fawcett, J. (2011). The Neuman systems model (5th ed.). Boston, MA: Pearson.

Nogueira, I. D., Servantes, D. M., Nogueira, P. A., Pelcerman, A., Salvetti, X. M., Salles, F., .. . Filho, J. A. (2010). Correlation between quality of life and functional capacity in cardiac failure. Arq Bras Cardiol, 95(2), 238-243.

Pallant, J. (2010). SPSS Survival Manual (4th ed.). New York: McGraw-Hill.

Parissis, J. T., Nikolaou, M., Birmpa, D., Farmakis, D., Paraskevaidis, I., Bistola, V., .. . Kremastinos, D. T. (2009). Clinical and prognostic value of Duke's Activity Status Index along with plasma B-type natriuretic peptide levels in chronic heart failure secondary to ischemic or idiopathic dilated cardiomyopathy. Am J Cardiol, 103(1), 73-75. doi:10.1016/j.amjcard.2008.08.045

Pfister, R., Michels, G., Sharp, S. J., Luben, R., Wareham, N. J., \& Khaw, K. T. (2014). Low bone mineral density predicts incident heart failure in men and women: the EPIC (European Prospective Investigation into Cancer and Nutrition)-Norfolk prospective study. JACC Heart Fail, 2(4), 380-389. doi:10.1016/j.jchf.2014.03.010

Pfister, R., Sharp, S. J., Luben, R., Wareham, N. J., \& Khaw, K. T. (2011). Plasma vitamin C predicts incident heart failure in men and women in European Prospective Investigation into Cancer and Nutrition-Norfolk prospective study. Am Heart J, 162(2), 246-253. doi:10.1016/j.ahj.2011.05.007

Plank, B., Kutyifa, V., Moss, A. J., Huang, D. T., Ruwald, A. C., McNitt, S., . . Aktas, M. K. (2014). Smoking is associated with an increased risk of first and recurrent ventricular tachyarrhythmias in ischemic and nonischemic patients with mild heart failure: a MADIT-CRT substudy. Heart Rhythm, 11(5), 822-827. doi:10.1016/j.hrthm.2014.02.007 
Polit, D. F., \& Beck, C. T. (2012). Nursing research: Generating and assessing evidence for nursing practice (9th ed.). Philadelphia, PA: Walters Kluwer Health/Lippincott Williams \& Wilkins.

Pollentier, B., Irons, S. L., Benedetto, C. M., Dibenedetto, A. M., Loton, D., Seyler, R. D., .. . Newton, R. A. (2010). Examination of the six minute walk test to determine functional capacity in people with chronic heart failure: a systematic review. Cardiopulm Phys Ther $J, 21(1), 13-21$.

Pressler, S. J., Subramanian, U., Shaw, R. M., Meyer, L. E., Stoudemire, K., \& Gradus-Pizlo, I. (2008). Research in patients with heart failure: challenges in recruitment. Am J Crit Care, 17(3), 198-203.

Qualtrics. (2016). Qualtrics software (Version January-May 2017). Provo, UT: Qualtrics. Retrieved from www.qualtrics.com

Quittan, M., Wiesinger, G. F., Crevenna, R., Nuhr, M. J., Posch, M., Hulsmann, M., . . FialkaMoser, V. (2001). Cross-cultural adaptation of the Minnesota Living with Heart Failure Questionnaire for German-speaking patients. J Rehabil Med, 33(4), 182-186.

Rankin, S. L., Briffa, T. G., Morton, A. R., \& Hung, J. (1996). A specific activity questionnaire to measure the functional capacity of cardiac patients. Am J Cardiol, 77(14), 1220-1223.

Rector, T. S. (2005). Overview of the Minnesota Living with Heart Failure Questionnaire. . Minneapolis, MN: University of Minnesota, Office for Technology Commercialization Retrieved from https://docs.google.com/a/umn.edu/viewer?a=v\&pid=sites\&srcid=dW1uLmVkdXx0bXN 8Z3g6MjQxYWMzOTBkMWYwMjAwZA. 
Rector, T. S., Kubo, S. H., \& Cohn, J. N. (1987). Patients' self-assessment of their congestive heart failure. Part 2: Content, reliability and validity of a new measure, the Minnesota Living with Heart Failure Questionnaire. Heart Failure(Oct/Nov), 198-209.

Retrum, J. H., Boggs, J., Hersh, A., Wright, L., Main, D. S., Magid, D. J., \& Allen, L. A. (2013). Patient-identified factors related to heart failure readmissions. Circ Cardiovasc Qual Outcomes, 6(2), 171-177. doi:10.1161/circoutcomes.112.967356

Riegel, B., Moser, D. K., Glaser, D., Carlson, B., Deaton, C., Armola, R., . . Albert, N. (2002). The Minnesota Living With Heart Failure Questionnaire: sensitivity to differences and responsiveness to intervention intensity in a clinical population. Nurs Res, 51(4), 209218.

Schmidt, M., Botker, H. E., Pedersen, L., \& Sorensen, H. T. (2014). Young adulthood obesity and risk of acute coronary syndromes, stable angina pectoris, and congestive heart failure: a 36-year cohort study. Ann Epidemiol, 24(5), 356-361.e351. doi:10.1016/j.annepidem.2014.01.011

Shah, A. M., Pfeffer, M. A., Hartley, L. H., Moye, L. A., Gersh, B. J., Rutherford, J. D., . . Solomon, S. D. (2010). Risk of all-cause mortality, recurrent myocardial infarction, and heart failure hospitalization associated with smoking status following myocardial infarction with left ventricular dysfunction. Am J Cardiol, 106(7), 911-916. doi:10.1016/j.amjcard.2010.05.021

Stevenson, C. W., Pori, D., Payne, K., Black, M., \& Taylor, V. E. (2015). Hearing the Veteran's Voice in Congestive Heart Failure Readmissions. Prof Case Manag, 20(4), 177-185; quiz 186-177. doi:10.1097/ncm.0000000000000080 
Suppan, J. (2001). Using the transtheoretical approach to facilitate change in the heart failure population. Congest Heart Fail, 7(3), 151-155.

Tabachnick, B. G., \& Fidell, L. S. (2007). Using Multivariate Statistics (5th ed.). Boston, MA: Pearson Education.

Tsang, W., Alter, D. A., Wijeysundera, H. C., Zhang, T., \& Ko, D. T. (2012). The impact of cardiovascular disease prevalence on women's enrollment in landmark randomized cardiovascular trials: a systematic review. J Gen Intern Med, 27(1), 93-98. doi:10.1007/s11606-011-1768-8

Vanhoof, M. M. J., Delcroix, M., Vandevelde, E., Denhaerynck, K., Wuyts, W., Belge, C., \& Dobbels, F. (2014). Emotional symptoms and quality of life in patients with pulmonary arterial hypertension. J Heart Lung Transplant, 33(8), 800-808. doi:10.1016/j.healun.2014.04.003

Verdejo, H. E., Ferreccio, C., \& Castro, P. F. (2015). Heart Failure in Rural Communities. Heart Fail Clin, 11(4), 515-522. doi:10.1016/j.hfc.2015.07.011

Wannamethee, S. G., Shaper, A. G., Whincup, P. H., Lennon, L., \& Sattar, N. (2011). Obesity and risk of incident heart failure in older men with and without pre-existing coronary heart disease: does leptin have a role? J Am Coll Cardiol, 58(18), 1870-1877. doi:10.1016/j.jacc.2011.06.057

Weierbach, F. M., Glick, D. F., \& Lyder, C. H. (2011). Family and friends to the rescue: experiences of rural older adults with heart failure. Res Gerontol Nurs, 4(4), 261-270. doi:10.3928/19404921-20110106-01

Weight Watchers. (2017). Follow the Plan 110\% Online. Retrieved from https://www.weightwatchers.com/us/plans\#/tabs/tab-22001 
Wu, J. R., Lennie, T. A., Frazier, S. K., \& Moser, D. K. (2016). Health-Related Quality of Life, Functional Status, and Cardiac Event-Free Survival in Patients With Heart Failure. $J$ Cardiovasc Nurs, 31(3), 236-244. doi:10.1097/jen.0000000000000248

WV Department of Health and Human Services. (2017). Division of Tobacco Prevention: West Virginia Tobacco Quitline. Retrieved from http://www.dhhr.wv.gov/wvdtp/cessation/Quitline/Pages/default.aspx

WV Health Statistics Center, Department of Health and Human Resources, Bureau for Public Health. (2012). West Virginia Vital Statistics 2012. Charleston, WV Retrieved from http://www.wvdhhr.org/bph/hsc/pubs/vital/2012/2012Vital.pdf.

WV Health Statistics Center, Department of Health and Human Resources, Bureau for Public Health. (2015). West Virginia behavioral risk factor surveillance system report, 2013. Charleston, WV Retrieved from http://www.wvdhhr.org/bph/hsc/pubs/brfss/2013/BRFSS2013.pdf.

Yancy, C. W., Jessup, M., Bozkurt, B., Butler, J., Casey, D. E., Jr., Colvin, M. M., . . Westlake, C. (2017). 2017 ACC/AHA/HFSA Focused Update of the 2013 ACCF/AHA Guideline for the Management of Heart Failure: A Report of the American College of Cardiology/American Heart Association Task Force on Clinical Practice Guidelines and the Heart Failure Society of America. Circulation. doi:10.1161/cir.0000000000000509

Yancy, C. W., Jessup, M., Bozkurt, B., Butler, J., Casey, D. E., Jr., Drazner, M. H., . . Wilkoff, B. L. (2013). 2013 ACCF/AHA guideline for the management of heart failure: a report of the American College of Cardiology Foundation/American Heart Association Task Force on Practice Guidelines. J Am Coll Cardiol, 62(16), e147-239.

doi:10.1016/j.jacc.2013.05.019 
Zambroski, C. H., Buck, H., Garrison, C. M., \& McMillan, S. C. (2014). Lessons from the field: challenges in accruing hospice heart failure patients to intervention research. $J$ Cardiovasc Nurs, 29(1), 91-97. doi:10.1097/JCN.0b013e3182784cc0

Zapatero, A., Barba, R., Gonzalez, N., Losa, J. E., Plaza, S., Canora, J., \& Marco, J. (2012). Influence of obesity and malnutrition on acute heart failure. Rev Esp Cardiol (Engl Ed), 65(5), 421-426. doi:10.1016/j.recesp.2011.09.011

Zizzi, S., Abildso, C., Henderson, N., \& Cobb, K. (2014). The West Virginia PEIA Weight Management Program: An innovative approach to obesity prevention and treatment in Appalachian communities. In V. M. Brennan, S. K. Kumanyika, \& R. E. Zambrana (Eds.), Obesity interventions in underserved communities: Evidence and directions (pp. 282-289). Baltimore, MD: Johns Hopkins University Press. 